\title{
VALUE-ADDED PRODUCTS FROM FGD SULFITE-RICH SCRUBBER MATERIALS
}

\author{
Final Scientific/Technical Report
}

Reporting Period: February 1, 2006 through January 31, 2010

\author{
Principal Author: Vivak M. Malhotra, \\ Department of Physics, \\ Southern Illinois University, Carbondale, \\ Illinois 62901
}

April, 2010

DOE Award Number: DE-FG26-06NT42689

Submitting Organization: Southern Illinois University-Carbondale Carbondale, Illinois 62901 


\section{DISCLAIMER}

This report was prepared as an account of work sponsored by an agency of the United States Government. Neither the United States Government nor any agency thereof, nor any of their employees, makes any warranty, express or implied, or assumes any legal liability or responsibility for the accuracy, completeness, or usefulness of any information, apparatus, product, or process disclosed, or represents that its use would not infringe privately owned rights. Reference herein to any specific commercial product, process, or service by trade name, trademark, manufacturer, or otherwise does not necessarily constitute or imply its endorsement, recommendation, or favoring by the United States Government or any agency thereof. The views and opinions of authors expressed herein do not necessarily state or reflect those of the United States Government or any agency thereof. 


\begin{abstract}
In this project, we explored a new strategy to find an effective utilization of sulfite-rich scrubber material, produced by wet flue gas desulfurization (FGD) scrubbers, by converting it into value-added wood-substitute composites.

The incoming scrubber materials were thoroughly characterized for their chemical and physical properties along with mercury's behavior in the sulfite-rich scrubber material at elevated pressures and temperatures. Our results suggested that at higher temperatures $\left(T<275^{\circ} \mathrm{C}\right)$, pressure played an important role whether mercury would be re-emitted from the scrubber material during the fabrication of products. The results also indicated that the chemical structure of the sulfite-rich scrubber material remained invariant during the product development though hannebachite crystallites were flattened and more crystalline fines were generated. We successfully showed that it was feasible to produce two types of products, i.e., wood-substitute composites and load-bearing wood-substitute composites. We were able to generate materials, which had strength as high as $90 \mathrm{MPa}(13,051 \mathrm{psi})$.
\end{abstract}




\section{Table of Contents}

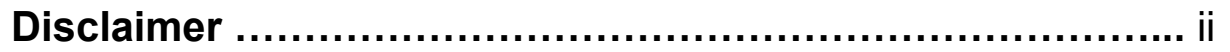

Abstract ................................................................ ii

Executive Summary............................................... 1

Report Details........................................................ 3

Introduction................................................... 3

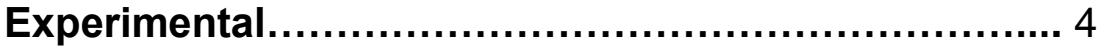

Sulfite-rich Scrubber Material.......................... 4

Infrared Measurements .............................. 4

Mercury Analysis ..................................... 4

Scanning Electron Microscopy ........................ 5

Differential Scanning Calorimetry Measurements ...... 5

Thermal Gravimetric Analysis and Differential

Thermal Analysis Measurements ...................... 6

Materials and Composite Fabrication .................. 6

Mechanical Testing .................................. 7

Results and Discussion................................... 7

Chemical Analysis .................................... 7

Bulk Densities and X-ray Analysis .................... 8

Drying and Thermal Behavior ......................... 9

Structural Analysis .................................... 12

Thermal Behavior of Sulfite-rich Scrubber Materials ... 14

Effects of composite Formulation Conditions on

the Structure of Scrubber Materials ...................... 18

Development and Performance of Wood-substitute

Composites ............................................... 24

Density Reduction .................................. 32

Synthetic Lumber ................................... 35

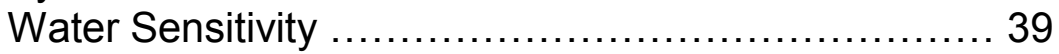

Large-size Samples .................................. 43

Conclusions ................................................ 47

References ............................................... 50 


\section{LIST OF FIGURES}

Figure 1. Observed XRD pattern for sulfite-rich but air-dried scrubber material.

Figure 2. The weight loss from the sulfite-rich scrubber material at ambient temperature and atmosphere.

Figure 3. The DSC curves obtained from sulfite-rich scrubber material from Power Plant A air-dried at ambient temperature for different lengths of time.

Figure 4. The effect of air-drying time on the mercury concentration in the scrubber materials.

Figure 5. The effect of fabrication temperature on the $\mathrm{Hg}$ concentration of the scrubber materials from Power Plants A and B at 5.6 MPa.

Figure 6. The effect of fabrication pressure on the $\mathrm{Hg}$ concentration of the scrubber materials from Power Plants $\mathrm{A}$ and $\mathrm{B}$ at $210^{\circ} \mathrm{C}$.

Figure 7. Scanning electron microscopy (SEM) picture of the as-received, but air-dried, sulfite-rich scrubber material obtained from Power Plant A.

Figure 8. Scanning electron microscopy (SEM) picture of the as-received, but air-dried, sulfite-rich scrubber material obtained from Power Plant B.

Figure 9. Differential thermal analyzer (DTA) curves of sulfite-rich scrubber material from Power Plant A (top curve) and of analytical grade hydrated calcium sulfite (bottom curve). The DTA curves were recorded under $\mathrm{N}_{2}$ gas environment.

Figure 10. Thermal gravimetric (TGA) curve of sulfite-rich scrubber material obtained from Power Plant B. The TGA data were recorded under $\mathrm{N}_{2}$ gas environment.

Figure 11. Differential thermal analyzer (DTA) curve of sulfite-rich scrubber material from Power Plant B. The DTA curve was recorded under $\mathrm{N}_{2}$ gas environment.

Figure 12. Differential scanning calorimetric (DSC) curve of sulfite-rich scrubber material from Power Plant $\mathrm{B}$. The DSC curve was recorded under $\mathrm{O}_{2}$ gas environment.

Figure 13. SEM picture showing how hot-pressing the scrubber material at $210^{\circ} \mathrm{C}$ under a load of $500 \mathrm{lbs}$ affected the structure of sulfite-rich sludge from Power Plant A.

Figure 14. SEM picture showing how hot-pressing the scrubber material at $210^{\circ} \mathrm{C}$ under a load of $7500 \mathrm{lbs}$ affected the structure of sulfite-rich sludge from Power Plant A.

Figure 15. Fourier transform infrared (FTIR) spectra of sulfite-rich scrubber material depicting how the applied load affected the structure of the scrubber material from Power Plant A.

Figure 16. This figure shows how the hot-pressing pressure at $210^{\circ} \mathrm{C}$ affected the intensity ratios of the observed infrared vibrational bands of the sulfite-rich scrubber material from Power Plant A.

Figure 17: SEM picture showing how hot-pressing the scrubber material at $150^{\circ} \mathrm{C}$ under a load of $3500 \mathrm{lbs}$ affected the structure of sulfite-rich sludge from Power Plant A.

Figure 18. SEM picture showing how hot-pressing the scrubber material at $210^{\circ} \mathrm{C}$ under 
a load of $3500 \mathrm{lbs}$ affected the structure of sulfite-rich sludge from Power Plant A.

Figure 19. Fourier transform infrared (FTIR) spectra of sulfite-rich scrubber material depicting how the formation temperature affected the structure of the scrubber material from Power Plant A when hot-pressed under a load of 3500 lbs.

Figure 20. This figure shows how the hot-pressing temperature at a pressure of 3500 lbs affected the intensity ratios of the observed infrared vibrational bands of the sulfite-rich scrubber material from Power Plant A.

Figure 21. This picture shows the natural fiber matrix composite formed with $10 \mathrm{wt} \%$ sulfite-rich scrubber material.

Figure 22. Stress-strain behavior of natural fiber matrix-based composite derived with scrubber material.

Figure 23. Strength and density of the sample as a function of amount of water soluble commercial polymer.

Figure 24. Strength and density dependence on the amount of water used for the composite fabrication from natural matrix, scrubber material, and water soluble polymer IV. Total mass of other ingredients was $25 \mathrm{~g}$.

Figure 25. Stress vs. strain behavior of composite material derived from water soluble polymer IV.

Figure 26. Effect of temperature on the mechanical properties of composites derived from scrubber material (50 wt\%), Crop A, and polymer II additive.

Figure 27. Flexural strength and density as a function of fiber content (Crop A).

Figure 28. Composites fabricated at various pressures using $5 \%$ of complex natural polymer.

Figure 29. The effects of external polymer on the mechanical properties of composites fabricated from sulfite-rich scrubber material and natural byproducts.

Figure 30. Mechanical properties of composites fabricated using 4:1 ratio of Polymer IIIto-fiber. The scrubber concentration was systematically varied.

Figure 31. The effect of fly ash concentration in the mix on the strength and density of the composites-derived from $50 \mathrm{wt} \%$ scrubber material.

Figure 32. The effect of fly ash on the specific strength of the composites-derived from $50 \mathrm{wt} \%$ scrubber material.

Figure 33. The effect of additive B's concentration in the mix on the strength and density of the composites-derived from $50 \mathrm{wt} \%$ scrubber material.

Figure 33. The effect of additive B's concentration in the mix on the strength and density of the composites-derived from 50 wt\% scrubber material.

Figure 34. The effect of additive B's concentration in the mix on the specific strength of the composites-derived from $50 \mathrm{wt} \%$ scrubber material.

Figure 35. The mechanical properties of commercial wood plastic composites.

Figure 36. How the thermoplastic HDPE concentration affected the mechanical properties of wood plastic composites.

Figure 37. How the thermoplastic HDPE concentration affected the specific strength (= (flexural strength)/density) of wood plastic composites.

Figure 38. Flexural strength and density of HDPE composites: a) as a function of additive concentration at 4:1 scrubber material-to- fiber ratio, and b) as a 
function of the amount of scrubber material ( HDPE was fixed at $70 \mathrm{wt} \%$ ).

Figure 39. Stress vs. strain characteristics of pure but recycled HDPE sample (a), and of composite material containing 70 wt\% of HDPE, 15 wt\% of scrubber material, and $15 \mathrm{wt} \%$ of natural fibers (b).

Figure 40. The weight gain of the decking-type composites as a function of time when submerged in water. Our composites were developed from FGD sulfite-rich scrubber material, while the commercial product contained fly ash.

Figure 41. The weight gain of the wood-substitute composites as a function of time when submerged in water. Our composites were developed from FGD sulfite-rich scrubber material.

Figure 42. Picture of 4" x 4" wood-substitute composite developed from FGD sulfite-rich scrubber material (>50 wt\%) and $<8 \mathrm{~mm}$ cellulosic fibers.

Figure 43. Picture of 4" x 4" wood-substitute composite developed from FGD sulfite-rich scrubber material (> $50 \mathrm{wt} \%)$ and $<8 \mathrm{~mm}$ cellulosic fibers.

Figure 44. Picture of 6" $\times 6$ " wood-substitute composite developed from FGD sulfite-rich scrubber material (> 50 wt\%) and cyclone-ground cellulosic fibers.

Figure 45. Picture of 4" $\times 4$ " and 8" x 2" wood-substitute composites developed from FGD sulfite-rich scrubber material (> $50 \mathrm{wt} \%$ ) and cyclone- ground cellulosic fibers.

Figure 46. Load-bearing decking (4" x 4" x 2") composite developed from sulfite-rich scrubber material.

Figure 47. Load-bearing decking (4" x 4" x 2") composite developed from sulfite-rich scrubber material.

Figure 48. Load-bearing decking (4" x 4" x 2") composite developed from sulfite-rich scrubber material and FBC fly ash.

Figure 49. Load-bearing decking (4" x 4" x 0.5 - 2") composite developed from sulfiterich scrubber material and FBC fly ash.

Figure 50. Load-bearing decking (4" x 4" x 0.5 - 2") composite developed from sulfiterich scrubber material and FBC fly ash.

Figure 51. This figure shows that a regular wood saw could be used to cut our loadbearing composites derived from scrubber material and FBC fly ash. 


\section{LIST OF TABLES}

Table 1. Chemical analysis of as-received but air-dried sulfite-rich scrubber materials.

Table 2. The thermal events observed for sulfite-rich scrubber material obtained from Power Plant B as recorded by TGA method.

Table 3. The DTA results for scrubber material from Power Plant B.

Table 4. This table summarizes the thermal parameters associated with the two endothermic events observed for Power Plant B's scrubber material. The data were obtained using the DSC technique under oxygen gas environment.

Table 5. The weight gained by various composites when submerged in water over two months. 


\section{EXECUTIVE SUMMARY}

The overall goal of this project was to develop technology which could effectively utilize FGD sulfite-rich scrubber material produced by power plants burning Midwestern highsulfur coal. In pursuit of meeting the aforementioned goal, we were to establish whether it was feasible to fabricate value-added products such as wood-substitute products from sulfite-rich scrubber materials.

According to the American Coal Ash Association, about 32,134,000 tons of FGD byproducts were produced in the USA in the year 2008. Out of 32.13 million tons of FGD byproducts, 17.754 million tons were FGD gypsum byproduct. On the other hand, sulfite-rich scrubber byproduct's production was 12.98 million tons in 2008. It is believed that $60 \%$ of the total FGD gypsum produced is consumed in wallboard, Portland cement, and agricultural application. The economical and environmentallyconducive management of wet FGD sulfite-rich scrubber byproduct is much bleaker. Out of $12,980,588$ tons of sulfite-rich scrubber material produced in 2008 , only about 685,104 tons, i.e., a mere $5.28 \%$, were used in mining applications. Clearly, environmentally-friendly and economically-conducive utilization of sulfite-rich scrubber material is of utmost importance for coal burning electric utilities. Our proposed research of developing wood-substitute products and synthetic lumber from sulfite-rich scrubber materials and renewable byproducts precisely does that.

The sulfite-rich scrubber materials were procured from two different power plants, which burn high sulfur Midwestern coals. The wet scrubber cakes were subjected to drying analysis besides chemically and physically characterizing them with the help of X-ray diffraction (XRD), differential scanning calorimetry (DSC), thermal gravimetric analysis ( TGA), differential thermal analysis (DTA), and Fourier transform infrared (FTIR). We used a standard ASTM procedure to ascertain the mercury's behavior in the scrubber material prior to, during, and after our product manufacturing. We used compressive molding techniques to fabricate our wood-substitute composites from sulfite-rich scrubber materials. The fabricated composites were subjected to various ASTM procedures to evaluate the mechanical characteristics of our composites.

The main findings of our project could be summarized as:

1. The physical structural analysis of the sulfite-rich scrubber material, obtained from two different power plants, indicated that the crystallites were typically hannebachite in appearance, i.e., platelet-like crystallites of $\mathrm{CaSO}_{3} \cdot 0.5 \mathrm{H}_{2} \mathrm{O}$. Our scanning electron microscopy (SEM) measurements also revealed that the scrubber material from one of the power plants had a strong tendency to agglomerate in which crystallites stacked one over the other rather than forming spherical-looking agglomerates. The scrubber material from the second power plant did not show this behavior.

2. The XRD diffraction of the as-received, but air-dried, scrubber cake indicated peaks at 11.7, 16.1, and 16.7 degrees, thus, suggesting the scrubber cake to be a mixed phase of $\mathrm{CaSO}_{3} \cdot 0.5 \mathrm{H}_{2} \mathrm{O}, \mathrm{CaSO}_{3} \cdot 4 \mathrm{H}_{2} \mathrm{O}$, and $\left(\mathrm{CaSO}_{4}\right)_{x} \cdot\left(\mathrm{CaSO}_{3}\right)_{1-\mathrm{x}} \cdot \mathrm{nH}_{2} \mathrm{O}$. 
3. On subjecting the scrubber material to high temperatures and pressures typically expected during our product development, we did not observe any statistically significant emission of mercury from the scrubber cake.

4. The detailed thermal measurements, i.e., TGA and DTA analyses at $50^{\circ} \mathrm{C} \leq \mathrm{T} \leq$ $1250^{\circ} \mathrm{C}$, on the scrubber materials suggested that there are four main thermal events by which scrubber material from both power plants decomposed. Consistent with the DSC results, TGA and DTA measurements also reinforced our suggestion that in our wood-substitute composites, the scrubber material would not decompose at $\mathrm{T}<400^{\circ} \mathrm{C}$. Above $400^{\circ} \mathrm{C}$, half a water molecule was lost from the hannebachite crystallites, thus this might retard the flammability of our composites.

5. The exposure of sulfite-rich scrubber material to high-pressure (ambient pressure $\leq$ $\mathrm{P}<3000 \mathrm{psi})$ and high-temperature $\left(25^{\circ} \mathrm{C}<\mathrm{T}<250^{\circ} \mathrm{C}\right)$ resulted in the compression of hannebachite crystallites though they maintained their platelet-like shape. However, it was noticed that higher pressures, i.e., $\mathrm{P}>1100 \mathrm{psi}$, and higher-temperatures, i.e., $\mathrm{T}>200^{\circ} \mathrm{C}$, generated a considerable number of fines. The production of these fines during composite fabrication conditions could result in higher densities of the material. The vibrational (infrared) analysis of the scrubber materials, which were subjected to high-temperatures at high-pressure, indicated that the sulfite-rich scrubber materials retained their chemical structure under the above-mentioned conditions.

6. Our results showed that it was feasible to make composite materials from FGD sulfite-rich scrubber material with flexural strengths up to $90 \mathrm{MPa}(13,050 \mathrm{psi})$. Formation pressure and temperature played an important role, besides the ingredients, in determining the final strength and elastic properties.

7. Depending upon the type of polymer, it appeared that wood-substitute composites could be formulated with sulfite-rich scrubber material with a concentration ranging from $60 \mathrm{wt} \%$ to $75 \mathrm{wt} \%$. It also appears that the density of the composites derived from sulfite-rich scrubber material could be lowered either by the addition of fly ash or hollow spherical particles. However, hollow spherical particles were more effective in lowering the density yet maintaining the higher strength.

8. Our results suggest that post-curing the wood substitute composites developed from sulfite-rich scrubber material resulted in defect sites and micropores. This effectively reduced the density slightly though the strength of the composite also decreased by about $4 \mathrm{MPa}$. Therefore, it is recommended that wood-substitute composites fabricated from scrubber material not be subjected to post-curing.

9. We demonstrated that by combining recycled thermoplastics obtained from consumer recycled products with scrubber materials load-bearing wood plastic composites could be formulated. Flexural strengths in the range of $15 \mathrm{MPa}-$ $30 \mathrm{MPa}$ were achieved, which is comparable to other engineered-wood composites. Storage modulus at sub-ambient temperatures was improved with the addition of calcium sulfite into recycled thermoplastic. 


\section{REPORT DETAILS}

\section{INTRODUCTION}

According to the American Coal Ash Association, about 32,134,000 tons of FGD byproducts were produced in the USA in the year 2008 [1-3]. Out of 32.13 million tons of FGD byproducts, 17.754 million tons were FGD gypsum byproduct. On the other hand, sulfite-rich scrubber byproduct's production was 12.98 million tons in 2008 . It is believed that $60 \%$ of the total FGD gypsum produced is consumed in wallboard, Portland cement, and agricultural application $[1,2]$. The rest of the FGD gypsum is landfilled.

The economical and environmentally-conducive management of wet FGD sulfite-rich scrubber byproduct is much bleaker. Out of 12,980,588 tons of sulfite-rich scrubber material produced in 2008 , only about 685,104 tons, i.e., a mere $5.28 \%$, were used in mining applications. The rest, i.e., 12,295,484 tons, was landfilled. Generally, wet FGD sulfite-rich scrubber material is stabilized or fixated by the addition of fly ash, cement, and/or lime prior to being landfilled. Unlike FGD gypsum, which when sold can garner resources for electric utilities, most power plants have to pay to dispose of sulfite-rich scrubber material. In fact, electric utilities paid to dispose of 2.08 million tons in 2000. Undoubtedly, the management problem is not only economical as the cost of landfilling continues to escalate but also may present environmental challenges for the long-term concerns associated with calcium sulfite landfills. Granted that in the near future most utilities are likely to install scrubber units which produce FGD gypsum, effective strategies are still required for managing the huge production of sulfite-rich scrubber material in the country. Clearly, environmentally-friendly and economically-conducive utilization of sulfite-rich scrubber material is of utmost importance for coal burning electric utilities. Our proposed research of developing wood-substitute products and synthetic lumber from sulfite-rich scrubber materials and renewable byproducts precisely does that.

Traditionally, engineered wood products are developed by co-processing a polymer, typically a thermoset or a thermoplastic, wood shavings, and/or wood flour [4-6]. The wood plastic composites are developed from high density polyethylene (HDPE), polypropylene (PP), or polyvinyl chloride (PVC). Largely, the wood plastic composite materials are used for decking, equestrian products, benching, and fencing applications. Most commercial wood plastic products generally contain wood byproducts with the plastic content ranging from 30 to $60 \mathrm{wt} \%$ [5]. In addition to wood byproducts and plastic, different inorganic additives are incorporated into the composite to improve its final stiffness. The other class of engineered wood composites is manufactured with the help of thermoset polymer, e.g., phenolic and/or polyurethane. These composite materials are generally used for outdoor construction applications and play an important role in the environment where humidity is high [7]. Typically, these products are developed from wood byproducts by gluing the byproducts with the resin material. 
As the name implies, the engineered wood materials are largely manufactured from wood and its byproducts. The technology for manufacturing engineered wood products is reasonably well established. However, in the coming decades, global warming is going to play an important role in the manufacturing processes followed worldwide. To mitigate the concerns associated with the emission of carbon dioxide $\left(\mathrm{CO}_{2}\right)$ and its role in global warming, a number of strategies are being proposed. Maintaining and enhancing our forested lands are expected to play a crucial role in environment remediation among different $\mathrm{CO}_{2}$ sequestration strategies being pursued. Therefore, there is a renewed urgency to develop technologies which might not totally eliminate the harvesting of the trees but can at least minimize their use.

For the last few years, we have been attempting to develop wood substitute products from annual crop-based fibrous materials [8-10]. However, to further reduce the wood substitute products' development costs and to seek a more conducive environmental management of FGD sulfite-rich scrubber material, we have been exploring whether two goals could be married. This was the focus of our project.

\section{EXPERIMENTAL TECHNIQUES AND APPROACHES}

\section{Sulfite-Rich Scrubber Material:}

The sulfite-rich scrubber material was provided by a power plant located in Illinois, which burns high-sulfur Illinois bituminous coal \{henceforth called Power Plant A (PPA)\}. The scrubber materials were in wet cake form and were collected throughout the life of this project. A second source of the wet scrubber material was from a power plant located in Indiana \{Power Plant B (PPB)\} which also burns high sulfur Midwestern coal.

\section{Infrared (IR) Measurements:}

The IR spectrum of the scrubber material was obtained using a Thermo Electron 670 Fourier transform infrared (FTIR) spectrometer equipped with a $\mathrm{KBr}$ beam splitter and a DTGS detector. We did not use the conventional $\mathrm{KBr}$ pellet approach to record our IR spectra because our past experience suggests that during $\mathrm{KBr}$ pellet formation, under high pressure, there is a potential of chemical reaction between $\mathrm{KBr}$ and $\mathrm{CaSO}_{3}$. Instead, we formed mulls by hand grinding the scrubber material with mineral oil. The sample mulls were smeared between two $\mathrm{KBr}$ window optical flats, and the samples' spectra were recorded by acquiring 50 scans at $4 \mathrm{~cm}^{-1}$ resolution.

\section{Mercury Analysis:}

We used EPA 7473 method to analyze the mercury concentration in the scrubber materials. A commercial mercury analyzer, i.e., DMA-80 (Milestone, Inc.), was used for this purpose. The scrubber materials were air-dried in cleaned dishes for various lengths of time before subjecting the samples to $\mathrm{Hg}$ analysis. The air-dried samples were weighed (approximately $0.4 \mathrm{~g}$ ) and loaded in nickel boats. The DMA-80 equipment consists of a thermal decomposition chamber followed by a catalytic conversion chamber, gold amalgamation system, and an atomic absorbance spectrophotometer. Controlled heating is used to first dry and then thermally decompose a sample in a quartz decomposition tube. A continuous flow of oxygen 
carries the decomposition products through a heated catalytic bed where $\mathrm{SO}_{2}, \mathrm{~N}_{2}$, and halogens are trapped. All mercury species are reduced to $\mathrm{Hg}^{0}$ and are carried over to the gold amalgamator where mercury is selectively trapped. The non-mercury vapors and decomposition products are flushed from the system prior to rapidly heating the gold amalgamator. The rapid heating of the amalgamator releases the mercury vapor, and the released vapors are subjected to a single beam, fixed wavelength $(253.7 \mathrm{~nm})$ atomic absorbance spectrophotometer. The output data are displayed as $\mathrm{ng} / \mathrm{g}$ or as $\mu \mathrm{g} / \mathrm{kg}$ of mercury concentration.

For our samples, we used the drying temperature of $300^{\circ} \mathrm{C}$ and decomposition temperature of $800^{\circ} \mathrm{C}$. For the results reproduced in this report, we ran each sample at least four to five times to ensure a representative concentration of $\mathrm{Hg}$ in the sample. The blank boats were run intermediately between sample runs to eliminate any mercury memory effects. This approach, i.e., running blank sample boats between sample runs, provided an additional check for AA spectrophotometer's ability to accurately measure mercury concentrations. To clean our sample boats, we first removed ash from the boats by simply wiping them. The wiped boats were then ultrasonically cleaned in distilled water for 2 to 3 hours. The ultrasonic cleaning was followed by heating the nickel boats in a furnace to $850^{\circ} \mathrm{C}$ to ensure the removal of residual $\mathrm{Hg}$. Between run days, the standard sample of apple leaves (Standard 1515) obtained from the National Institute of Standards and Technology (NIST) was run to ensure the accuracy of the system at low mercury concentration levels.

It is known that most scrubber units facilitate the capture of mercury, especially water soluble oxidized mercury while scrubbing $\mathrm{SO}_{2}$. Because our composites were to be formulated at higher temperatures, i.e., $140^{\circ} \mathrm{C}<\mathrm{T}<230^{\circ} \mathrm{C}$, and at higher pressures, i.e., $\mathrm{P}>30 \mathrm{psi}$, there was a concern whether mercury captured by the scrubber materials could be re-emitted. As mentioned above, the mercury analysis of sulfite-rich scrubber was performed on the air-dried material. However, to determine whether any mercury would be re-emitted during our product manufacturing conditions, we prepared samples by hot-pressing pure scrubber material in a high pressure stainless steel die, simulating actual sample fabrication conditions. First, the temperature series was performed by preparing samples under $1000 \mathrm{psi}(7 \mathrm{MPa})$ pressure at $140^{\circ} \mathrm{C}, 155^{\circ} \mathrm{C}$, $170^{\circ} \mathrm{C}, 185^{\circ} \mathrm{C}, 200^{\circ} \mathrm{C}, 215^{\circ} \mathrm{C}, 230^{\circ} \mathrm{C}$, and $245^{\circ} \mathrm{C}$. Then, the point corresponding to an onset of change in mercury behavior was picked to perform a pressure series where samples were prepared using fabrication pressures from $0(0 \mathrm{MPa})$ psi to $11000 \mathrm{psi}$ (75.9 MPa).

\section{Scanning Electron Microscopy (SEM):}

The crystalline behavior of the as-received sulfite-rich scrubber materials from Power Plants A was ascertained by obtaining their microscopic picture, using SEM technique. We used a Hitachi S570 scanning electron microscope to record our pictures.

\section{Differential Scanning Calorimetry (DSC) Measurements:}

The thermal behavior of as-received scrubber material was ascertained by subjecting it to DSC measurements at $30^{\circ} \mathrm{C}<\mathrm{T}<500^{\circ} \mathrm{C}$. The DSC data were acquired on a Perkin- 
Elmer DSC7 system, interfaced with a PC computer using a Pyris (Perkin-Elmer) software. The DSC was calibrated for temperature and enthalpy. The temperature calibration was performed by the two-point method, using the melting transitions of indium $\left(157^{\circ} \mathrm{C}\right)$ and zinc $\left(420^{\circ} \mathrm{C}\right)$. The accuracy in temperature between $30^{\circ} \mathrm{C}$ and $420^{\circ} \mathrm{C}$, based on our calibration procedure, was estimated to be $\pm 1^{\circ} \mathrm{C}$. The enthalpy calibration was performed using indium heat of fusion as the standard. After the enthalpy calibration, the DSC data on zinc metal were re-recorded, and the observed enthalpy of the melting transition of zinc was consistent with the values reported in the literature. The conditions under which the instrument calibration was performed exactly matched the experimental run conditions, namely the scan rate of $10^{\circ} \mathrm{C} / \mathrm{min}$, oxygen gas purge at 30 psi pressure. Also, during both calibration and heating runs, the dry box assembly over the sample head was flushed with nitrogen gas to maintain thermodynamic equilibrium. Aluminum (Al) sample pans in an unsealed mode generally were used to determine the thermal behavior of the scrubber materials. This was achieved by pushing down the top sample pan cover gently onto the bottom pan containing the sample.

\section{Thermal Gravimetric Analysis (TGA) and Differential Thermal Analyzer (DTA)}

\section{Measurements:}

The high temperature thermal stability of the sulfite-rich scrubber materials was evaluated by subjecting the scrubber materials to TGA and DTA measurements at $50^{\circ} \mathrm{C}$ $\leq \mathrm{T} \leq 1200^{\circ} \mathrm{C}$. Both TGA and DTA curves were obtained under nitrogen gas environment. We used Perkin-Elmer's Diamond TGA system to record gravimetric curves.

The high temperature thermal behavior of sulfite-rich scrubber sludges was probed using a Perkin-Elmer DTA7 system capable of operating at $50^{\circ} \mathrm{C}<\mathrm{T}<1650^{\circ} \mathrm{C}$. This DTA equipment is capable of operating under various gas environments. A heating rate of $10^{\circ} \mathrm{C} \mathrm{min}{ }^{-1}$ was used. We used $\alpha-\mathrm{Al}_{2} \mathrm{O}_{3}$ powder as a reference material for our experiments.

\section{Materials and Composite Fabrication Procedures:}

Sulfite-rich scrubber material was air dried for at least 24 hours prior to analysis and composite fabrication. Agricultural crop byproducts were used as additive material for our products. Crop material was first ground with a large scale hammer mill to obtain particle size of $\sim 2$ to $3 \mathrm{~cm}$ in length, and this material was further ground in a cyclone mill to obtain micron-sized particles. The crop materials used for our composite manufacturing were largely composed of cellulose (40-60\%), hemicelluloses (20 - 40 $\%)$, and lignin (10 - $25 \%)$. For the additive material, we used three different crops which have a slightly different cellulose-hemicellulose-lignin ratio. In general, these crop materials are very cheap and are readily available in the USA.

We used scrubber material obtained from PPA and crop materials obtained from Illinois sources for our composite fabrication. Even though by using high pressures and temperatures the composites could be fabricated purely from these two components, it was believed that the addition of a small amount of additives could greatly enhance the 
mechanical properties of the final product. Therefore, we tested various synthetic polymers in small quantities. The scrubber material along with crop byproducts and additives were mixed in a high-speed, high-shear blender prior to adding the ingredients in a high-pressure, high-temperature stainless steel die. The die was hot pressed at the predetermined temperature and pressure. After hot-pressing, the samples were ejected from the stainless steel die and were subjected to mechanical testing.

\section{Mechanical Testing:}

The composites were cut into rectangular strips measuring approximately $4 \mathrm{~mm} \times 6 \mathrm{~mm}$ $x 50 \mathrm{~mm}$ and were then subjected to mechanical testing. The flexural strength of the composites was determined with the help of a commercial (ELE International) universal testing machine equipped with an in-house built three point bending fixture. The sample was placed on two parallel stainless steel pins, and the load was applied in the middle. The applied load was increased at a constant rate. The loading nose was attached to the load cell which precisely measured the pressure applied to the sample. The linear vertical displacement sensor values were used to determine the strain that the sample sustained during the measurement. Flexural strength was determined according to ASTM D790 standard method, which is a maximum sustained stress by the sample at break and was calculated using the following equation:

$$
\sigma=\frac{3 F l}{2 b h^{2}},
$$

where $\mathrm{F}, \mathrm{I}, \mathrm{b}$, and $\mathrm{h}$ are the load at failure, span length, width, and thickness, respectively.

Strain values were determined from the displacement data:

$$
r=\frac{6 D d}{L^{2}},
$$

where $D$ is the mid-span deflection, $d$ is the depth of the beam, and $L$ is the support span. Load and displacement data were used to generate stress vs. strain curves.

\section{RESULTS AND DISCUSSION}

\section{Chemical Analysis:}

The as-received sulfite-rich scrubber materials from PPA and PPB were sent to a commercial laboratory for chemical analysis. The scrubber material was air-dried for more than a week at ambient temperature prior to sending the samples for analysis. Table 1 lists the concentrations of chlorine (Cl), arsenic (As), selenium (Se), boron (B), and cadmium $(\mathrm{Cd})$ in the scrubber material from both power plants. It should be noticed from Table 1 that the chlorine content of Power Plant B's scrubber material was much higher than for the scrubber material from Power Plant A. Moreover, it appeared that 
the scrubber material from Power Plant $\mathrm{B}$ had higher selenium and boron content than that for Power Plant A.

Table 1. Chemical analysis of as-received but air-dried sulfite-rich scrubber materials.

\begin{tabular}{|c|c|c|}
\hline Chemical & Power Plant A (PPA) & Power Plant B (PPB) \\
\hline $\begin{array}{c}\text { Chlorine } \\
\text { (as-received) }\end{array}$ & $0.01 \%$ & $0.16 \%$ \\
\hline $\begin{array}{c}\text { Chlorine } \\
\text { (dry) }\end{array}$ & $0.01 \%$ & $0.16 \%$ \\
\hline Arsenic (As) & $<1 \mathrm{mg} / \mathrm{g}$ & $<1 \mathrm{mg} / \mathrm{g}$ \\
\hline Selenium (Se) & $<1 \mathrm{mg} / \mathrm{kg}$ & $<4 \mathrm{mg} / \mathrm{kg}$ \\
\hline Boron (B) & $20 \mathrm{mg} / \mathrm{g}$ & $127 \mathrm{mg} / \mathrm{g}$ \\
\hline Cadmium (Cd) & $<1 \mathrm{mg} / \mathrm{kg}$ & $<1 \mathrm{mg} / \mathrm{kg}$ \\
\hline
\end{tabular}

\section{Bulk Densities and X-ray Analysis:}

We measured the apparent bulk density of the PPA scrubber material at $689 \mathrm{~kg} / \mathrm{m}^{3}$, while the Crop A material had an apparent density of $215 \mathrm{~kg} / \mathrm{m}^{3}$. High fabrication pressures, however, may greatly increase the density of composites.

Figure 1 shows the X-ray diffraction patterns observed for air-dried sulfite-rich scrubber material for PPB. It should be noted that the scrubber material had not undergone fixation, thus, the material is not expected to contain fly ash particles unless the particles are due to impurities. In the $2 \theta$ range of 5 to $65^{\circ}$, the main diffraction d-spacing was observed at $7.6,5.5,5.3,4.3,4.25,3.78,3.15,3.07,2.67$, and $4.25 \AA$. The main dspacing for $\mathrm{CaSO}_{3} .0 .5 \mathrm{H}_{2} \mathrm{O}$ (in the order of descending intensity) was at $3.16,2.63$, and $5.56 \AA$, while for $\mathrm{CaSO}_{3} .4 \mathrm{H}_{2} \mathrm{O}$ crystals the d-spacing match with $5.74,3.62$, and $2.67 \AA$. The major reflections observed for gypsum $\left(\mathrm{CaSO}_{4} .2 \mathrm{H}_{2} \mathrm{O}\right)$ are at $7.56,4.27,3.06,2.87$, and $2.68 \AA$. The reflections observed at 7.6, 4.25, and $3.07 \AA$ did suggest the presence of $\mathrm{CaSO}_{4} .2 \mathrm{H}_{2} \mathrm{O}$ in the scrubber material; however, as reported by Gadalla and Gupta [1], it is more likely that sulfate exists in a solid solution in the form $\left(\mathrm{CaSO}_{4}\right)_{\mathrm{n}}\left(\mathrm{CaSO}_{3}\right)_{1-n} \cdot \mathrm{xH}_{2} \mathrm{O}$. The observed diffraction patterns of sulfite-rich scrubber material, as expected, did indicate the presence of $\mathrm{CaSO}_{3} \cdot \mathrm{xH}_{2} \mathrm{O}$. However, based on the observed d-spacing values, we could not discount either $\mathrm{CaSO}_{3} \cdot 0.5 \mathrm{H}_{2} \mathrm{O}$ or $\mathrm{CaSO}_{3} .4 \mathrm{H}_{2} \mathrm{O}$ crystalline phase in the scrubber material. It is more likely that both hydrated sulfite phases are present in the scrubber material. 


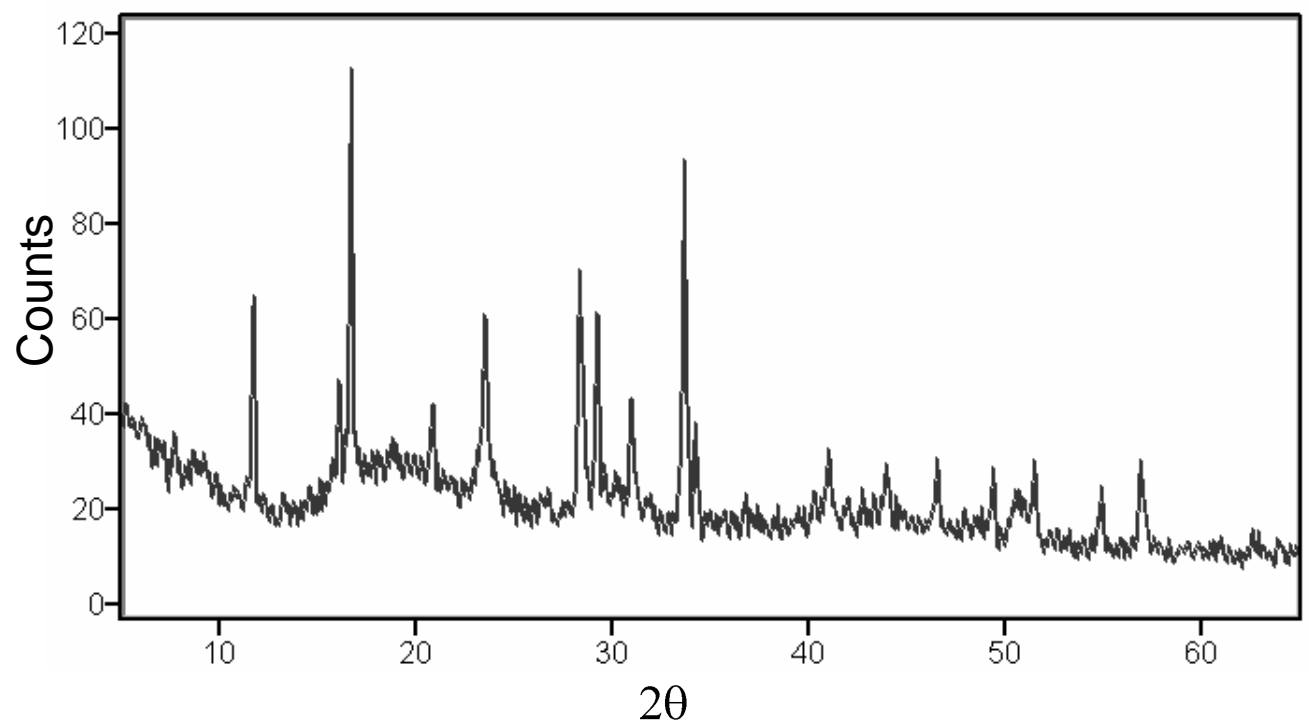

Figure 1. Observed XRD pattern for sulfite-rich but air-dried scrubber material.

\section{Drying and Thermal Behavior:}

Figure 2 reproduces the weight loss from wet sulfite-rich scrubber material at ambient atmosphere and temperature. As can be seen, the bulk of weight loss occurred during the first 24 hours, and thereafter the rate of weight loss decreased dramatically. It appears that for the development of composites from sulfite-rich scrubber material, the air-drying of the scrubber material for 48 hours will be adequate to sufficiently reduce the moisture content.

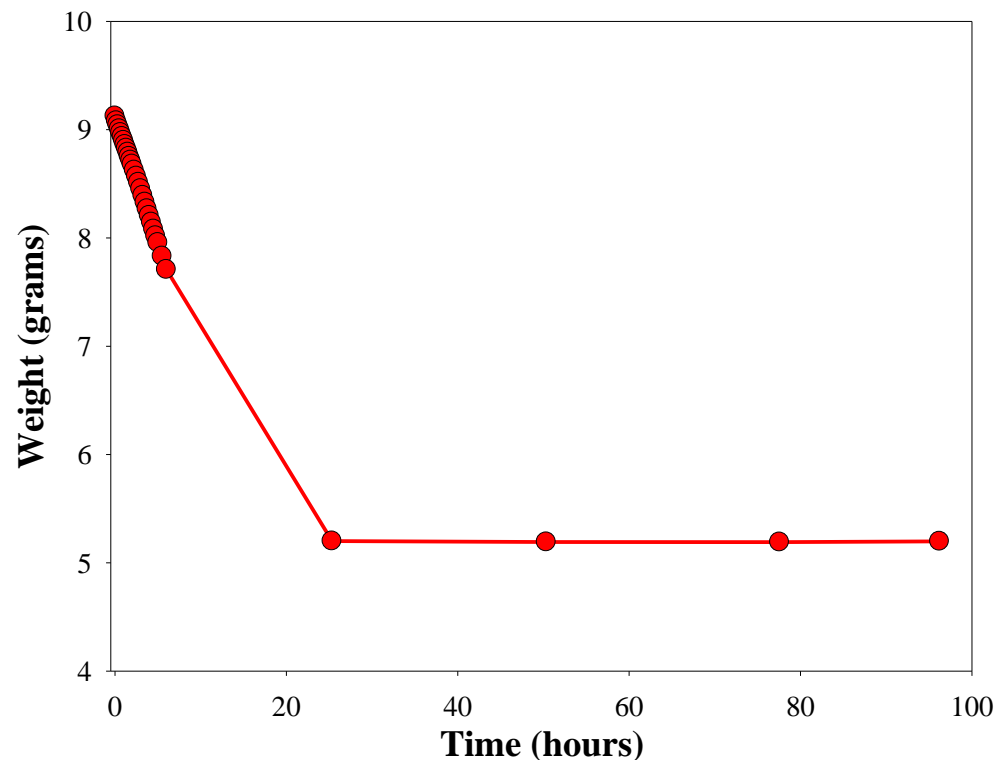

Figure 2. The weight loss from the sulfite-rich scrubber material at ambient temperature and atmosphere.

Figures 3 shows the effects of air drying time on the DSC curves obtained from sulfiterich scrubber material. Strong endothermic reactions were observed at $134^{\circ} \mathrm{C}$ and 
$447^{\circ} \mathrm{C}$. On air-drying the scrubber material at ambient temperature, the intensity of the $134^{\circ} \mathrm{C}$ endothermic peak steadily decreased and eventually disappeared for the sample which was air dried for 288 hours. The peak at $447^{\circ} \mathrm{C}$ persisted irrespective of the length of air-drying. The first endothermic peak at around $134^{\circ} \mathrm{C}$ represents the breakup and evaporation of loosely hydrogen-bonded water. The peak at $447^{\circ} \mathrm{C}$ indicated that the water associated with $\mathrm{CaSO}_{3}$ in the scrubber material was much more strongly bonded.

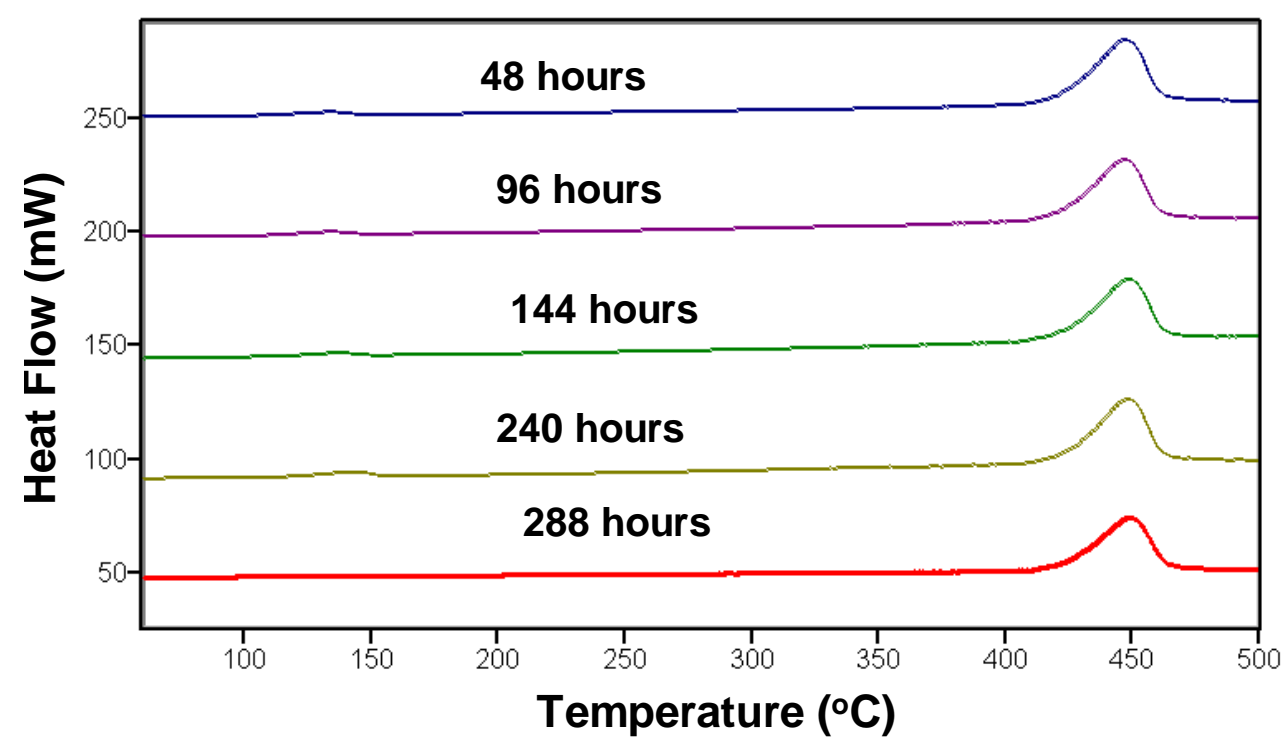

Figure 3. The DSC curves obtained from sulfite-rich scrubber material from Power Plant A air-dried at ambient temperature for different lengths of time.

Figure 4 reproduces the mercury concentration in the PPA and PPB scrubber materials as a function of air-drying time. Initially, the mercury concentrations in the PPA and PPB scrubber materials were 161 and $226 \mu \mathrm{g} / \mathrm{kg}$, respectively. After one day of air drying, the mercury concentrations dramatically increased for both scrubber materials. This increase in concentration seems reasonable if it is argued that mercury in the scrubber material is not associated with water and as water evaporated the mercury concentration by weight increased. After 14 days of air drying time, the mercury in the PPA scrubber material increased to $283 \mu \mathrm{g} / \mathrm{kg}$, while this increase was to $435 \mu \mathrm{g} / \mathrm{kg}$ for PPB scrubber material. The data presented in Figure 4 suggested that water continues to evaporate from the scrubber materials even after 14 days of air drying. However, it does seem more water was lost from PPB than PPA scrubber material for the first 14 days of air drying. 


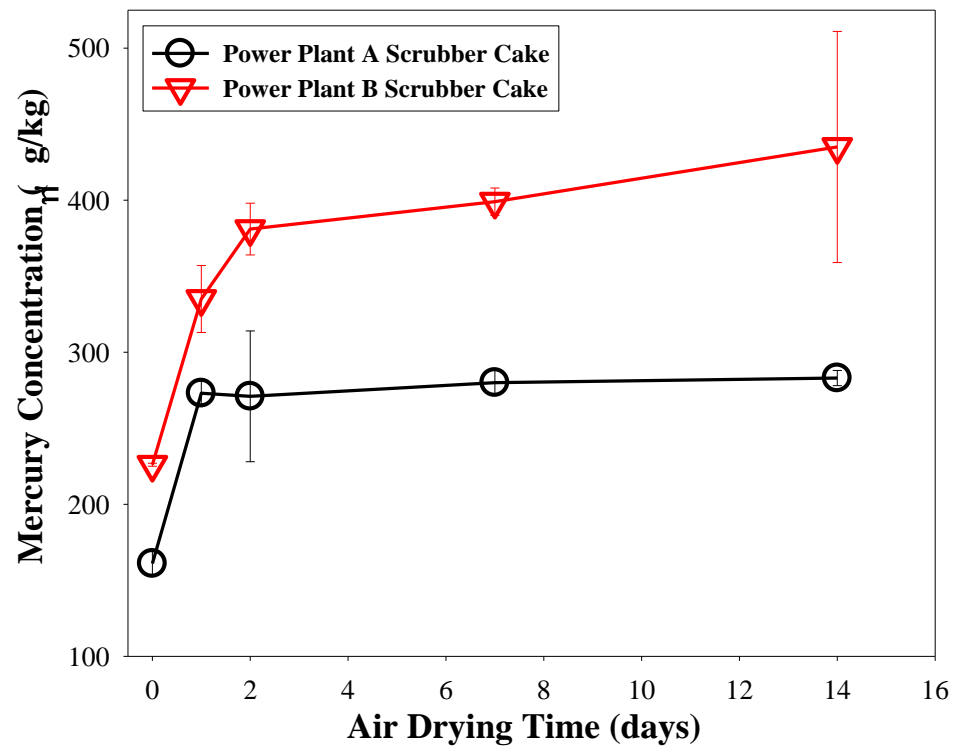

Figure 4. The effect of air-drying time on the mercury concentration in the scrubber materials.

As mentioned earlier, the development of value-added composites will require processing the scrubber material at $140^{\circ} \mathrm{C}<\mathrm{T}<250^{\circ} \mathrm{C}$ under high pressures $(1 \mathrm{MPa}<$ $\mathrm{P}<20 \mathrm{MPa}$ ). When sulfite-rich scrubber material was subjected to heat treatment at $25^{\circ} \mathrm{C} \leq \mathrm{T} \leq 250^{\circ} \mathrm{C}$ at ambient pressure under air, the mercury concentration in the scrubber material rapidly decreased as the temperature increased beyond $150^{\circ} \mathrm{C}$. This can be clearly seen in Fig. 5 . In fact, between $150^{\circ} \mathrm{C}$ and $250^{\circ} \mathrm{C}, 35 \%$ of the mercury content of the scrubber material was lost, suggesting re-emission of mercury. This raised a serious concern whether during our product manufacturing significant amounts of mercury would be re-emitted. However, at higher pressures the thermodynamic properties of the solid mercury compounds are expected to be modified. Unfortunately, no detailed information is available in the literature listing how mercury compounds' vapor pressures are modified at elevated pressures. Moreover, at present the speciation of solid mercury compounds in the scrubber materials is lacking. Therefore, we subjected scrubber materials, obtained from PPA and PPB, to conditions, i.e., pressure and temperature, under which our composites will be formulated to ascertain whether our manufacturing approach will require mercury scrubbing.

Figure 5 depicts how the fabrication temperature affected the mercury concentration in the scrubber materials. It appeared that the mercury behavior in the scrubber material for PPA was considerably modified at a higher pressure of 5.6 MPa. We did not observe any statistically significant loss of mercury from the PPA's scrubber material as long as the $\mathrm{T} \leq 210^{\circ} \mathrm{C}$. The PPA samples hot-pressed at $250^{\circ} \mathrm{C}$ showed some loss of mercury from the scrubber material which was statistically significant. On the other hand, the scrubber material from PPB when hot-pressed at $250^{\circ} \mathrm{C}$ did not show any statistically significant mercury loss. 


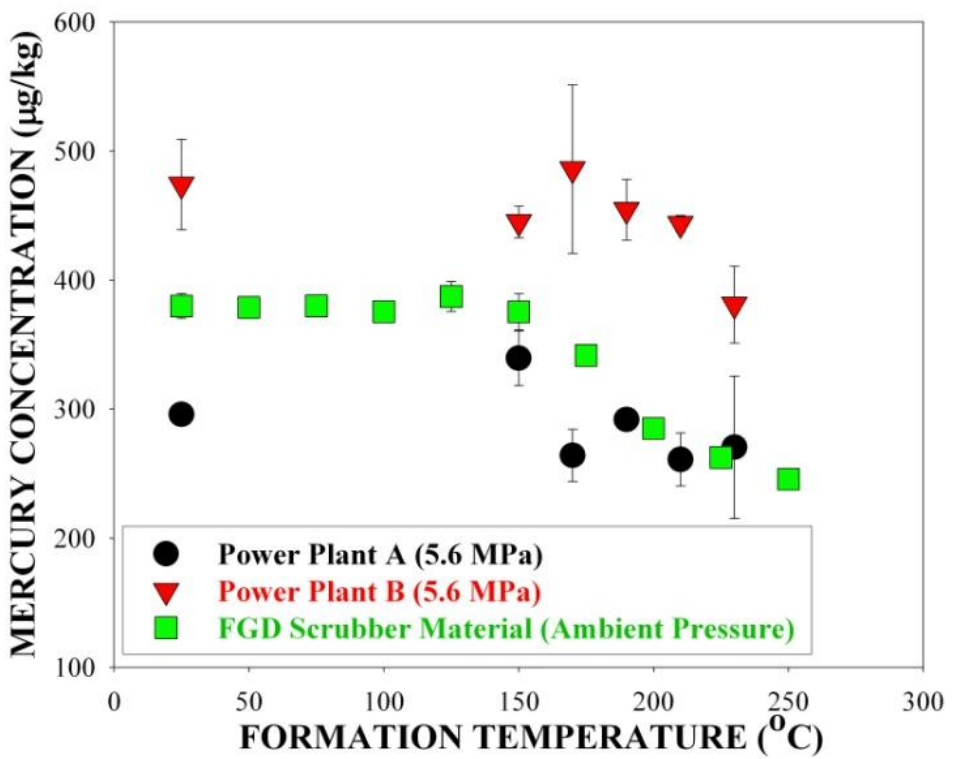

Figure 5. The effect of fabrication temperature on the $\mathrm{Hg}$ concentration of the scrubber materials from Power Plants $A$ and $B$ at $5.6 \mathrm{MPa}$.

Figure 6 shows how the formation pressure affected the mercury concentration in the scrubber material on hot-pressing it at $210^{\circ} \mathrm{C}$. When the scrubber material was heated under ambient pressure to $210^{\circ} \mathrm{C}$, we observed that sulfite-rich scrubber material lost about $32 \%$ of the mercury. As can be seen from Fig. 6 , the higher pressures inhibited any statistically significant loss of mercury from scrubber material from PPA even though samples were hot-pressed at $210^{\circ} \mathrm{C}$. Unlike PPA scrubber material, we did observe a much larger variation in the mercury concentration of the PPB's scrubber material as a function of pressure. It appears at the lower pressures, i.e., $\mathrm{P}<4 \mathrm{MPa}$, some mercury was volatized from PPB's scrubber material. However, as the pressure increased, no statistically significant loss of mercury was observed.

\section{Structural Analysis:}

Figures 7 and 8 show the SEM photomicrograph of as-received scrubber material from PPA and PPB, respectively. The as-received scrubber materials, which were in wet cake form, were first air-dried at $25^{\circ} \mathrm{C}$ for seven days prior to recording their photomicrographs. According to Randolph et al. [12], a wide variety of crystal growth habits of calcium sulfite is observed depending upon dopants' and/or additives present in the liquor from which crystallites are precipitated. They suggested that in the absence of additives, typically platelet-like growth is the predominant crystal growth behavior. As can be seen from Figs. 7 and 8 , both scrubber materials showed plateletlike structures. 


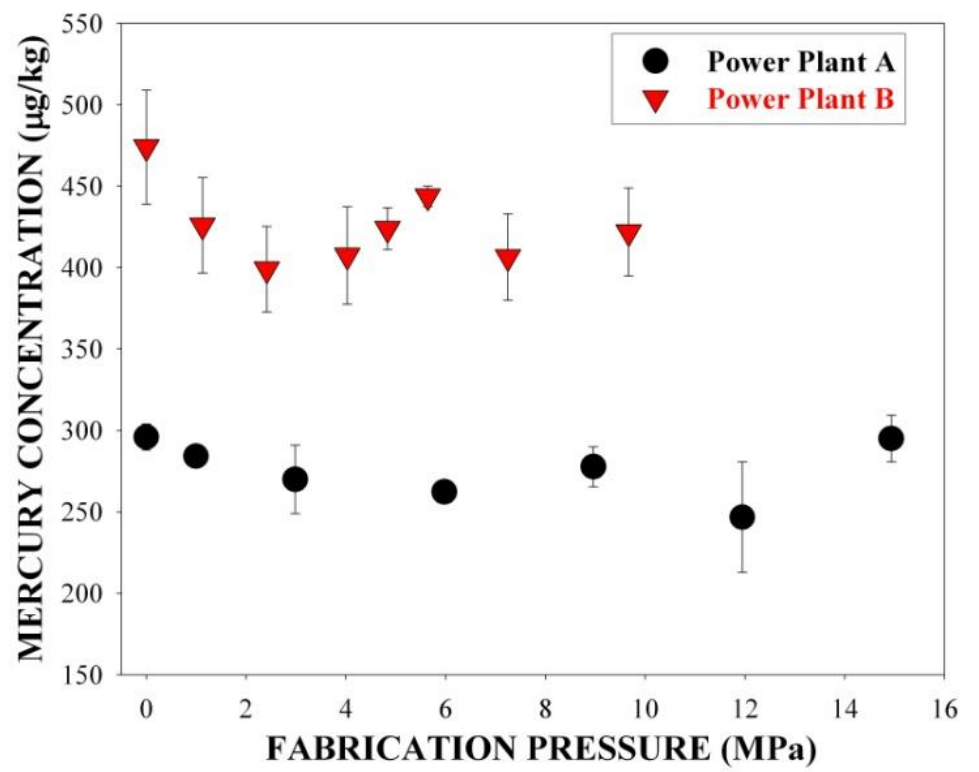

Figure 6. The effect of fabrication pressure on the $\mathrm{Hg}$ concentration of the scrubber materials from Power Plants $\mathrm{A}$ and $\mathrm{B}$ at $210^{\circ} \mathrm{C}$.

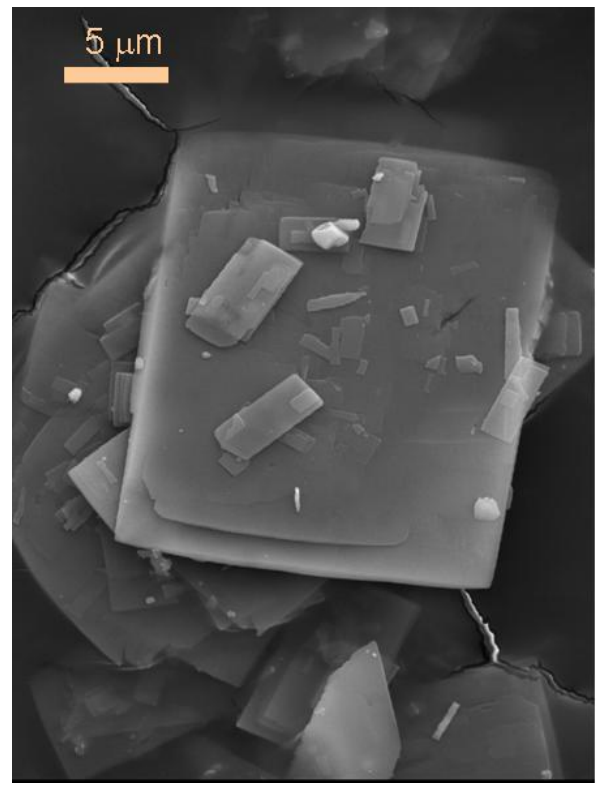

Figure 7: Scanning electron microscopy (SEM) picture of the as-received, but air-dried, sulfite-rich scrubber material obtained from Power Plant $A$.

However, while we observed a strong tendency for the crystallites from sulfite-rich material from Power Plant A to stack one above the other, no such tendency was observed for the scrubber material from Power Plant B. At present, it is not clear how these different agglomeration behaviors would affect the fabrication of the composite materials from these two scrubber products. Another important observation was that while we did see some small fly ash particles in the scrubber material obtained from Power Plant B, we did not see similar fly ash particles in Power Plant A's scrubber material. 


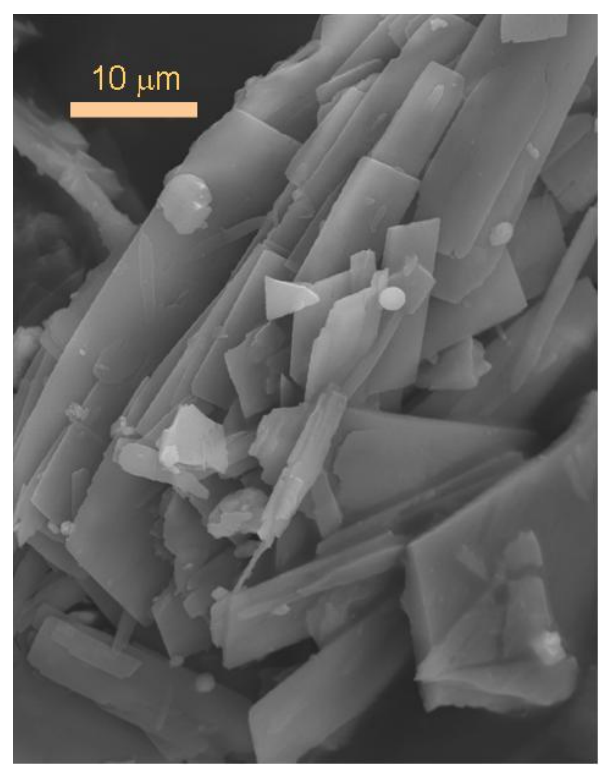

Figure 8: Scanning electron microscopy (SEM) picture of the as-received, but air-dried, sulfite-rich scrubber material obtained from Power Plant B.

\section{Thermal Behavior of Sulfite-Rich Scrubber Materials:}

The thermal behavior of the as-received but air-dried scrubber material from Power Point $A$ is shown in Fig. 9. The DTA curve showed six endothermic events at $109^{\circ} \mathrm{C}$ (broad peak), $161^{\circ} \mathrm{C}, 396^{\circ} \mathrm{C}$ (shoulder), $419^{\circ} \mathrm{C}, 722^{\circ} \mathrm{C}$, and $1028^{\circ} \mathrm{C}$ and an exothermic event at $688^{\circ} \mathrm{C}$. To facilitate the DTA analysis, we also recorded the thermal behavior of analytical grade $\mathrm{CaSO}_{3} \cdot \mathrm{nH}_{2} \mathrm{O}$ (Aldrich Chemical) under identical conditions used for scrubber materials. The $\mathrm{CaSO}_{3} \cdot \mathrm{nH}_{2} \mathrm{O}$ 's DTA curve showed endothermic peaks at $115^{\circ} \mathrm{C}$ (broad peak), $160^{\circ} \mathrm{C}, 400^{\circ} \mathrm{C}$, and $983^{\circ} \mathrm{C}$, and a weak exothermic peak at $700^{\circ} \mathrm{C}$. The broad endothermic peak observed at $\mathrm{T}<120^{\circ} \mathrm{C}$, for both scrubber material and $\mathrm{CaSO}_{3} \cdot \mathrm{nH}_{2} \mathrm{O}$, could be associated with the evaporation of the bulk-type water from the samples. The second endothermic peak at $161^{\circ} \mathrm{C}$ suggested the presence of more strongly bonded, perhaps hydrogen bonded, water in both samples. Gadalla and Gupta [11] and Zaremba et al. [13] have reported the thermal behavior of FGD scrubber materials, including DTA measurements. They suggested that the second endothermic peak at $\mathrm{T}<200^{\circ} \mathrm{C}$ may be due to the presence of gypsum in the scrubber material. We discount this possibility for our scrubber material sample from Power Plant A because of the following:

(a) It is highly unlikely that the analytical grade $\mathrm{CaSO}_{3} \cdot \mathrm{nH}_{2} \mathrm{O}$ will have a significant amount of $\mathrm{CaSO}_{4} \cdot 2 \mathrm{H}_{2} \mathrm{O}$ to produce a strong but sharp peak in our DTA curves (see Fig. 9).

(b) The dehydration of gypsum occurs in two distinct steps, resulting in two sharp endothermic peaks at $125^{\circ} \mathrm{C}<\mathrm{T}<190^{\circ} \mathrm{C}$. We did not observe these double peaks for our samples.

(c) Gypsum undergoes a structural phase transition at $\sim 360^{\circ} \mathrm{C}$, which results in an exothermic peak. We did not observe this exothermic peak for our samples though we did see this peak when gypsum samples were investigated. 


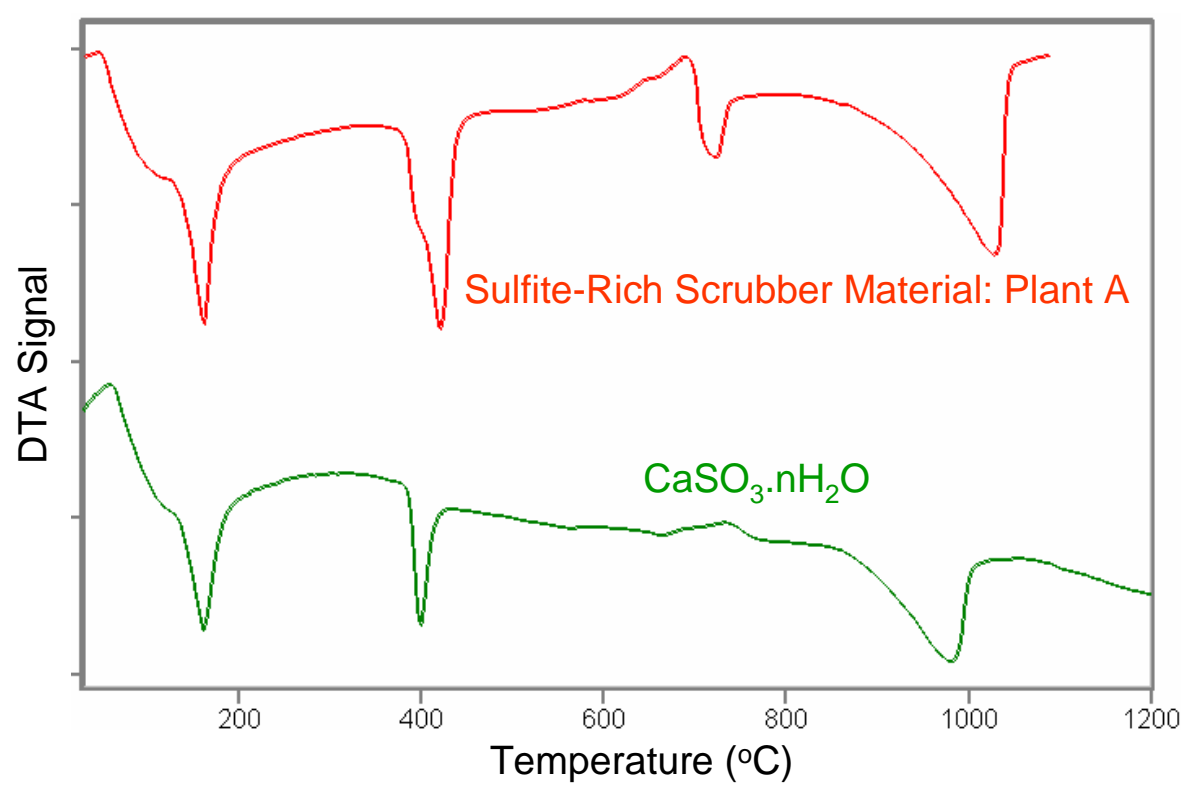

Figure 9. Differential thermal analyzer (DTA) curves of sulfite-rich scrubber material from Power Plant A (top curve) and of analytical grade hydrated calcium sulfite (bottom curve). The DTA curves were recorded under $\mathrm{N}_{2}$ gas environment.

The endothermic peak observed at $400^{\circ} \mathrm{C}$ for $\mathrm{CaSO}_{3} \cdot \mathrm{nH}_{2} \mathrm{O}$ could be associated with the following decomposition reaction $[11,13]$,

$$
\left(\mathrm{CaSO}_{3}\right)_{x}\left(\mathrm{CaSO}_{4}\right)_{1-\mathrm{x}} \cdot 0.5 \mathrm{H}_{2} \mathrm{O}(\mathrm{s}) \rightarrow\left(\mathrm{CaSO}_{3}\right)_{\times}\left(\mathrm{CaSO}_{4}\right)_{1-\mathrm{x}}(\mathrm{s})+0.5 \mathrm{H}_{2} \mathrm{O}(\uparrow) \text { eq.(1). }
$$

The fact that we observed two endothermic peaks at $396^{\circ} \mathrm{C}$ and $419^{\circ} \mathrm{C}$ for scrubber material from Power Plant $A$ raises the possibility of a more complex structure for the calcium sulfite crystallites produced during the scrubbing process.

The weak exothermic peak at $670^{\circ} \mathrm{C}<\mathrm{T}<705^{\circ} \mathrm{C}$ suggested the disproportionation reaction of $\mathrm{CaSO}_{3}[3,5]$, i.e.,

$$
4 \mathrm{CaSO}_{3}(\mathrm{~s}) \rightarrow 3 \mathrm{CaSO}_{4}(\mathrm{~s})+\mathrm{CaS} \quad \text { eq. (2). }
$$

We observed an endothermic peak at $722^{\circ} \mathrm{C}$ for the scrubber material from Power Plant A but not for analytical $\mathrm{CaSO}_{3} \cdot \mathrm{nH}_{2} \mathrm{O}$. Zaremba et al. [13] have attributed this endothermic reaction to the decomposition of $\mathrm{CaCO}_{3}$, i.e.,

$$
\mathrm{CaCO}_{3}(\mathrm{~s}) \rightarrow \mathrm{CaO}(\mathrm{s})+\mathrm{CO}_{2}(\uparrow) \quad \text { eq. (3). }
$$

Because Power Plant A uses limestone as a scrubbing material, therefore, it is not surprising to see the presence of $\mathrm{CaCO}_{3}$ in our samples. It is also consistent with the fact that we should not have observed this exothermic reaction for analytical $\mathrm{CaSO}_{3} \cdot \mathrm{nH}_{2} \mathrm{O}$, which is the case here. 
The final endothermic peak observed for both scrubber material from Power Plant $A$ and $\mathrm{CaSO}_{3} \cdot \mathrm{nH}_{2} \mathrm{O}$ at $950^{\circ} \mathrm{C}<\mathrm{T}<1050^{\circ} \mathrm{C}$ could be assigned to the following reactions [11,13]:

$$
\begin{aligned}
& \mathrm{CaS}(\mathrm{s}) \rightarrow \mathrm{CaS}_{x}(\mathrm{~s})+(1-\mathrm{x}) \mathrm{S}(\uparrow) \\
& \mathrm{CaSO}_{3}(\mathrm{~s}) \rightarrow \mathrm{CaO}(\mathrm{s})+\mathrm{SO}_{2}(\uparrow)
\end{aligned}
$$

The mass loss of scrubber material from Power Plant $B$ is shown in Fig. 10, while Fig. 11 depicts the DTA curve obtained at $50^{\circ} \mathrm{C}<\mathrm{T}<1250^{\circ} \mathrm{C}$ under nitrogen gas environment. Tables 2 and 3 summarize the thermal events observed for Power Plant B's scrubber material. The fact that 6 weight percent loss could be associated with the decomposition of $\mathrm{CaCO}_{3}$, indicated that a significant amount of $\mathrm{CaCO}_{3}$ is present in the scrubber material from Power Plant $\mathrm{B}$. The observed DSC curve under $\mathrm{O}_{2}$ gas environment is shown in Fig. 12, and the observed thermal events' parameters are listed in Table 4. The DSC curve showed two endothermic peaks at $T<210^{\circ} \mathrm{C}$ suggesting that under an oxygen-rich environment water would be lost from the scrubber material in two distinct steps.

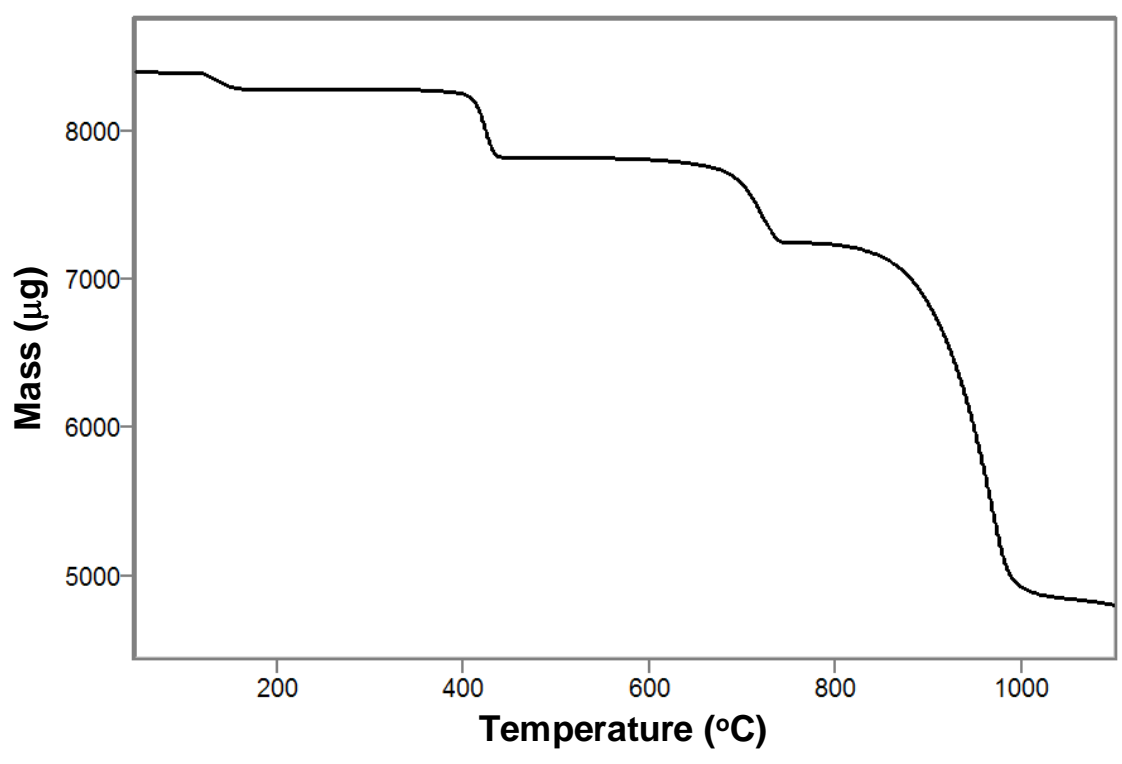

Figure 10. Thermal gravimetric (TGA) curve of sulfite-rich scrubber material obtained from Power Plant $B$. The TGA data were recorded under $\mathrm{N}_{2}$ gas environment. 


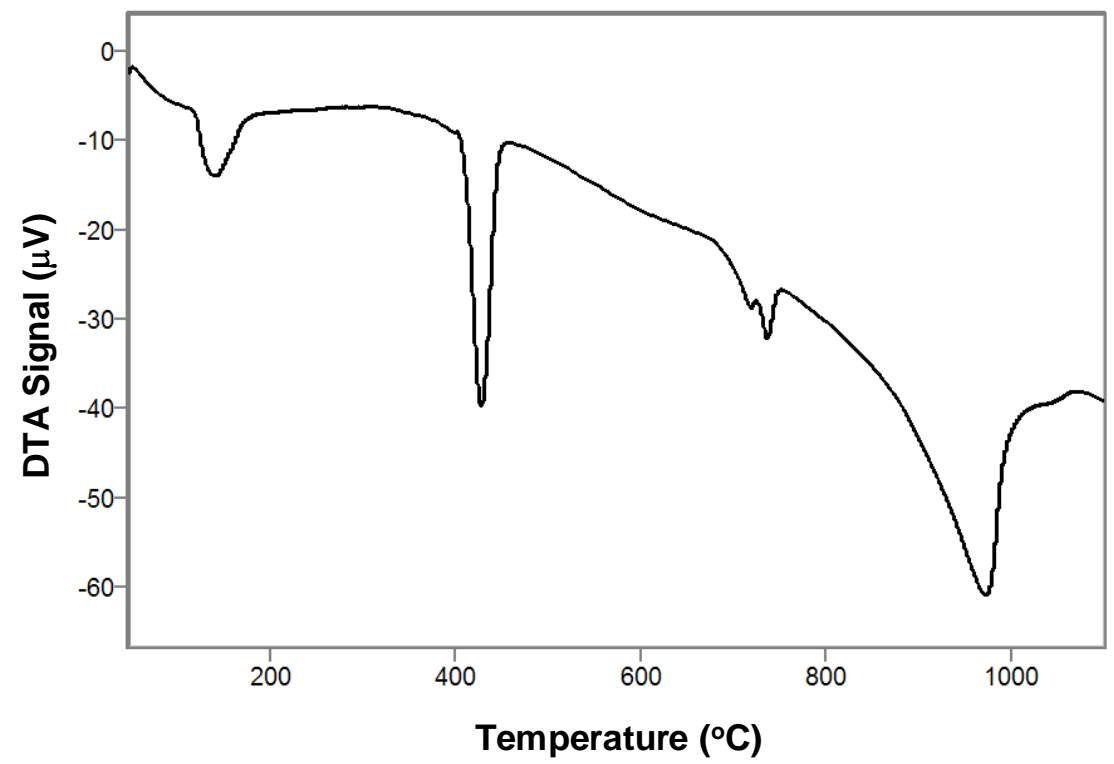

Figure 11. Differential thermal analyzer (DTA) curve of sulfite-rich scrubber material from Power Plant B. The DTA curve was recorded under $\mathrm{N}_{2}$ gas environment.

Table 2. The thermal events observed for sulfite-rich scrubber material obtained from Power Plant B as recorded by TGA method.

\begin{tabular}{|c|c|c|c|c|c|}
\hline $\begin{array}{c}\text { Thermal } \\
\text { Event } \\
\text { Number }\end{array}$ & $\begin{array}{c}\text { Mass } \\
\text { Loss } \\
\text { Begins } \\
\left({ }^{\circ} \mathbf{C}\right)\end{array}$ & $\begin{array}{c}\text { Mass } \\
\text { Loss } \\
\text { Ends } \\
\left({ }^{\circ} \mathbf{C}\right)\end{array}$ & $\begin{array}{c}\text { Peak Mass } \\
\text { Loss } \\
\text { Temperature } \\
\left({ }^{\circ} \mathbf{C}\right)\end{array}$ & $\begin{array}{c}\text { Weight Loss } \\
(\%)\end{array}$ & Assignment \\
\hline 1 & 121 & 151 & 136 & 1.3 & $\begin{array}{c}\mathrm{H}_{2} \mathrm{O} \\
\text { evaporation }\end{array}$ \\
\hline 2 & 410 & 432 & 421 & 5.2 & Eq. 1 \\
\hline 3 & 692 & 736 & 714 & 6.2 & Eqs. 2 and 3 \\
\hline 4 & 909 & 987 & 947 & 27.4 & Eqs. 4 and 5 \\
\hline
\end{tabular}

Table 3. The DTA results for scrubber material from Power Plant B.

\begin{tabular}{|c|c|c|c|}
\hline Peak Number & $\begin{array}{c}\text { Peak } \\
\text { Temperature } \\
\left({ }^{\circ} \mathbf{C}\right)\end{array}$ & $\begin{array}{c}\text { Peak Area } \\
(\mu \mathrm{V} . \mathbf{s} / \mathbf{m g})\end{array}$ & Assignment \\
\hline 1 & 139 & 90 & $\begin{array}{c}\mathrm{H}_{2} \mathrm{O} \\
\text { evaporation }\end{array}$ \\
\hline 2 & 427 & 213 & Eq. 1 \\
\hline 3 & 719 and 736 & 67 & Eq. 3 \\
\hline 4 & 970 & 712 & Eq. 4 and 5 \\
\hline
\end{tabular}




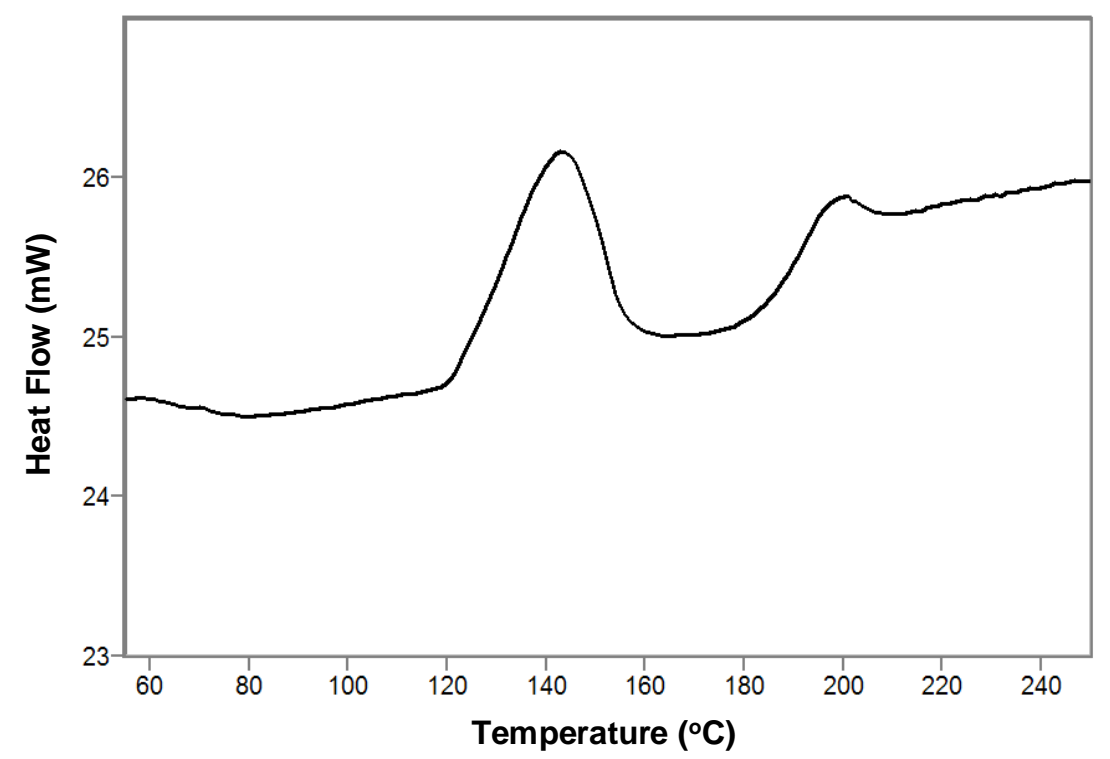

Figure 12. Differential scanning calorimetric (DSC) curve of sulfite-rich scrubber material from Power Plant B. The DSC curve was recorded under $\mathrm{O}_{2}$ gas environment.

Table 4. This table summarizes the thermal parameters associated with the two endothermic events observed for Power Plant B's scrubber material. The data were obtained using the DSC technique under oxygen gas environment.

\begin{tabular}{|c|c|c|c|}
\hline Peak Number & $\begin{array}{c}\text { Peak onset } \\
\left({ }^{\mathbf{0}} \mathbf{C}\right)\end{array}$ & $\begin{array}{c}\text { Peak } \\
\text { Temperature } \\
\left({ }^{\mathbf{}} \mathbf{C}\right)\end{array}$ & $\begin{array}{c}\text { Delta } \mathbf{H} \\
(\mathbf{J} / \mathbf{g})\end{array}$ \\
\hline 1 & 123 & 143 & 23.4 \\
\hline 2 & 189 & 199 & 5.4 \\
\hline
\end{tabular}

\section{Effect of Composite Formulation Conditions on the Structure of Scrubber}

\section{Materials:}

The fabrication of wood-substitute composites from sulfite-rich scrubber materials would require subjecting these materials to high temperature and high pressure. Therefore, it was important that we understood how the chemical and crystalline structures of the scrubber materials were affected when subjected to high-pressure at high-temperature.

Pressure Effect: To evaluate the pressure effects on the structure of scrubber materials at high-temperature, we subjected the scrubber material to a load ranging from $500 \mathrm{lbs}(2.22 \mathrm{kN})$ to $7500 \mathrm{lbs}(33.36 \mathrm{kN})$. The loads were applied at $210^{\circ} \mathrm{C}$. The air-dried scrubber material was mixed with a known amount of water, and the resulting paste was poured into a 2-inch diameter hardened stainless steel die. The die was inserted between the platens of a floor mounted high-temperature, high-pressure press. The plunger which fitted into the die applied the load to the sample. The platens were pre-heated to $210^{\circ} \mathrm{C}$ before the die was introduced into the press. The sample was held at the desired load for 1 hour before the pressure on the die was released and the die removed from the platens. The resultant disk was ejected from the die, and the sample was subjected to various analyses. 
Figures 13 and 14 show how a load of $500 \mathrm{lbs}(\mathrm{P}=160$ psi or $1.10 \mathrm{MPa})$ and $7500 \mathrm{lbs}$ $(\mathrm{P}=2390$ psi or $16.5 \mathrm{MPa})$, respectively, affected the crystallites of the scrubber material from Power Plant A. It can be seen from Fig. 13 that for a pressure of $160 \mathrm{psi}$, most of the crystallites maintained their platelet-like shape at $210^{\circ} \mathrm{C}$. However, much more fines $(<2 \mu \mathrm{m})$ were observed relative to as-received scrubber material suggesting that fines were generated during the application of the load. Increasing the applied pressure to 2390 psi substantially increased the generation of fines as can be seen from Fig. 14. There was also evidence that an applied load of $7500 \mathrm{lbs}$ compresses the crystallites indicating that scrubber material is a soft material and will compress under our product manufacturing conditions.

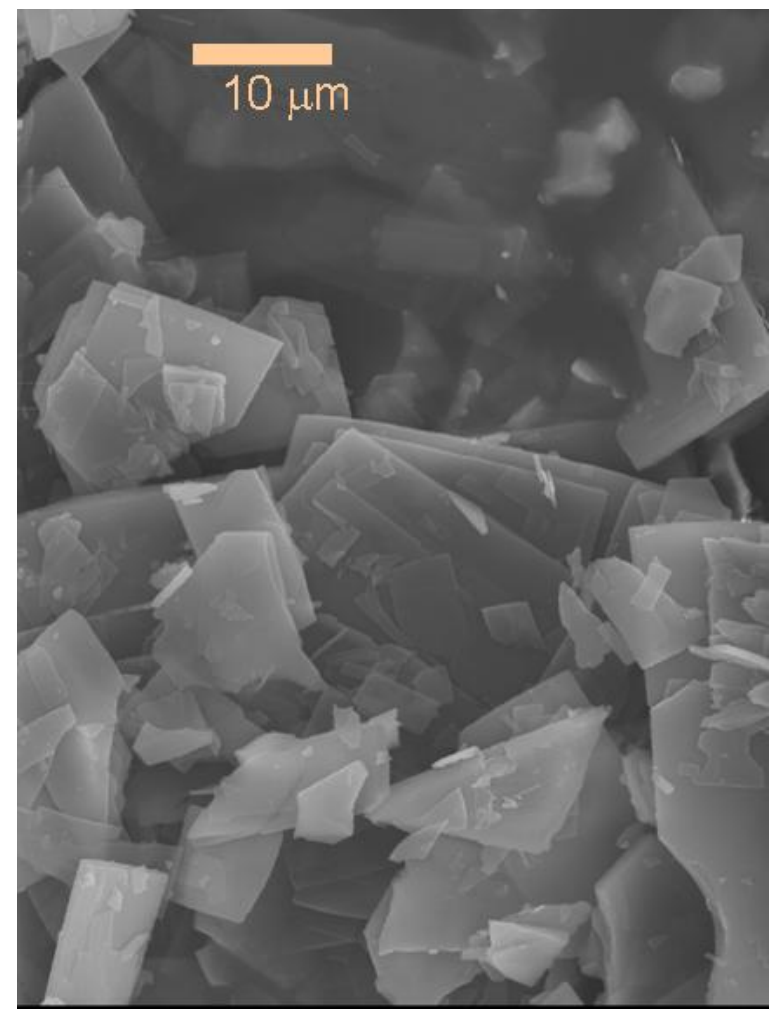

Figure 13. SEM picture showing how hot-pressing the scrubber material at $210^{\circ} \mathrm{C}$ under a load of $500 \mathrm{lbs}$ affected the structure of sulfite-rich sludge from Power Plant A. 


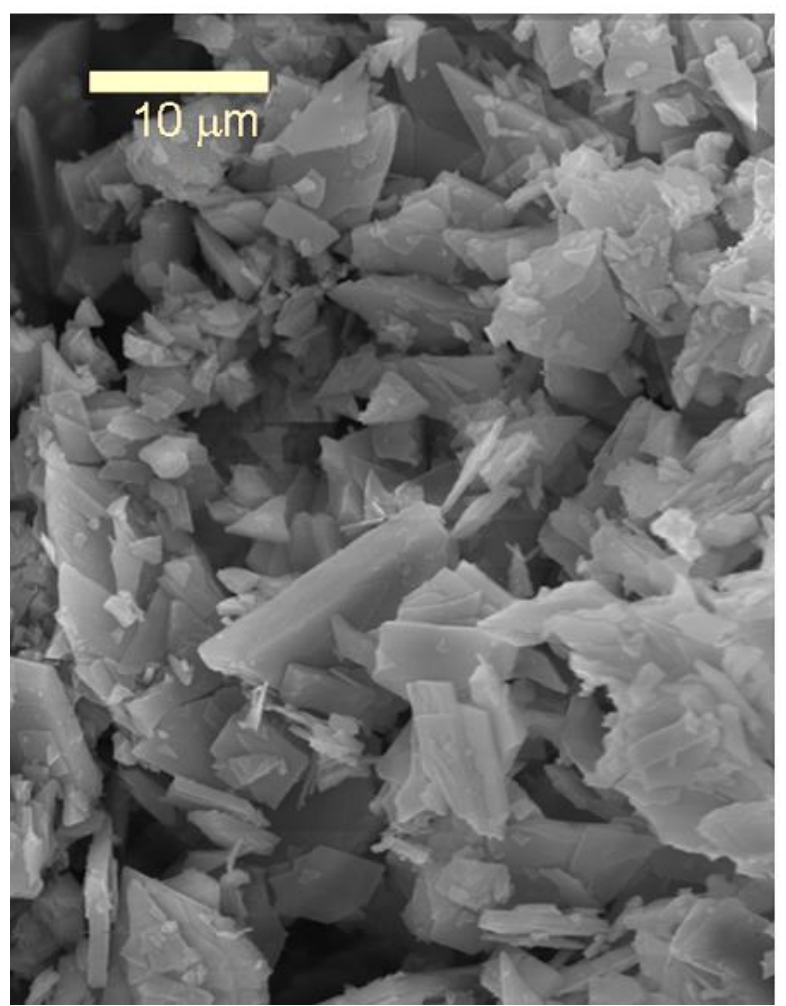

Figure 14. SEM picture showing how hot-pressing the scrubber material at $210^{\circ} \mathrm{C}$ under a load of $7500 \mathrm{lbs}$ affected the structure of sulfite-rich sludge from Power Plant A.

Figure 15 reproduces how the applied load affected the FTIR spectra of scrubber material from Power Plant A. Because we recorded our FTIR spectra using smears of mineral oil, it was not possible to monitor the quantitative changes in the intensities of the observed oscillators. However, to monitor how the applied pressure at $210^{\circ} \mathrm{C}$ affected the structure of the scrubber material we generated the intensity ratios. The ratios were generated by dividing the S-O bending mode vibration intensity. Figure 16 shows how the applied load affected the vibrational intensities' ratios of the scrubber material. As can be seen from this figure, there was no discontinuity in the graph which would have suggested a change in the structure of the calcium sulfite. Therefore, we conclude that the structure of the scrubber material remains intact under the applied load. 


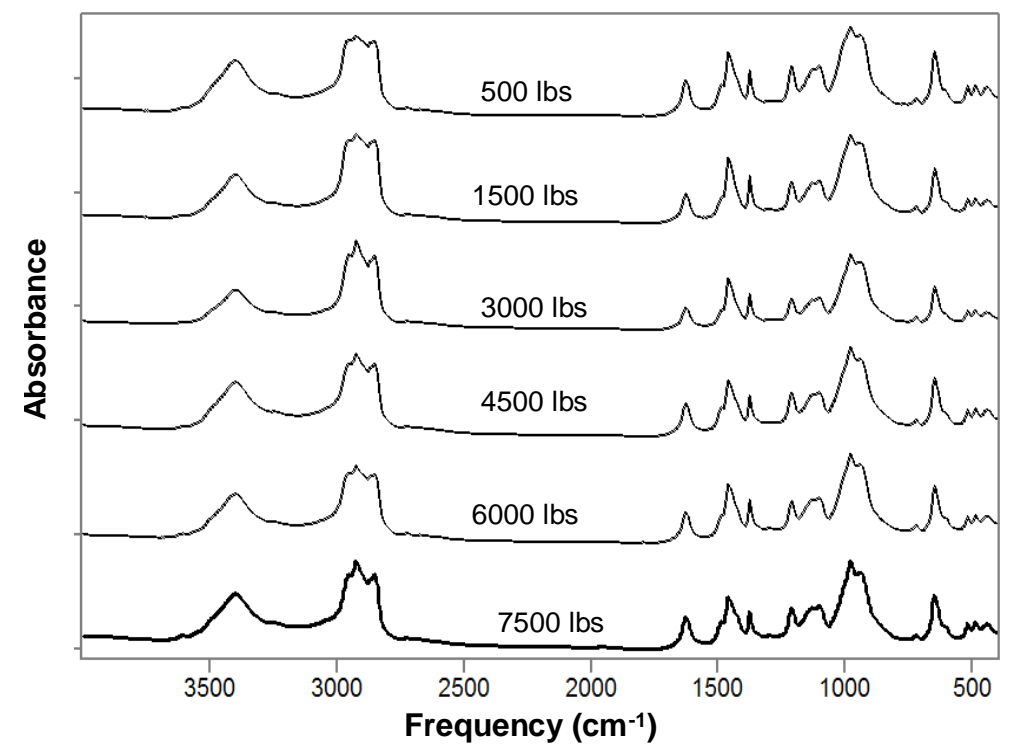

Figure 15. Fourier transform infrared (FTIR) spectra of sulfite-rich scrubber material depicting how the applied load affected the structure of the scrubber material from Power Plant A.

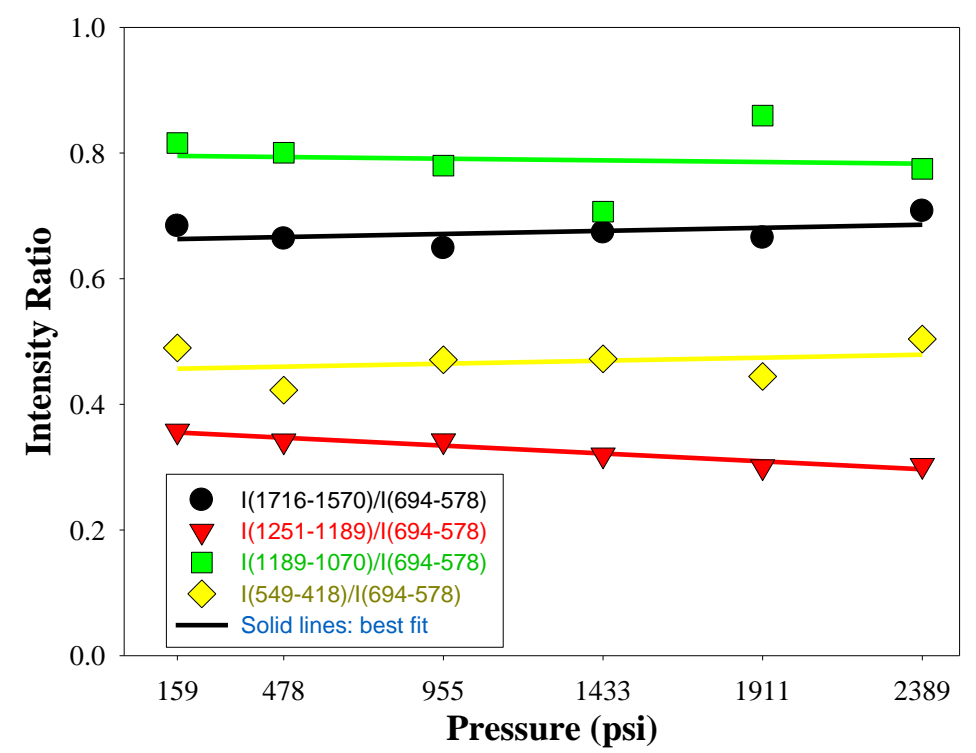

Figure 16. This figure shows how the hot-pressing pressure at $210^{\circ} \mathrm{C}$ affected the intensity ratios of the observed infrared vibrational bands of the sulfite-rich scrubber material from Power Plant A.

Temperature Effect: How the composite fabrication temperature would affect the structure of scrubber material under high-pressure was evaluated by subjecting the scrubber material to temperatures in the range of $150^{\circ} \mathrm{C}$ to $230^{\circ} \mathrm{C}$ under load of 3500 Ibs $(\mathrm{P}=1115 \mathrm{psi}$ or $7.7 \mathrm{MPa})$. The temperature treatments were carried out in a stainless steel die as described earlier. Figures 17 and 18 show how the applied temperature of $150^{\circ} \mathrm{C}$ and $210^{\circ} \mathrm{C}$, respectively, affected the crystallites of the scrubber material from Power Plant A. It appears from these photomicrographs that the hannebachite crystallites were compressed and showed considerable amounts of fine 
generation at $210^{\circ} \mathrm{C}$. It is possible that during composite fabrication the compression of the crystallites and the generation of fines could contribute to higher densities of the final product.

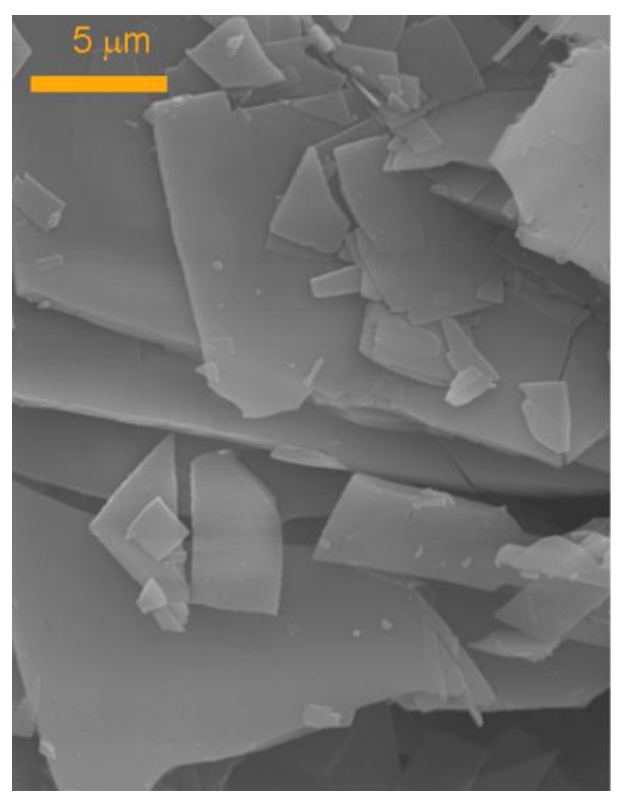

Figure 17: SEM picture showing how hot-pressing the scrubber material at $150^{\circ} \mathrm{C}$ under a load of $3500 \mathrm{lbs}$ affected the structure of sulfite-rich sludge from Power Plant A.

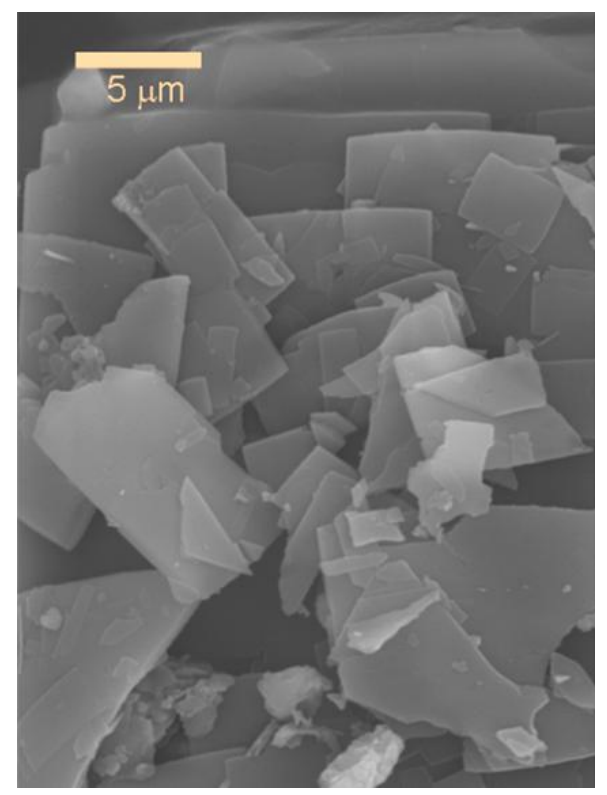

Figure 18. SEM picture showing how hot-pressing the scrubber material at $210^{\circ} \mathrm{C}$ under a load of $3500 \mathrm{lbs}$ affected the structure of sulfite-rich sludge from Power Plant A.

Figure 19 shows how the hot-pressing temperature affected the vibrational spectra of sulfite-rich scrubber material from Power Plant A. Our thermal analysis results, described earlier, suggested that at ambient pressure bulk water as well as some weakly hydrogen-bonded water were lost when the scrubber material's temperature was 
raised to $200^{\circ} \mathrm{C}$. It should be noted from Fig. 20 that the intensity of the water oscillators, in the stretching $\left(3700-2900 \mathrm{~cm}^{-1}\right)$ and bending $\left(1800-1550 \mathrm{~cm}^{-1}\right)$ region, was not affected as a function of hot-pressing temperature. This was surprising. It appeared that a pressure of 1115 psi on the sample inhibited water loss. Figure 20 reproduces how the hot-pressing temperature affected the structure of the scrubber material. Again, no discontinuity in the intensity ratios was observed as a function of temperature. Therefore, it was reasonable for us to conclude that under our composite fabrication temperature the sulfite-rich scrubber material will maintain its structure.

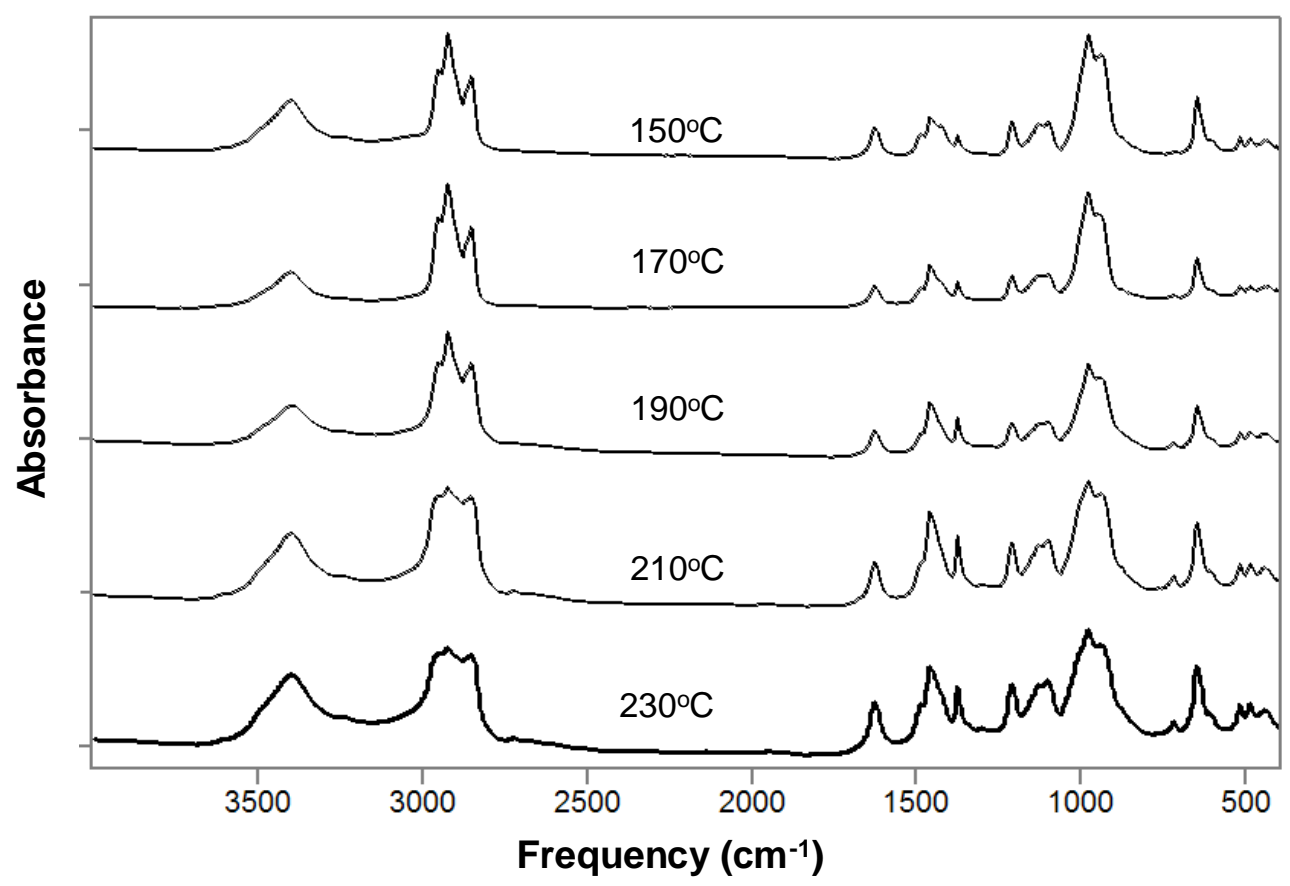

Figure 19. Fourier transform infrared (FTIR) spectra of sulfite-rich scrubber material depicting how the formation temperature affected the structure of the scrubber material from Power Plant A when hot-pressed under a load of 3500 lbs. 


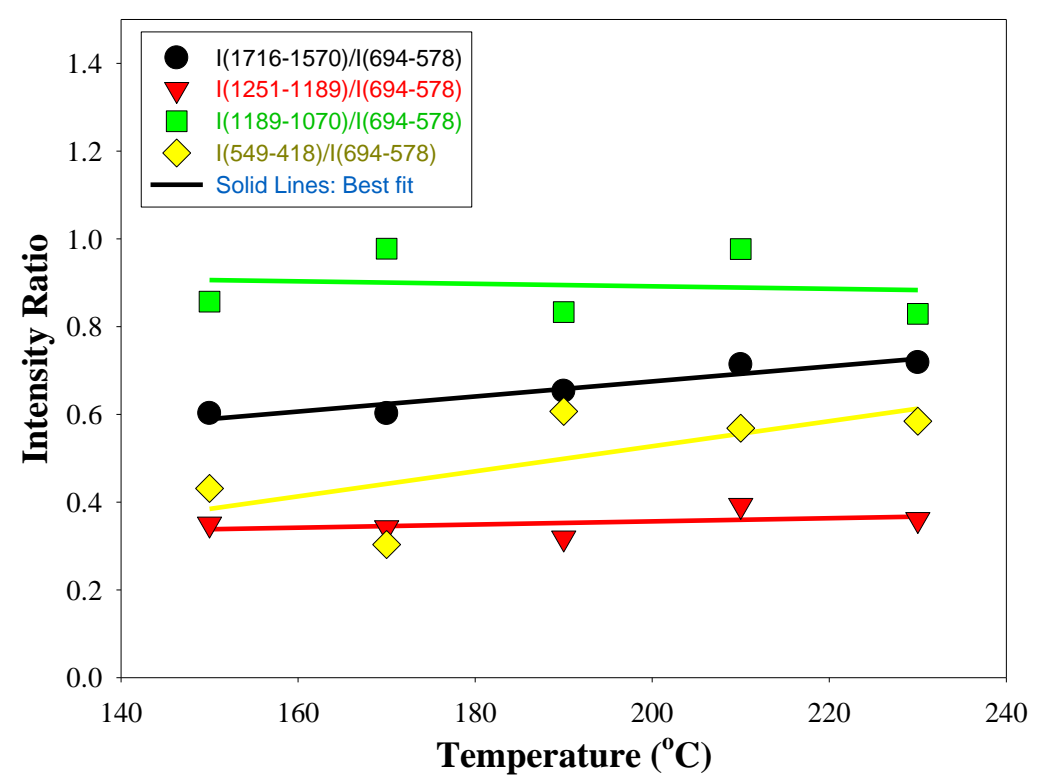

Figure 20. This figure shows how the hot-pressing temperature at a pressure of 3500 Ibs affected the intensity ratios of the observed infrared vibrational bands of the sulfiterich scrubber material from Power Plant A.

\section{Development and Performance of Wood-Substitute Composites:}

Typical composite materials have two or more distinct phases, usually referred to as a matrix and fillers, additives, or reinforcements. Sulfite-rich scrubber material could be formed into a solid sample just by the addition of water, which results in the reaction where weak hydrogen bonds are formed that hold the sample together. The material, however, was very brittle and dense. To achieve a high strength and modulus, which was comparable in magnitude to the load bearing wood material, we proposed to develop composite materials from sulfite-rich scrubber material and matrix of natural fibers and polymers. Having a matrix composed of such natural polymers as cellulose, hemicelluloses, and lignin, which are the same polymers that make up the chemical composition of wood, would give our composite material derived from scrubber sludge wood-like appearance and behavior. Moreover, it was expected that our crop matrix material would help in reducing the density of the final product.

Crop A material used in this study could be formed into a composite material all by itself by applying specific temperature and pressure. Figure 21 shows a composite material formed mainly from the Crop A matrix, reinforced with $10 \%$ of scrubber material from PPA. This composite was formed at $190^{\circ} \mathrm{C}$ under a load of $83 \mathrm{MPa}$. It can be seen from the figure that the natural fibers have fused together to form a composite structure.

Figure 22 depicts the mechanical behavior, i.e., stress-strain curve, of the composite derived with $10 \%$ scrubber material. It can be observed that the composite has fairly high flexural strength and high modulus. Typically, composites derived with $10 \%$ scrubber material were stiff and broke at the strain values which were lower than $1 \%$. However, it should be noticed that these composites did not undergo catastrophic brittle 
failure. It appears that the fibers held the composite together even after cracks had been generated by the applied load.

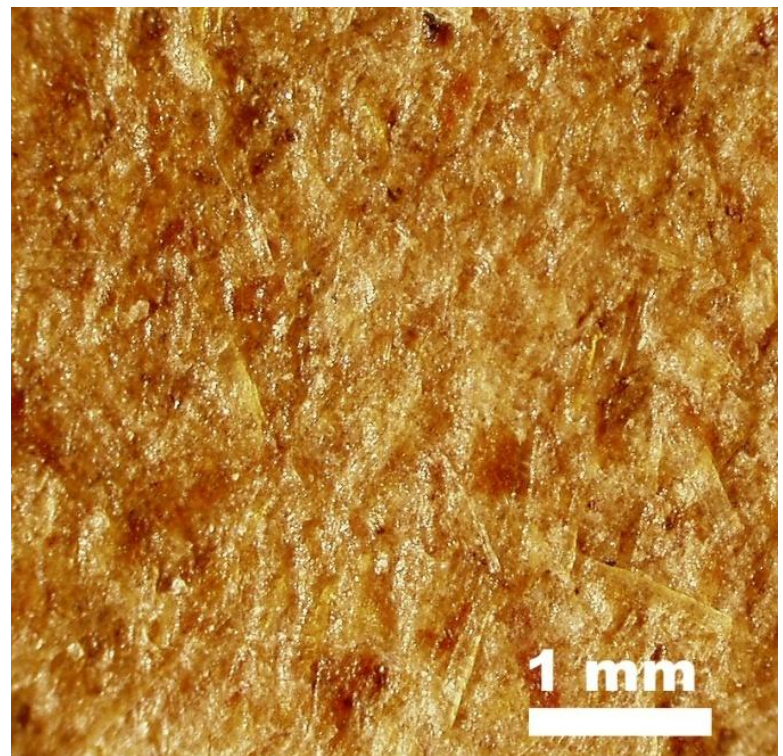

Figure 21. This picture shows the natural fiber matrix composite formed with $10 \mathrm{wt} \%$ sulfite-rich scrubber material.

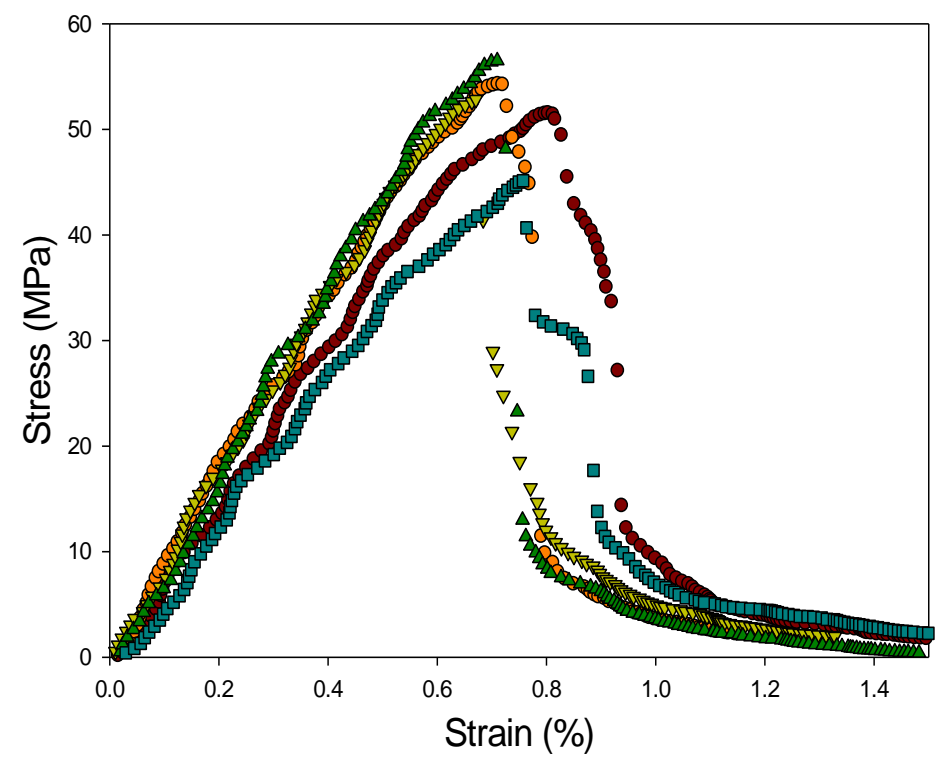

Figure 22. Stress-strain behavior of natural fiber matrix-based composite derived with scrubber material.

Specific properties of matrix material and eventually of the composites depend significantly on the additives used. Our matrix mainly utilizes natural resins to hold the composite together, however, high pressures and high temperatures are required to access these polymers which may not always be a viable processing route. Therefore we have examined how small amounts of various natural and synthetic polymeric 
materials may enhance the properties of our composites and possibly reduce the fabrication costs.

Both sulfite rich scrubber material and Crop A material are in the fine powder form, which poses a challenge when trying to add a small quantity of liquid-based resin into the mixture. The resin gets adsorbed by the powder which inhibits good dispersion. One of the ways to get around this problem could be by using a water-based polymer and mixing a polymer in a water-sludge-fiber slurry in order to achieve uniform dispersion. Figure 23 represents flexural strength and density results of such an attempt, where $50 / 50$ scrubber-crop mixture was combined with a water-dispersible commercial epoxy resin.

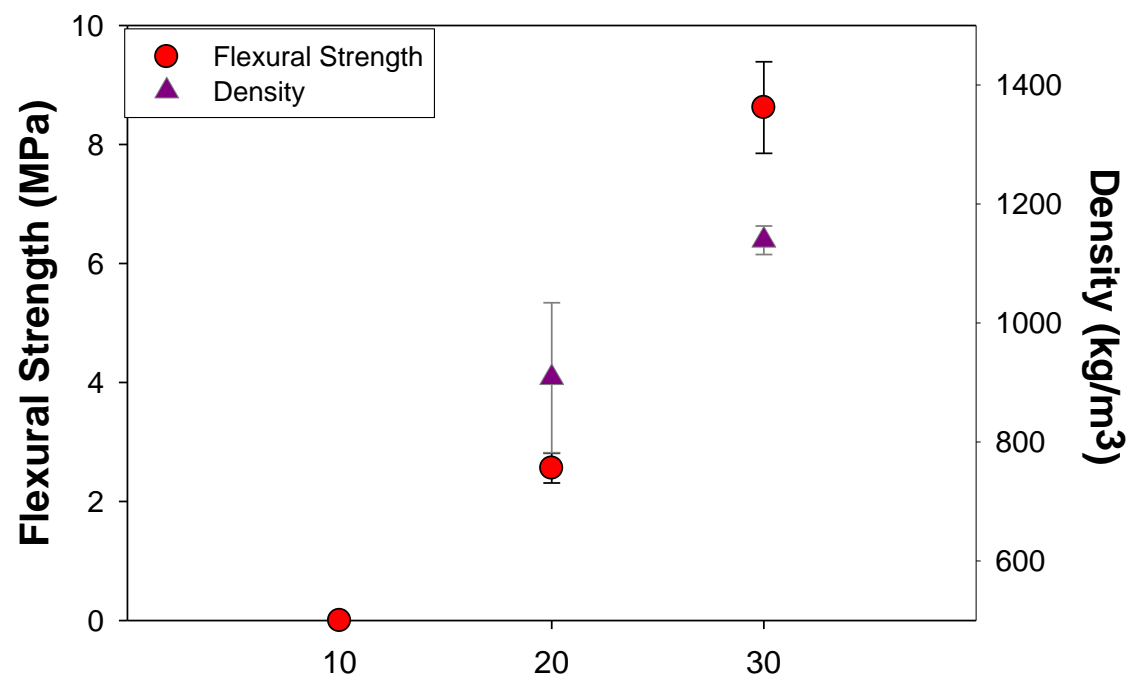

Amount of Polymer IV (\%)

Figure 23. Strength and density of the sample as a function of amount of water soluble commercial polymer.

Although good dispersion of the fibers and additives was observed in the composites, the composite materials suffered from low flexural strength. The density of the composites was low though (see Fig. 23). It should be noticed that even the composites, which contained $30 \%$ resin by weight, barely reached the strength of 9 $\mathrm{MPa}(1305 \mathrm{psi})$. It was felt that the amount of water used to formulate these composites may have contributed significantly to the observed reduced flexural strength. Therefore, we varied the water concentration used to formulate the composites from water-soluble polymer IV. How the water content affected the mechanical properties is shown in Fig. 24, while typical stress-strain behavior of the composites is depicted in Fig. 25. It is evident from the graph that the amount of water in the initial mix did play an important role in determining the mechanical properties of the formulated composites. The composites formulated with $20 \mathrm{~g}$ water yielded the highest mechanical strength for this series. A composite containing $10 \mathrm{~g}$ of water showed poor performance mainly due to the inadequate dispersion of the additives. This was because the mixture was very thick and difficult to mix. The sample containing $30 \mathrm{~g}$ of water was too soft to be even tested. One of the reasons for such a low flexural strength of these samples is low fabrication 
temperature of the composites, which was limited due to the specifications of the polymer used. Fabrication temperature of $120^{\circ} \mathrm{C}$ was used, which was the curing temperature of the water-based resin. However, by using such a low temperature, we could not observe the benefits of the natural resins, the condensation of which require much higher processing temperatures. On the other hand, the water soluble polymers allowed us to fabricate composites at the very low pressure of $1.2 \mathrm{MPa}$ (174 psi). Moreover, the composites resulted in low densities ranging between $900 \mathrm{~kg} / \mathrm{m}^{3}$ and $1300 \mathrm{~kg} / \mathrm{m}^{3}$. The stress-strain results of these composites also exhibited the desired behavior. Figure 25 depicts stress vs. strain curves. As can be seen from this figure, though composites underwent failure at around $1 \%$ strain they did not show classical brittle behavior.

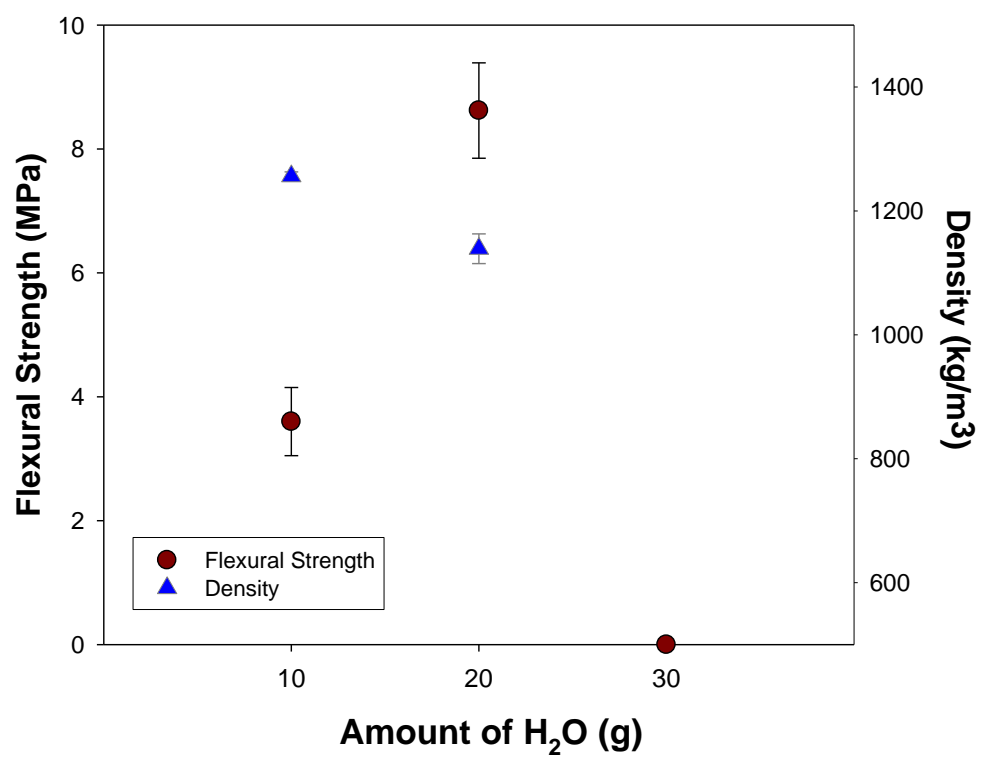

Figure 24. Strength and density dependence on the amount of water used for the composite fabrication from natural matrix, scrubber material, and water soluble polymer IV. Total mass of other ingredients was $25 \mathrm{~g}$. 


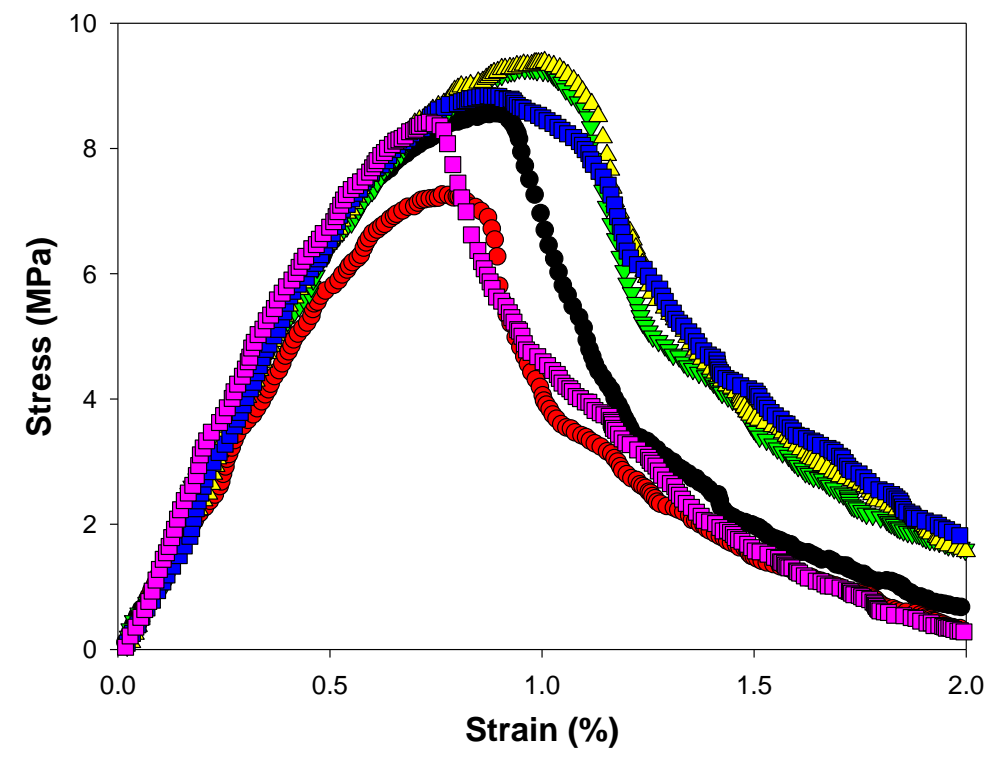

Figure 25. Stress vs. strain behavior of composite material derived from water soluble polymer IV.

In view of the results presented for water-soluble polymer, it was felt that to enhance the mechanical properties of the composites derived from scrubber materials, they should be fabricated at $\mathrm{T}>170^{\circ} \mathrm{C}$ in order to get the benefit of the natural resins contained within Crop A material. Therefore, we chose those polymeric materials as an additive which could be processed above $170^{\circ} \mathrm{C}$ without undergoing degradation. Moreover, the choice of polymer additive was dictated by whether it could be mixed in powder form to facilitate easy handling and dispersion in the mix. Figure 26 depicts how the formation temperature affected the mechanical properties of the composites derived from scrubber material and Crop A material.

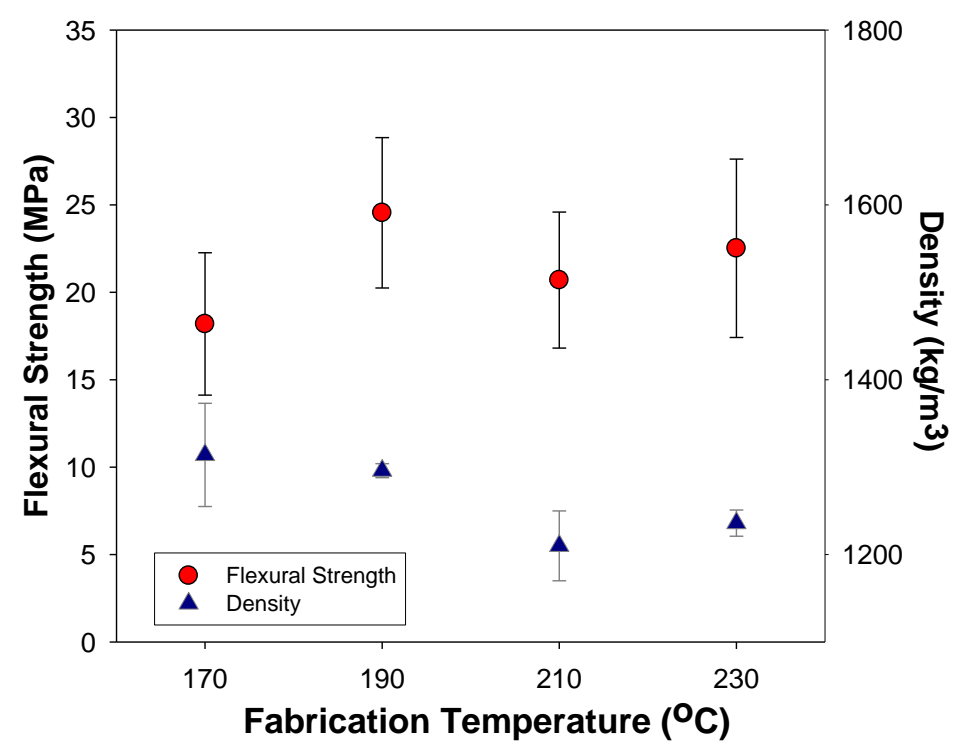

Figure 26. Effect of temperature on the mechanical properties of composites derived from scrubber material (50 wt\%), Crop A, and polymer II additive. 
It is evident from Fig. 26 that statistically there is no effect of formation temperature on the flexural strength of the composites at $170^{\circ} \mathrm{C}<\mathrm{T}<230^{\circ} \mathrm{C}$. From our previous analysis of plant material and from the specifications of the commercial polymer used in these composites, it was, however, expected that the fabrication temperature beyond $230^{\circ} \mathrm{C}$ would drastically hinder mechanical behavior of the samples. Fabrication temperatures above $230^{\circ} \mathrm{C}$ approach the decomposition range of Crop A material, whereas $\mathrm{T}<170^{\circ} \mathrm{C}$ is below the curing temperature of polymer II and of the natural polymers. Another advantage of using Polymer II is that this polymer has a chemically similar structure to that of lignin and has been shown to have high compatibility with natural additives, such as cellulose fibers. Composites represented in Fig. 26 were fabricated at a low fabrication pressure of $1.2 \mathrm{MPa}$ and were composed of $50 \%$ scrubber material, $15 \%$ of Polymer II, and $35 \%$ of Crop A material. Low fabrication pressure enabled samples to maintain reasonably low density of $\sim 1200 \mathrm{~kg} / \mathrm{m}^{3}$ while still achieving strength close to $25 \mathrm{MPa}$ (3625 psi). The optimum fiber-to-resin ratio might exist at which the polymer-natural fiber matrix would give the most benefit to the composite. We have explored this behavior by fixing the amount of scrubber material in the composite as well as the amount of Polymer II and varied only the amount of fibers from Crop A. The resulting flexural strength and density for this series are represented in Fig. 27. Composites were fabricated at $1.2 \mathrm{MPa}(174 \mathrm{psi})$ pressure and $210^{\circ} \mathrm{C}$ temperature.

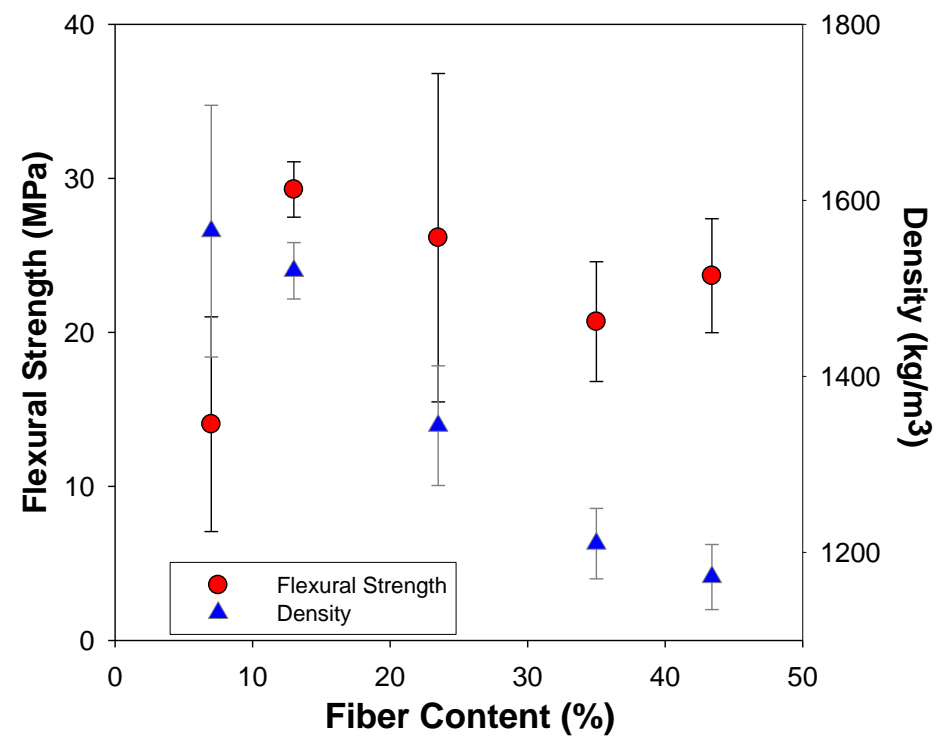

Figure 27. Flexural strength and density as a function of fiber content (Crop A).

Figure 27 shows that the optimal Polymer II to Crop A material ratio was achieved when the fiber amount in the composite was about $15 \%$. The amount of polymer here was also close to $15 \%$, which suggested that composites should be fabricated using 1:1 polymer to fiber ratio. Decreasing the amount of plant material and polymer below $15 \%$ appeared to have a negative effect on both flexural strength and density of composites. On the other hand, increasing the amount of plant material helped to lower the density of the material, while still maintaining similar strength. This should not be surprising because sulfite-rich scrubber material is much denser than plant material. 
Another polymer that we have explored as a potential additive to our composites was a complex natural carbohydrate polymer (further referred to as Polymer V). This thermoplastic polymer has proved to be very effective even in small quantities. However, the composite fabrication required larger pressures in order to reach the desired result (see Figure 28). Figure 28 depicts mechanical properties of the composites formulated at $190^{\circ} \mathrm{C}$ under various loads. These composites were composed of $60 \mathrm{wt} \%$ Crop A material, $25 \mathrm{wt} \%$ scrubber materials, $10 \mathrm{wt} \%$ water and 5 wt \% Polymer V. Water was required because it acts as a plasticizer for Polymer V. Our results suggested excellent composite strength was achieved if the fabrication pressure was greater than $50 \mathrm{MPa}$. However, higher pressure resulted in enhanced density of our products, e.g., $1800 \mathrm{~kg} / \mathrm{m}^{3}$. It is worth mentioning that though the addition of Polymer V produced much stronger materials, it also produced products which had much poorer water resistance. This was not the case when Polymer I or Polymer II (chemically, Polymer I and Polymer II are very similar) was used. Our results also showed that if we used Polymer I or Polymer II, high strength composites were achieved at considerably lower fabrication loads. Figure 29 summarizes the results. The composite which had no polymer (see Fig. 29) was composed of Crop A material (80 wt\%) and scrubber material (20 wt\%). It should be observed from Fig. 29 that when a small amount of polymer was added to the mix, the flexural strength of the composite jumped from $\sim 50 \mathrm{MPa}(7250 \mathrm{psi})$ to $\sim 90 \mathrm{MPa}(13050 \mathrm{psi})$. Thus, it can be concluded that the addition of a small amount of external polymer, i.e., $\leq 5 \mathrm{wt} \%$, would impart considerable strength to the composites developed from sulfite-rich scrubber materials and natural byproducts.

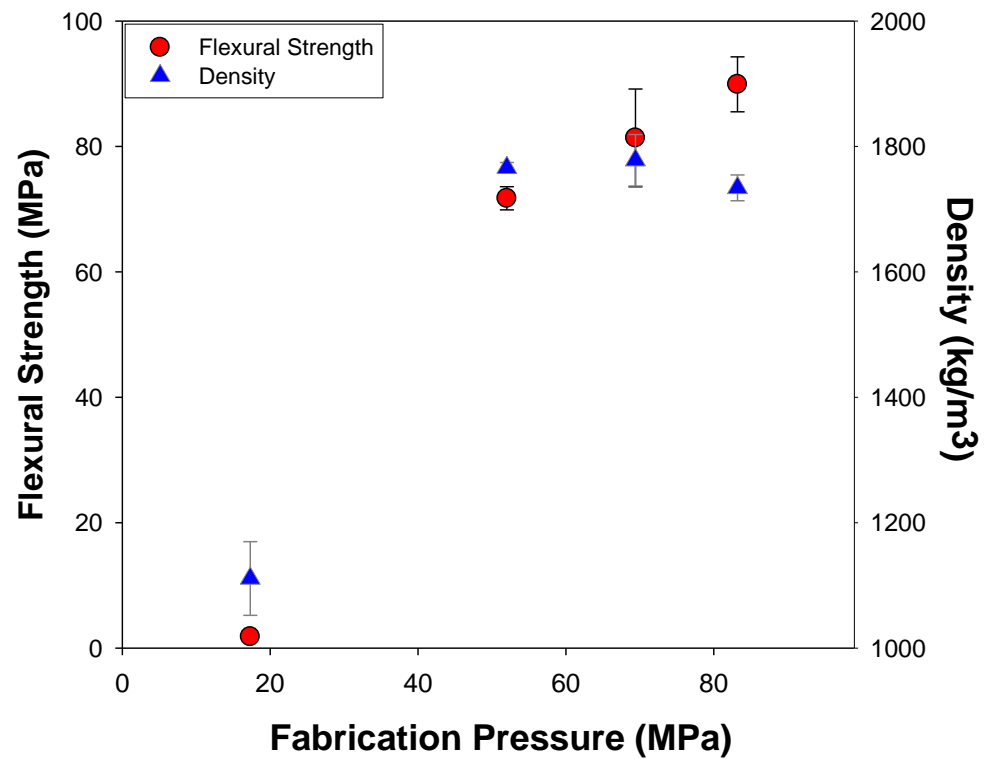

Figure 28. Composites fabricated at various pressures using $5 \%$ of complex natural polymer. 


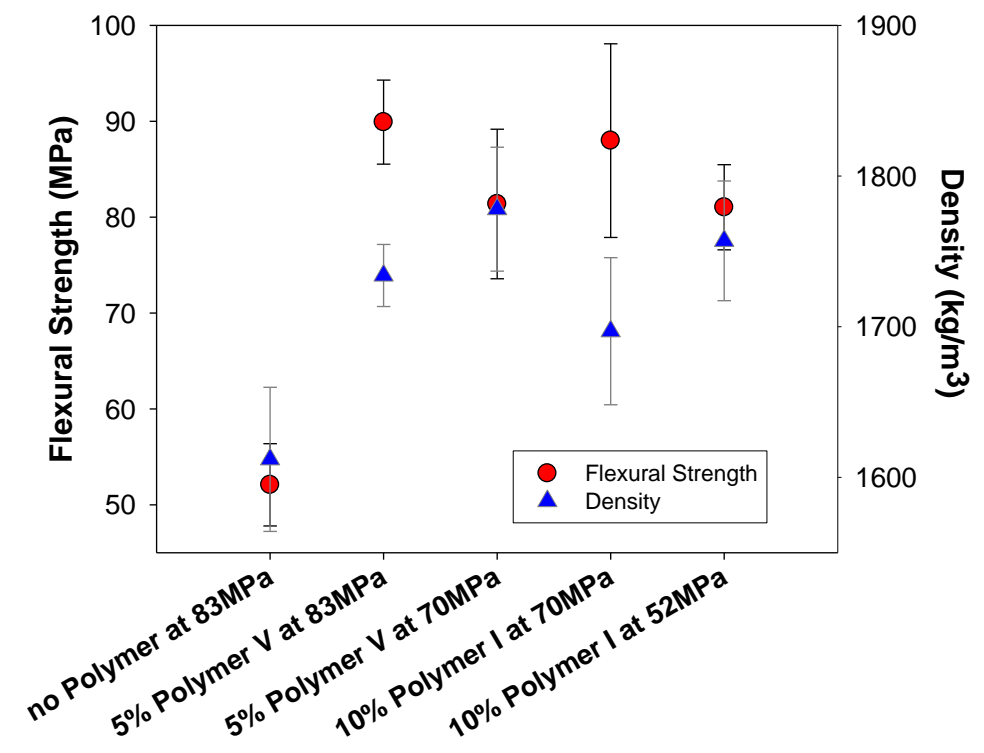

Figure 29. The effects of external polymer on the mechanical properties of composites fabricated from sulfite-rich scrubber material and natural byproducts.

Statistically there was no significant difference in the mechanical properties, i.e., flexural strength and density, when different polymers were used as can be seen in Fig. 29. However, it is worth mentioning that substantially less load was applied to fabricate composites when using Polymer I as an additive.

Based on the experiments described above, it was felt that the best results would be achieved if composites were fabricated using a 4:1 ratio of polymer-to-fiber (Crop A). The next step was to ascertain how much scrubber material could be used in our composites and still achieve comparable properties to wood-substitute materials. Therefore, we systematically varied the concentration of the scrubber material and the results are reproduced in Fig. 30. 


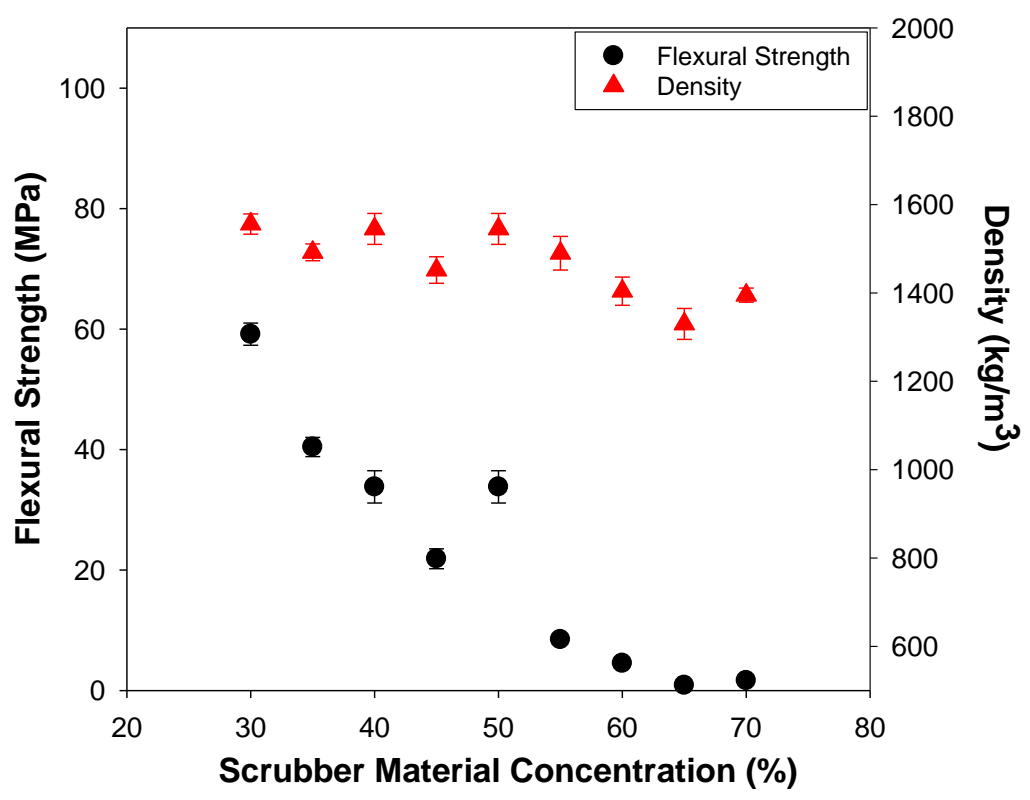

Figure 30. Mechanical properties of composites fabricated using 4:1 ratio of Polymer IIIto-fiber. The scrubber concentration was systematically varied.

It is clearly evident from Fig. 30 that the strength of these composites diminishes as the concentration of the sulfite-rich scrubber material was raised beyond $50 \mathrm{wt} \%$. The "sweet spot" of this composition lies somewhere between $40-50$ wt $\%$ of the scrubber material concentration. Beyond $50 \mathrm{wt} \%$ scrubber material concentration in the mix, the strength of the composite dramatically decreased. Based on the results presented in Fig. 30 and the fact that higher strengths for composites could be achieved by increasing the fabrication pressure, it was feasible to produce products which exceed the commercial engineered wood strength and yet use scrubber material concentration $>50 \mathrm{wt} \%$.

\section{Density Reduction:}

As pointed out earlier, a considerable effort was devoted towards reducing the density of wood-substitute composites derived from sulfite-rich scrubber material. The major problem in reducing the density is the high density of sulfite-rich scrubber material itself, i.e., for hydrated $\mathrm{CaSO}_{3} \cdot 0.5 \mathrm{H}_{2} \mathrm{O}$, the density ranges between 2450 to $2550 \mathrm{~kg} / \mathrm{m}^{3}$.

Therefore, if we were to maximize the amount of scrubber material to be used in our composites and yet remain competitive with commercial wood-substitute composites, strategies would be needed to reduce the density of our product. It was equally important that we explored density reduction approaches which did not add considerable expense to our potential wood-substitute composites. Therefore, we explored the addition of two cheap additives, i.e., fly ash and additive B.

We added fly ash (up to $15 \mathrm{wt} \%$ ) into our mix prepared from $50 \mathrm{wt} \%$ scrubber material and equal weights of crop A and Polymer II. It is worth pointing out that we did not incorporate any coupling agents or lubricants into our mix. The mix was thoroughly blended, and the composites were fabricated at low pressure, i.e., $1.21 \mathrm{MPa}(175 \mathrm{psi})$. The composites were fabricated at $190^{\circ} \mathrm{C}$. Figures 31 and 32 reproduce how the 
addition of fly ash affected the strength and density of sulfite-rich scrubber material composites.

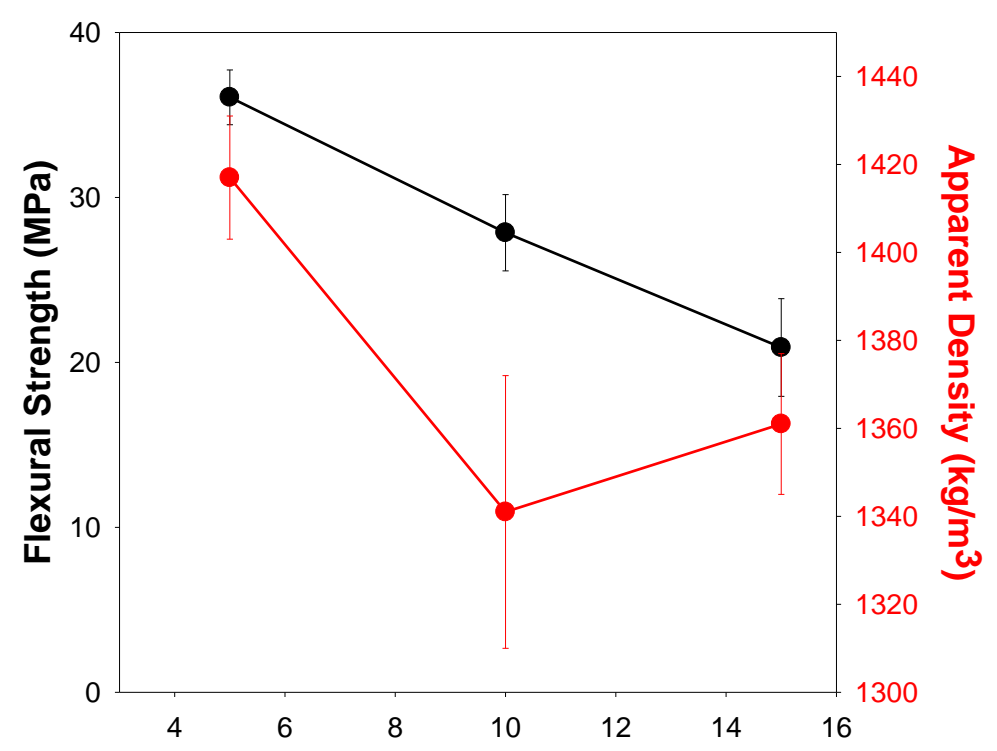

Fly Ash (wt\%)

Figure 31. The effect of fly ash concentration in the mix on the strength and density of the composites-derived from $50 \mathrm{wt} \%$ scrubber material.

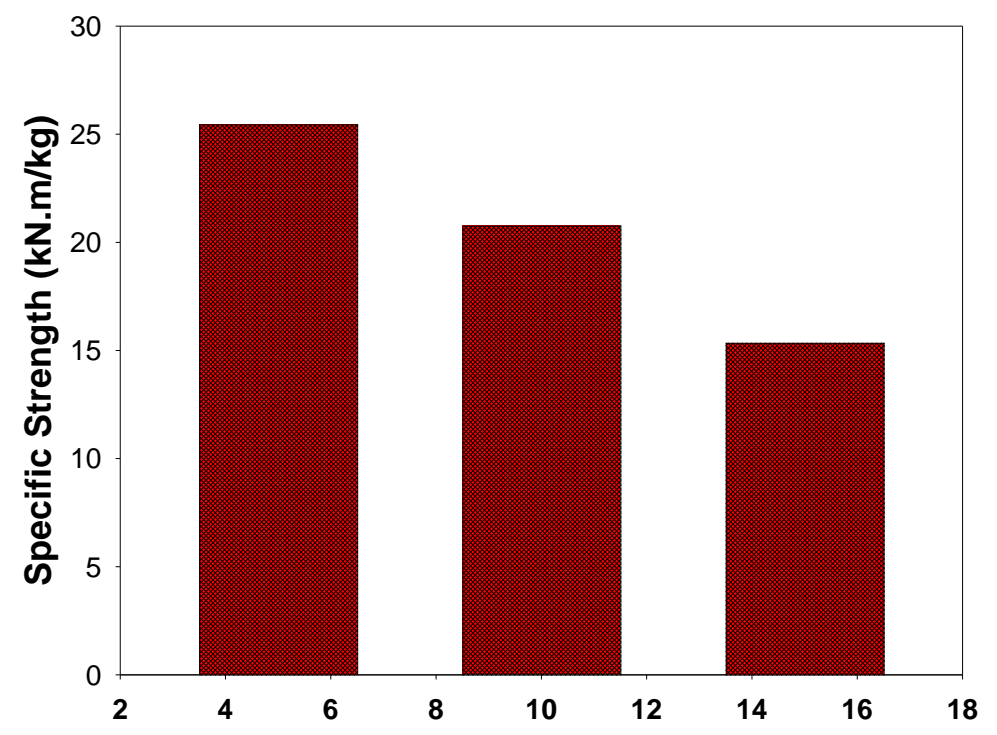

Fly Ash (wt\%)

Figure 32. The effect of fly ash on the specific strength of the composites-derived from $50 \mathrm{wt} \%$ scrubber material.

Clearly, as the fly ash concentration increased in the mix, the resultant composite's density decreased (see Figure 31). Unfortunately, this also resulted in the reduction of the strength of the material. In fact, for $15 \mathrm{wt} \%$ fly ash loading, the strength of scrubber material-derived composite decreased to about $20 \mathrm{MPa}$. One way to compare the 
performance of commercial products and our laboratory scale products would be to compare their specific strength. The specific strength is defined as:

$$
\text { Specific Strength }\left(k N \cdot \frac{m}{k g}\right)=\frac{\text { Flexural Strength }(M P a)}{\text { Density }\left(\frac{k g}{m^{3}}\right)} \text {. }
$$

It is interesting to note that the specific strength of $15 \mathrm{wt} \%$ fly ash composite is comparable to commercial wood-substitute composites, which contained almost 37 wt $\%$ HDPE thermoplastic. Moreover, for 5 wt\% fly ash composite, the specific strength far exceeded that of commercial wood-substitute composite containing thermoplastic concentration of $\sim 42 \mathrm{wt} \%$. It appeared that fly ash might hold promise in reducing the density of our composites as they are upscaled in the future.

We also tested how additive B, which like fly ash has a hollow spherical structure, would affect the density of the composites-derived from sulfite-rich scrubber material. For these composites, we added additive B (up to $5 \mathrm{wt} \%$ ) to our mix containing $50 \mathrm{wt} \%$ scrubber material, crop A and Polymer II in equal proportions. Again, no coupling agents or lubricants were added to our mix. The composites were formulated at $190^{\circ} \mathrm{C}$.

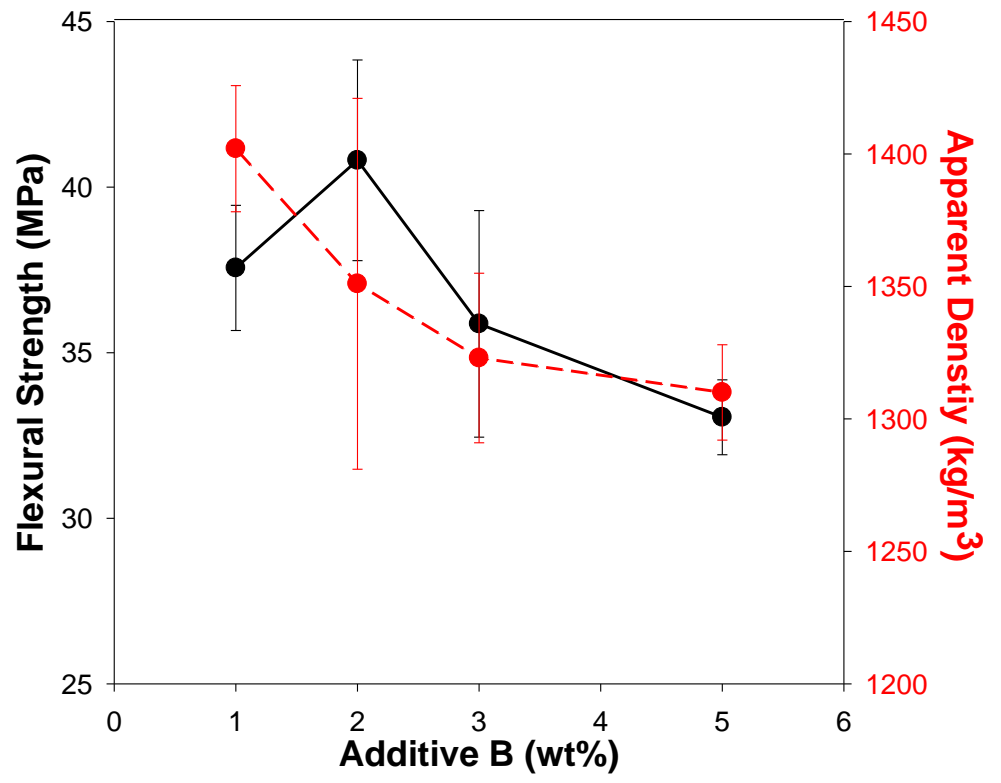

Figure 33. The effect of additive B's concentration in the mix on the strength and density of the composites-derived from $50 \mathrm{wt} \%$ scrubber material.

Figures 33 and 34 show how the concentration of additive $B$ in the mix affected the mechanical properties of the wood-substitute composites. Just like fly ash, additive $B$ also reduced the density; however, reduction in the density was steeper than that observed for the fly ash additive. Moreover, it should be noticed from Fig. 33 that we observed much more reduction in density (to $\sim 1300 \mathrm{~kg} / \mathrm{m}^{3}$ ) for only $5 \mathrm{wt} \%$ additive. Again, just like fly ash, additive $\mathrm{B}$ showed great promise in reducing the density of our products derived from sulfite-rich scrubber material. It was equally clear that additive B 
results in much higher specific strength than either commercial products or the products which contain fly ash.

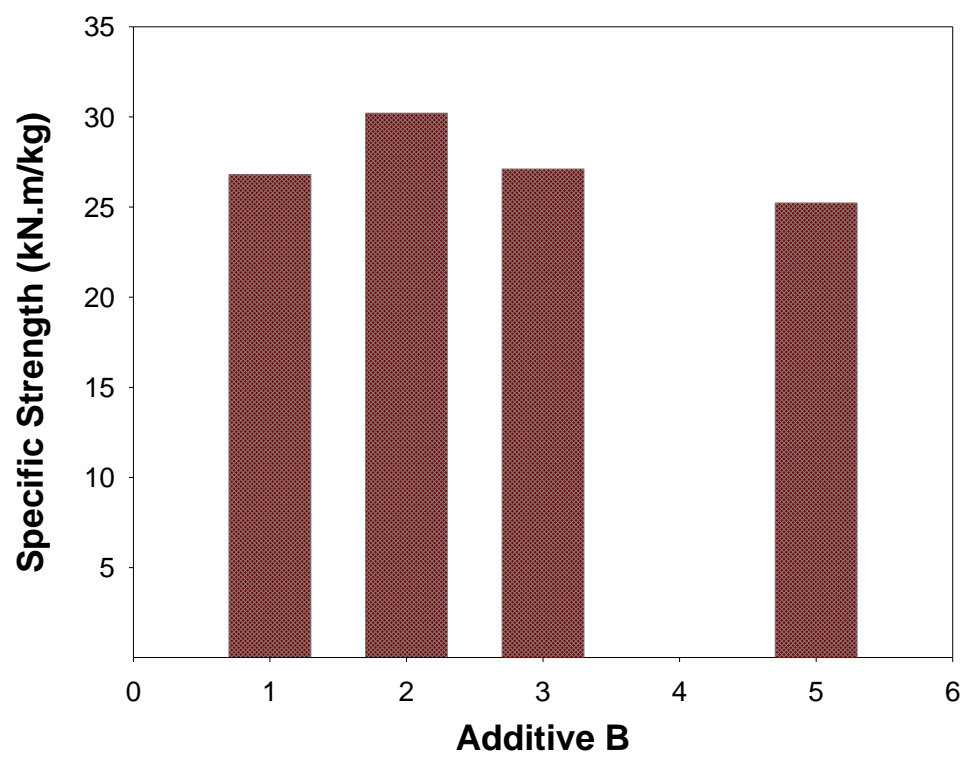

Figure 34. The effect of additive B's concentration in the mix on the specific strength of the composites-derived from $50 \mathrm{wt} \%$ scrubber material.

\section{Synthetic Lumber:}

We also attempted to develop wood-plastic composites (WPC) from sulfite-rich scrubber material. Therefore, it was worthwhile to briefly examine some of the commercial products on the market against which our products could be contrasted and compared. In this section we discuss the commercial wood-plastic composites (WPC).

It is believed that the WPC industry is a $\$ 2$ billion industry. The WPC are generally fabricated from:

- high-density polyethylene (HDPE) thermoplastic,

- polypropylene (PP) thermoplastic, and

- poly vinyl chloride (PVC) thermoplastic.

In the last decade, a number of commercial products have attempted to use recycled thermoplastics for their WPC products. Besides the thermoplastics, i.e., HDPE, PP, or PVC, the other major ingredient of WPC is cellulosic fibers. The most commonly used cellulosic fibers are wood flour, rice hulls, etc. The thermoplastics are blended with cellulosic fibers in the presence of additives such as lubricants, coupling agents, pigments, antimicrobial agents, UV stabilizers, and antioxidants. Most of the commercial WPC composites have been fabricated from HDPE thermoplastics. In the last 10 years, attempts have been made to use various solid inorganic fillers, e.g., fly ash and $\mathrm{CaCO}_{3}$, to reduce polymer costs. However, one of the problems of fly ashbased WPC is the higher wear of mixing and extruding equipment during the product manufacturing. 
Figure 35 shows the mechanical properties of commercial WPC fabricated from thermoplastic HDPE. The density of the product ranged from $\sim 1025 \mathrm{~kg} / \mathrm{m}^{3}$ to $\sim 1250$ $\mathrm{kg} / \mathrm{m}^{3}$, while the strength varied between $\sim 10 \mathrm{MPa}$ (1450 psi) to $\sim 18 \mathrm{MPa}$ (2610 psi). Similar to the strength, flexural modulus of the WPC increases as the density of the product increases. It can be seen from Figs. 36 and 37 that the increase in the concentration of thermoplastic HDPE in the mix not only increases the strength of the material but also its density. Therefore, to successfully compete against the current WPC products on the market, the products developed from sulfite-rich scrubber material must not only be cheaper but must also have superior mechanical properties.

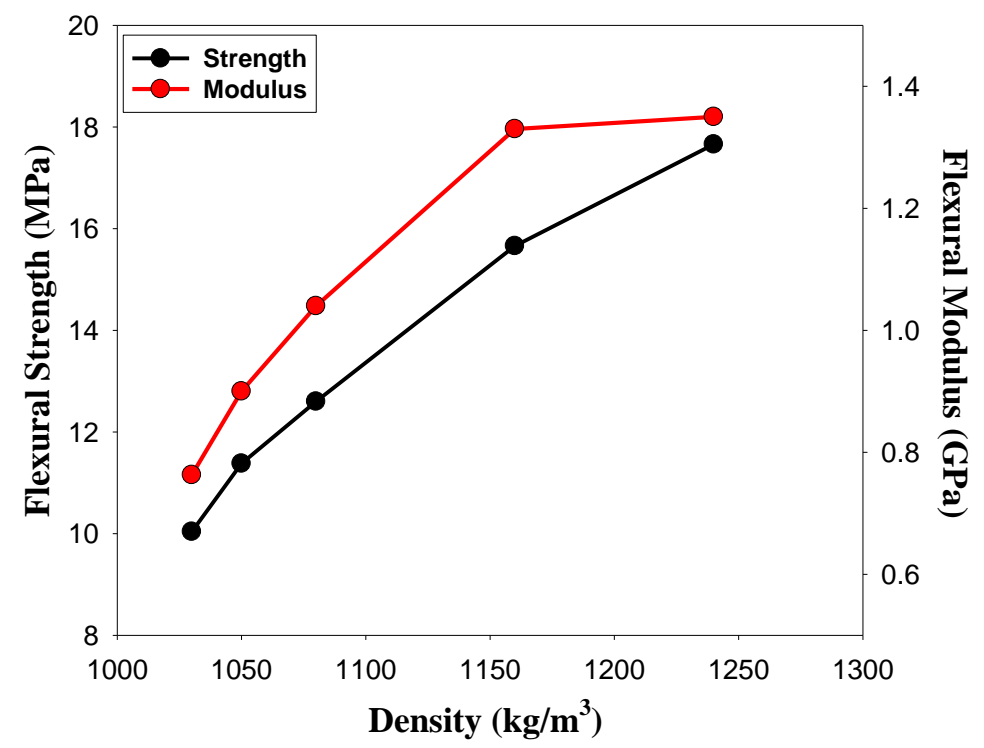

Figure 35. The mechanical properties of commercial wood plastic composites.

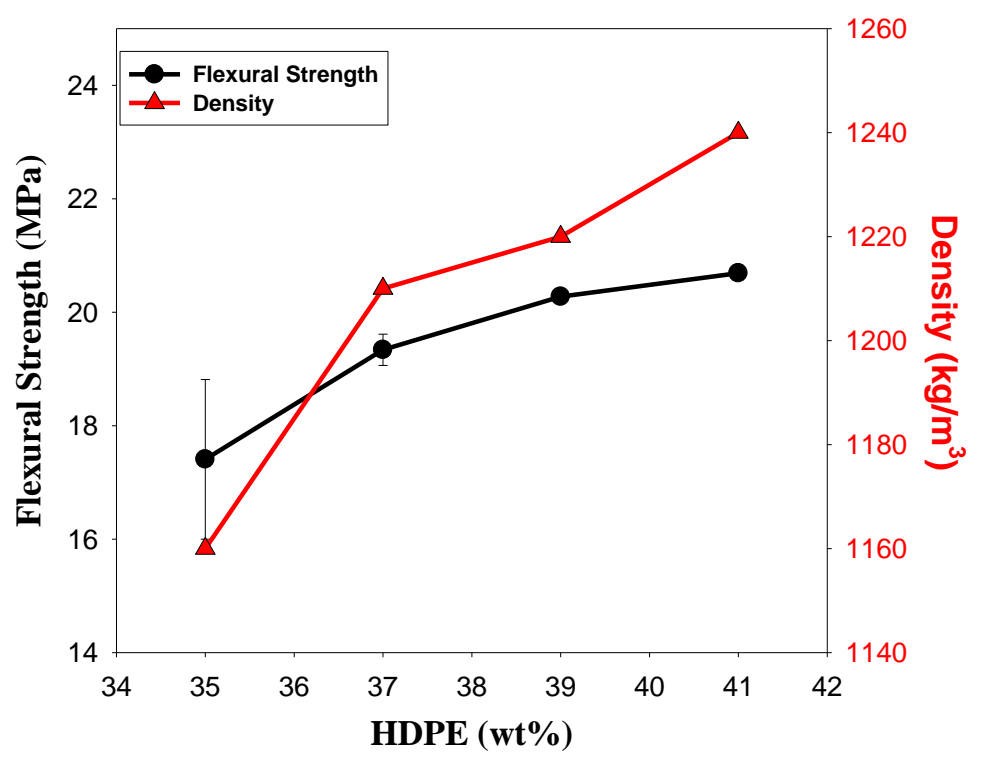

Figure 36. How the thermoplastic HDPE concentration affected the mechanical properties of wood plastic composites. 


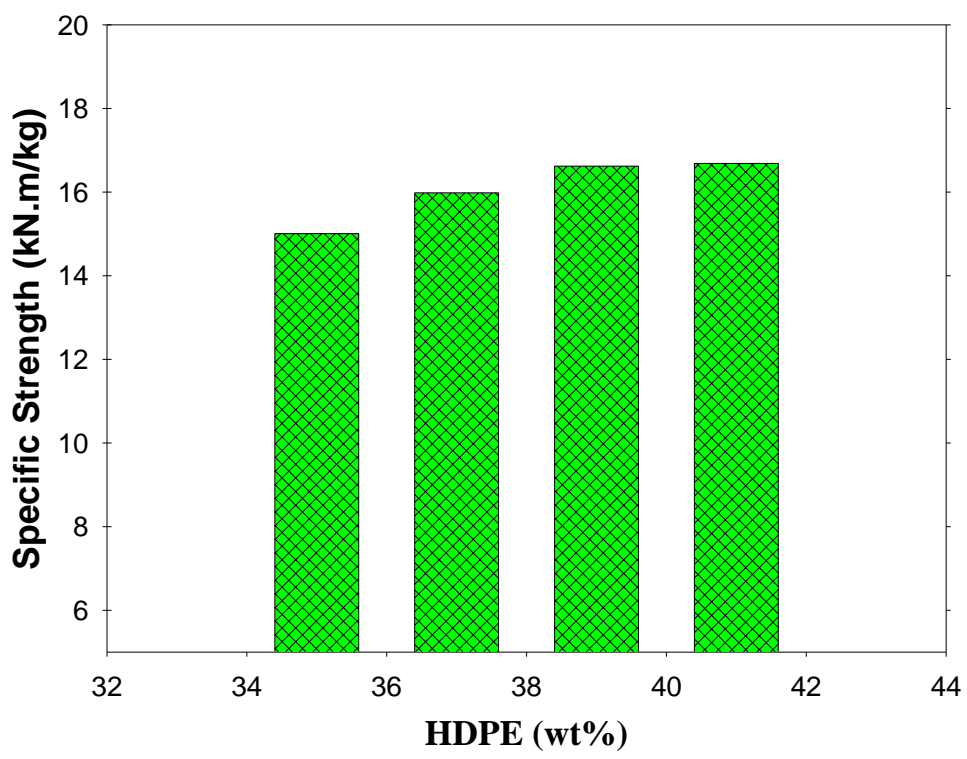

Figure 37. How the thermoplastic HDPE concentration affected the specific strength (= (flexural strength)/density) of wood plastic composites.

We formulated our WPC materials from sulfite-rich scrubber material, natural fibers and HDPE. To keep the cost of our products low, we used recycled HDPE. Recycled HDPE was generated from post-consumer milk containers. The plastic bottles were initially shredded, using a cutting mill fitted with a screen with $8 \mathrm{~mm}$ mesh size. Following that, the shreds were further reduced with the help of a cyclone grinding mill, which resulted in HDPE beads with the average size of about $100 \mu \mathrm{m}$ in diameter.

HDPE - scrubber material - fiber composites were fabricated via compression molding. Raw materials were thoroughly mixed with a motorized high speed (propeller shaped) mixing rod and were molded in the $50 \mathrm{~mm}$ diameter high pressure stainless steel die. Two series of samples were prepared. First, HDPE to additive ratio was varied, while keeping scrubber material-to-natural fiber ratio fixed 4:1 (by weight). The second series contained fixed HDPE content (70\% by weight), while scrubber material-to-natural fiber ratio was varied. Composites were cut into approximately $5 \mathrm{~mm}$ sections using a band saw for flexural strength test.

Figure 38 shows the flexural strength and density variation as the amount of additive (at 4:1 scrubber material-to-natural fiber ratio) changed. There was an initial drop in flexural strength observed as the filler was introduced into the composite. The strength values dropped to $\sim 20 \mathrm{MPa}$, about half of that of the pure HDPE. The strength was, however, maintained as the filler concentration was increased up to $40 \mathrm{wt} \%$ after which it slowly declined. The density followed the opposite trend of the flexural strength as the additives were introduced into the polymer. This was expected because the sulfite-rich FGD material is denser than both HDPE and natural fibers. This was also reflected in Fig. 39, which shows how the flexural strength and density of the composites were affected when the HDPE concentration was kept fixed at 70 wt\% but the FGD materialto-natural fibers ratio was varied. Figure 38 shows that calcium sulfite-to-miscanthus 
ratio of 1:1 might yield the optimum performance with the flexural strength of $26 \mathrm{MPa}$ and density values just around $1000 \mathrm{~kg} / \mathrm{m}^{3}$. The stress vs. strain behavior of this composite was compared to the stress vs. strain behavior of pure HDPE sample in Figure 39.

Other than the conservation of natural resources, there are two main reasons for incorporating both calcium sulfite and natural fibers into the HDPE matrix. Not only should substitute engineered wood composites have high enough strength but they should also mimic the appearance and workability of wood. Though recycled but pure HDPE sample by itself has a higher flexural strength, it is a very flexible and ductile material, which makes it more difficult to work with using conventional wood-working tools. For example, this type of material may be difficult to nail, or drive a screw into, as well as chisel, or even cut. From the stress vs. strain behavior of pure HDPE, shown in Fig. 39, it was evident that the material is very elastic and stretches up to $6 \%$ of strain without breaking. After the incorporation of sulfite crystallites and natural fibers, the stress vs. strain behavior more closely resembled that of natural wood. While material did fail at the higher strain values, the failure was gradual. It is also interesting to note that the stress values at $2 \%$ of strain for both of the samples were about the same around $22 \mathrm{MPa}$.

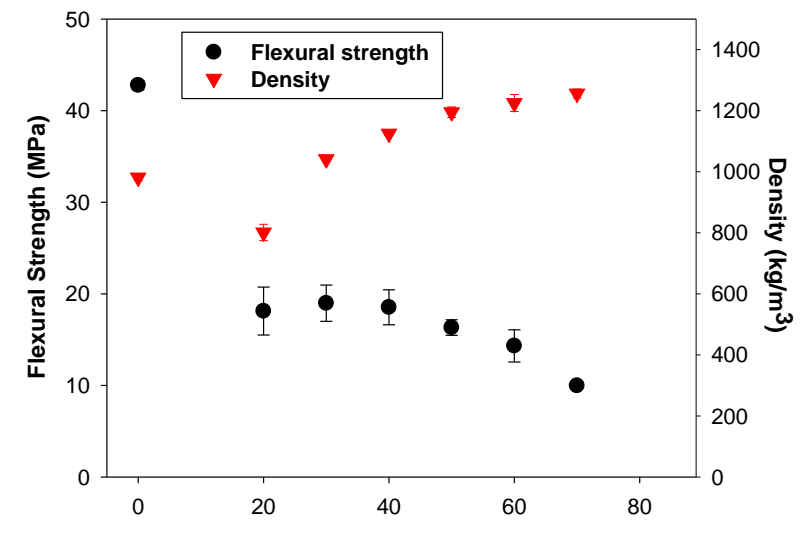

a.

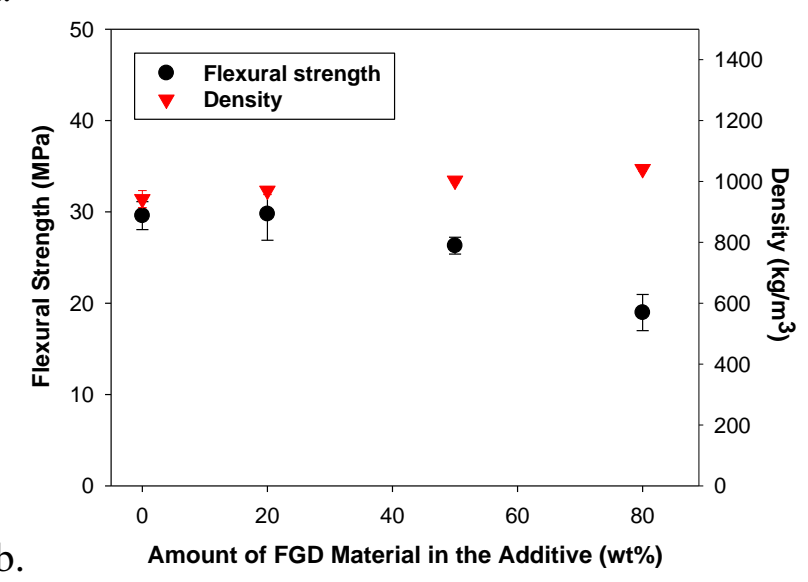

Figure 38. Flexural strength and density of HDPE composites: a) as a function of additive concentration at 4:1 scrubber material-to- fiber ratio, and b) as a function of the amount of scrubber material ( HDPE was fixed at $70 \mathrm{wt} \%$ ). 


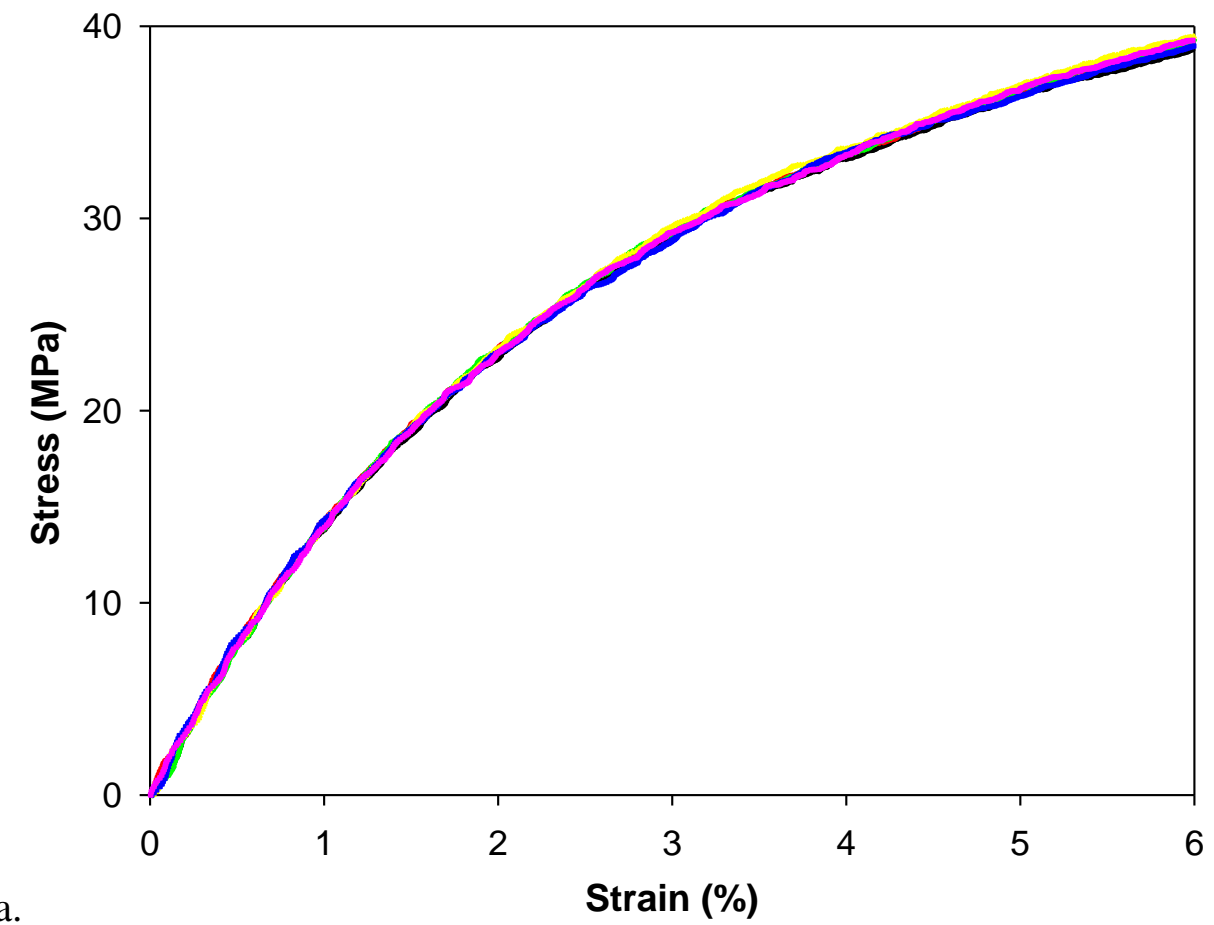

a.

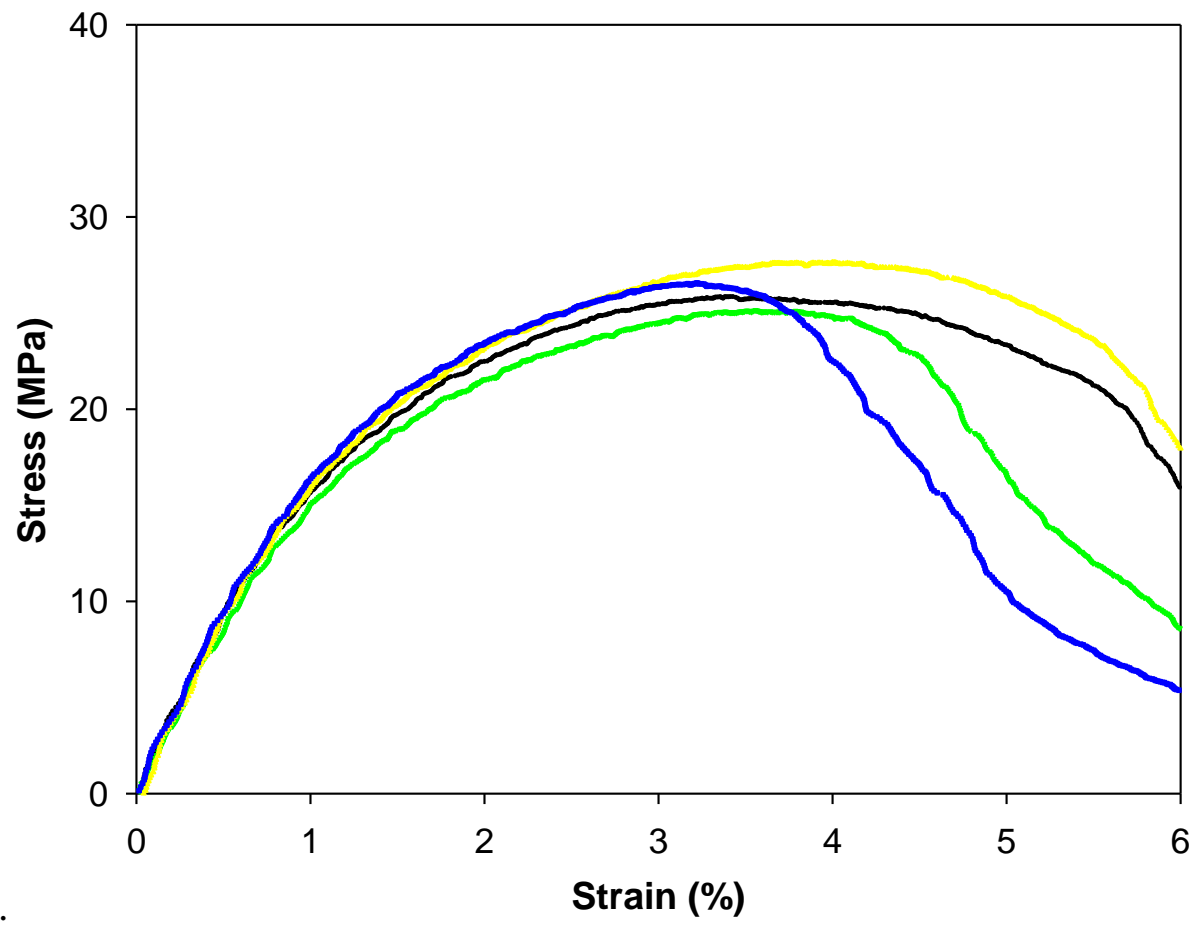

Figure 39. Stress vs. strain characteristics of pure but recycled HDPE sample (a), and of composite material containing $70 \mathrm{wt} \%$ of HDPE, $15 \mathrm{wt} \%$ of scrubber material, and $15 \mathrm{wt} \%$ of natural fibers (b).

\section{Water Sensitivity:}

As described in the previous sections, our research has focused on developing two types of structural composite materials from FGD sulfite-rich scrubber materials, i.e., 
load-bearing decking composites and wood-substitute materials for interior applications. To test their water sensitivity, a 2" x 2" block of either decking material or woodsubstitute composites was cut using an ordinary saw. The cut samples were totally submerged in water in large-size beakers $(1 \mathrm{~L})$. The samples were kept at ambient temperature and pressure. As water evaporated, additional water was periodically added to the beakers to ensure they remained fully submerged. After every week, the samples were withdrawn from the beakers, air-dried for 4 hours, and their weight was determined using an analytical balance. After weighing the sample, the composites were returned to the beakers. The procedure was repeated every week for 8 weeks.

Table 5 summarizes how water affected the weight of various composites developed from FGD sulfite-rich scrubber material. The results are also reproduced graphically in Fig. 40 for the load-bearing decking composites and in Fig. 6 for wood-substitute composites. In Table 5 and Fig. 40, we have also included our water sensitivity results on a commercial-decking material fabricated from fly ash. The sample was obtained from the vendor and was cut into a 2" x 2" piece and submerged in water similar to that of our decking samples.

The results presented in Fig. 40 show that our composites were much less water sensitive than the commercial-decking material produced from fly ash. After two months of water submersion, the commercial product weight increased by almost $10 \%$, while our decking materials showed a weight gain of $<1 \%, 4 \%$, and $5 \%$. Even the samples which had 10 wt $\%$ cellulosic fibers increased their weight only by $5 \%$ after continuous water submersion for 8 weeks.

As expected, the wood-substitute composites were much more water sensitive and showed a weight gain of $40 \%$ after two months of water submersion. However, as explained earlier, these products are being developed for interior applications and are not expected to be exposed to water for long times. 
Table 5. The weight gained by various composites when submerged in water over two months.

\begin{tabular}{|c|c|c|c|c|c|c|c|c|c|}
\hline $\begin{array}{c}\text { Sample } \\
\text { ID }\end{array}$ & $\begin{array}{c}\text { Week } \\
0 \\
(\mathrm{~g}) \\
\end{array}$ & $\begin{array}{c}\text { Week } \\
1 \\
(g) \\
\end{array}$ & $\begin{array}{c}\text { Week } \\
2 \\
(g) \\
\end{array}$ & $\begin{array}{c}\text { Week } \\
3 \\
(\mathrm{~g}) \\
\end{array}$ & $\begin{array}{c}\text { Week } \\
4 \\
(g) \\
\end{array}$ & $\begin{array}{c}\text { Week } \\
5 \\
(g)\end{array}$ & $\begin{array}{c}\text { Week } \\
6 \\
(g) \\
\end{array}$ & $\begin{array}{c}\text { Week } \\
7 \\
(g) \\
\end{array}$ & $\begin{array}{c}\text { Week } \\
8 \\
(\mathrm{~g}) \\
\end{array}$ \\
\hline $\begin{array}{c}\text { Decking } \\
\text { Material } \\
20\end{array}$ & 72.6 & 72.6 & 72.6 & 72.6 & 72.5 & - & 72.7 & 72.7 & 72.8 \\
\hline $\begin{array}{c}\text { Decking } \\
\text { Material } \\
40\end{array}$ & 16.1 & 16.2 & 16.3 & 16.3 & 16.3 & - & 16.6 & 16.7 & 16.7 \\
\hline $\begin{array}{l}\text { Decking } \\
\text { Material } \\
\text { 40-M10 }\end{array}$ & 3.6 & 3.8 & 3.8 & - & 3.8 & 3.8 & 3.8 & - & - \\
\hline $\begin{array}{c}\text { Wood } \\
\text { Substitute } \\
50-F 10\end{array}$ & 19.3 & 25.6 & 26.4 & 26.6 & - & - & 26.9 & 27.1 & 27.2 \\
\hline $\begin{array}{c}\text { Wood } \\
\text { Substitute } \\
25\end{array}$ & 19.9 & 22.2 & 22.7 & - & 24 & 24.2 & 24.6 & - & - \\
\hline $\begin{array}{l}\text { Commercial } \\
\text { Decking } \\
\text { Material } \\
\text { (derived } \\
\text { from fly } \\
\text { ash) }\end{array}$ & 22.2 & 22.9 & 23.1 & 23.3 & 23.4 & - & 23.8 & 24 & 24.3 \\
\hline
\end{tabular}




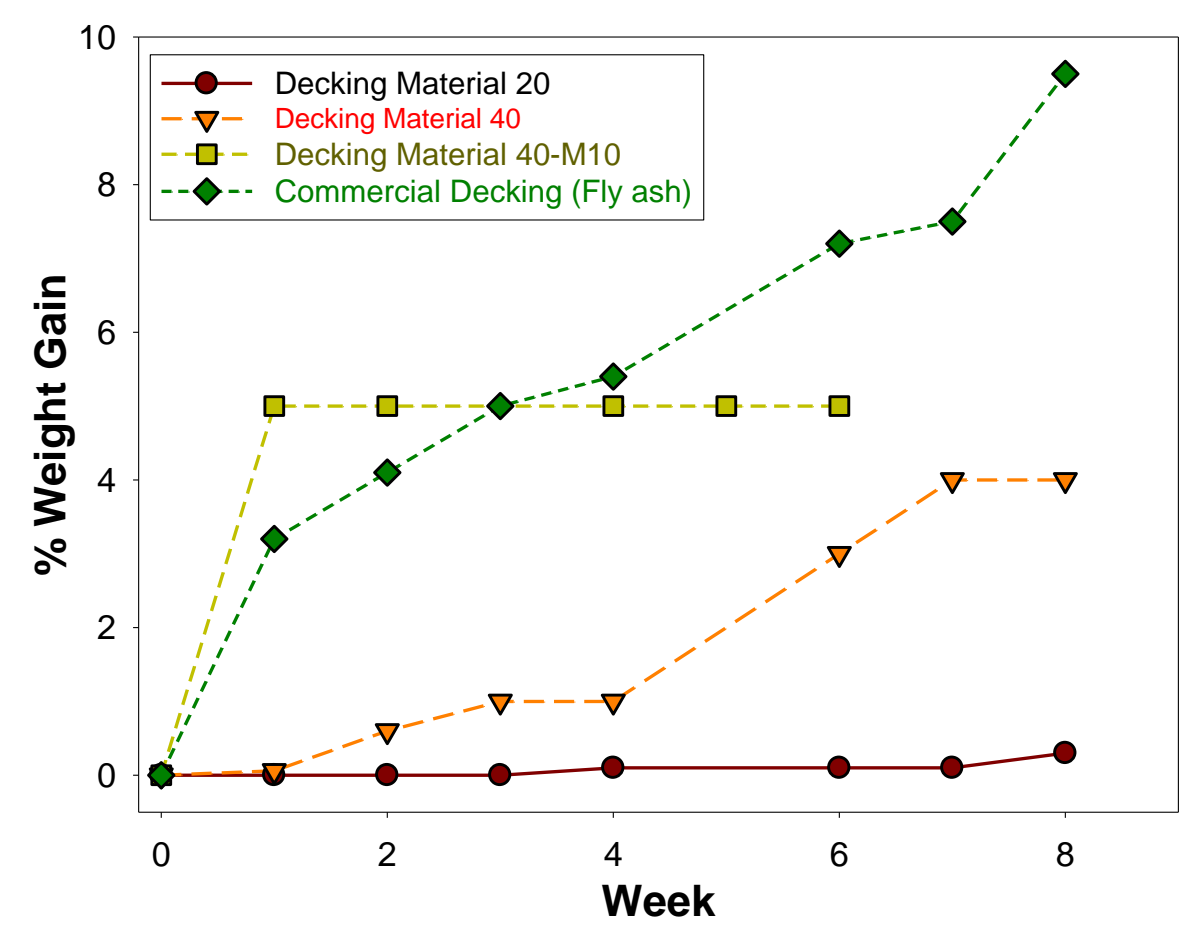

Figure 40. The weight gain of the decking-type composites as a function of time when submerged in water. Our composites were developed from FGD sulfite-rich scrubber material, while the commercial product contained fly ash.

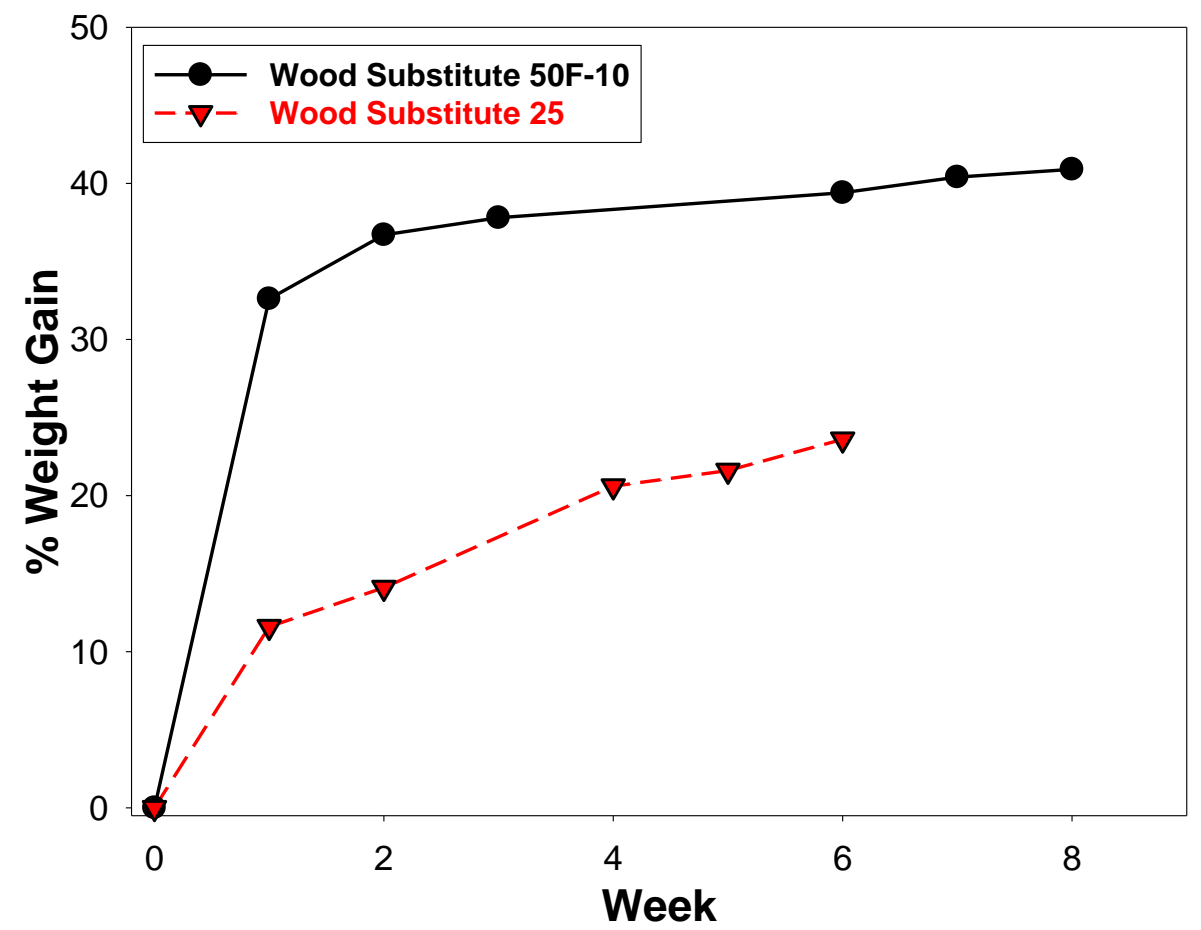

Figure 41. The weight gain of the wood-substitute composites as a function of time when submerged in water. Our composites were developed from FGD sulfite-rich scrubber material. 


\section{Large-Size Samples}

Wood-Substitute Composites: Four different models of wood-substitute composites were developed as shown in Figs. 42, 43, 44, and 45. While composites shown in Figs. 42 and 43 were developed using $<8 \mathrm{~mm}$ size crop A cellulosic fibers, the products shown in Figs. 3 and 4 were fabricated from cyclone-ground crop A cellulosic fibers. Clearly, our results suggest that there is a strong potential to upscale products developed from FGD sulfite-rich scrubber material using our technology.

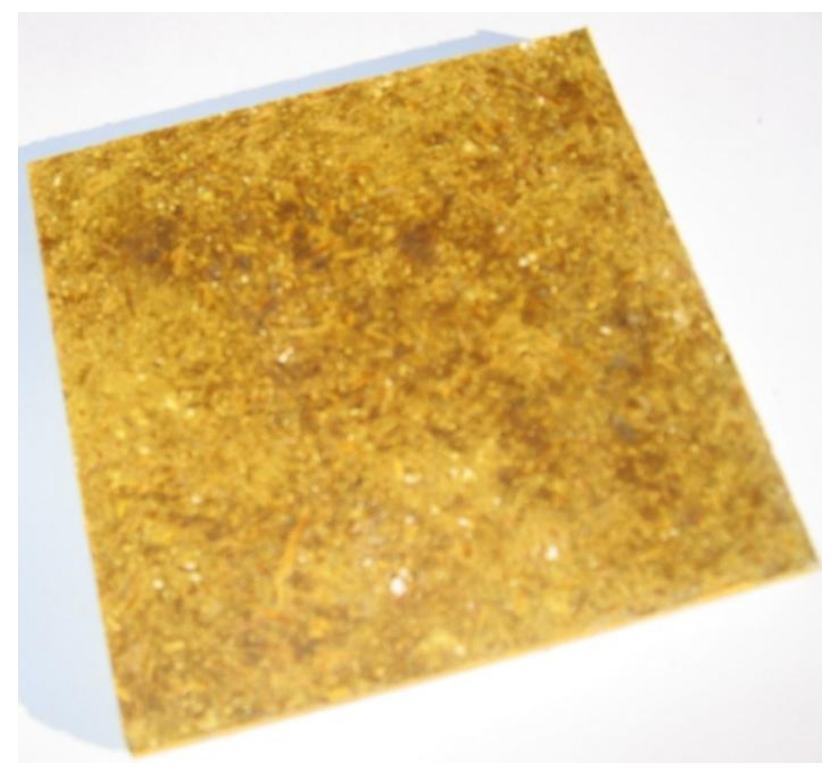

Figure 42. Picture of 4" x 4" wood-substitute composite developed from FGD sulfite-rich scrubber material (> $50 \mathrm{wt} \%$ ) and $<8 \mathrm{~mm}$ cellulosic fibers.

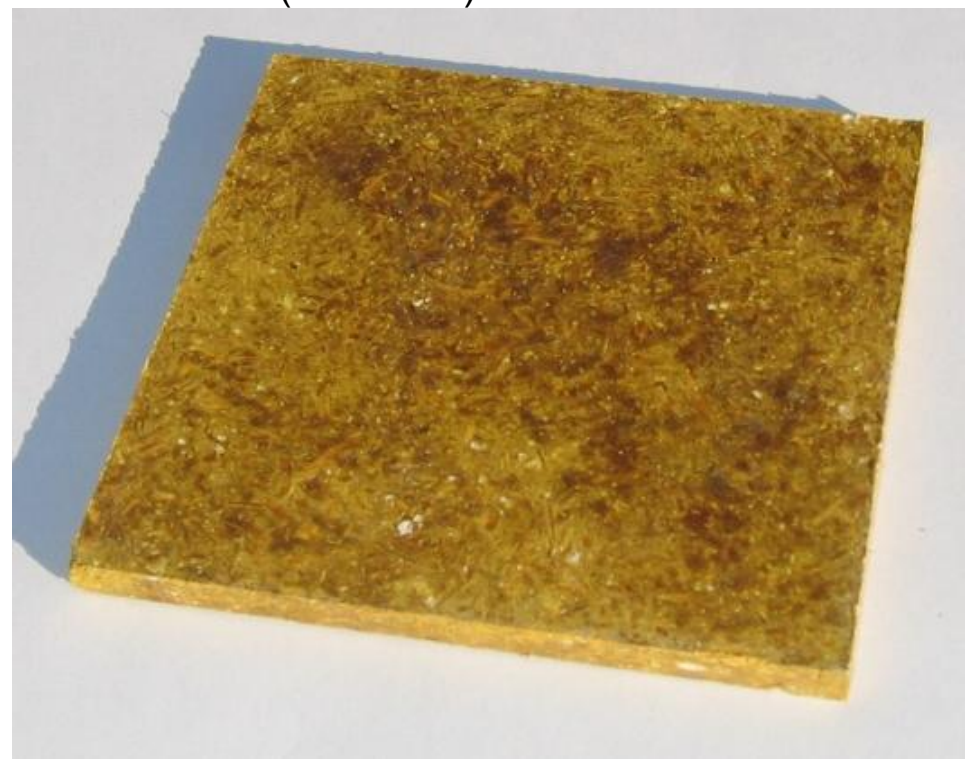

Figure 43. Picture of 4" x 4" wood-substitute composite developed from FGD sulfite-rich scrubber material (> $50 \mathrm{wt} \%$ ) and $<8 \mathrm{~mm}$ cellulosic fibers. 


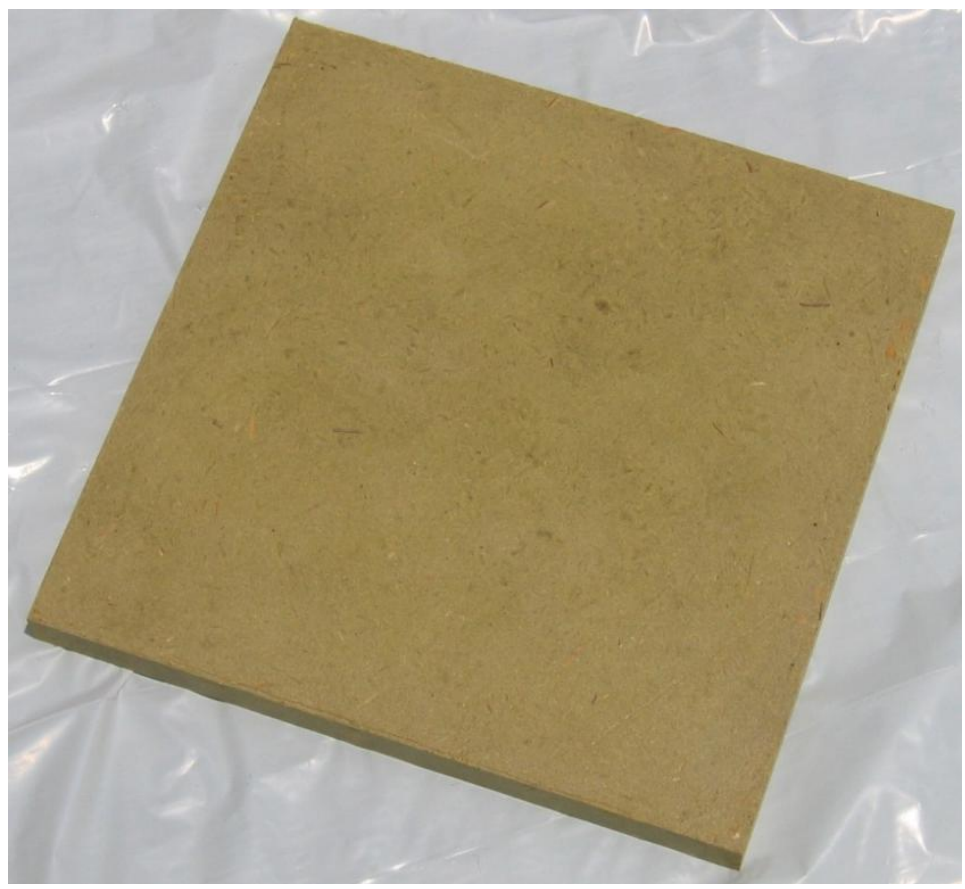

Figure 44. Picture of 6" $\times 6$ " wood-substitute composite developed from FGD sulfite-rich scrubber material (> $50 \mathrm{wt} \%$ ) and cyclone-ground cellulosic fibers.

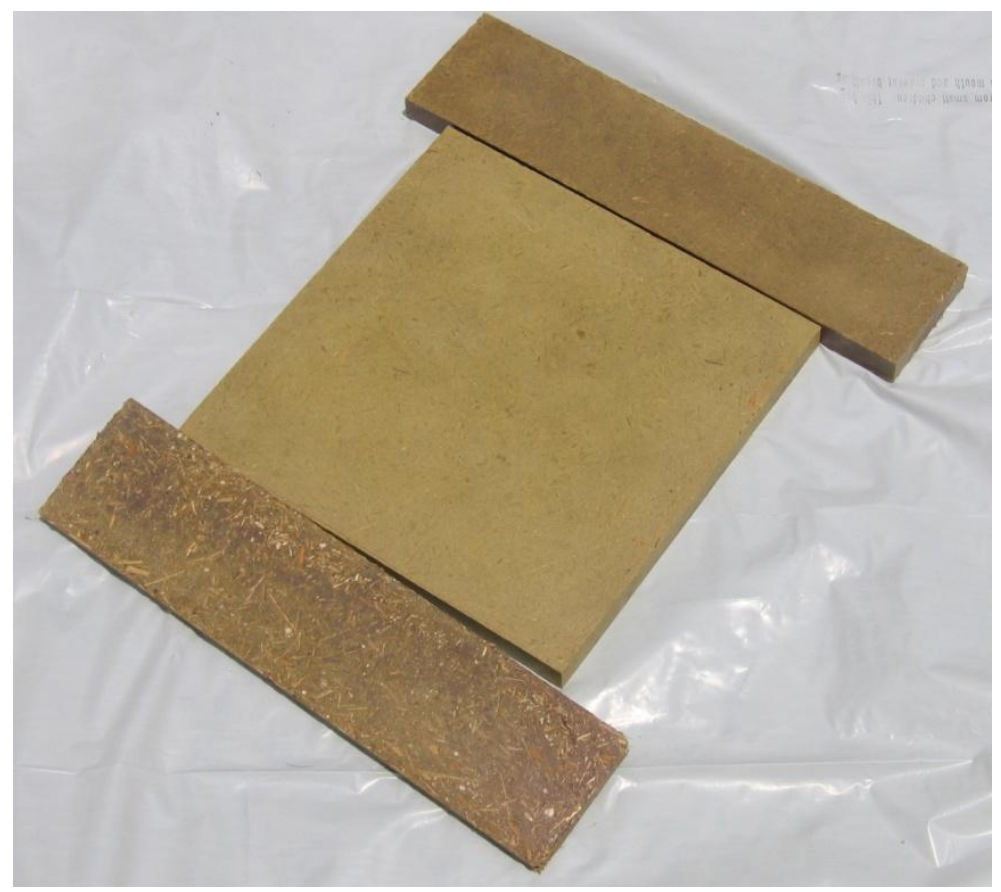

Figure 45. Picture of 4" x 4" and 8" x 2" wood-substitute composites developed from FGD sulfite-rich scrubber material (> $50 \mathrm{wt} \%$ ) and cyclone- ground cellulosic fibers. 
Load-Bearing Composites: Figures 46 and 47 show the 4" x 4" x 2" sized composites developed from sulfite-rich scrubber material and HDPE. In these composites, no FBC fly ash particles were added. These composites were non-water wettable. The addition of FBC fly ash particles in the mix changed the color of the final product, though it did not alter the non-water wetting properties of the composites. Moreover, we noticed that the mechanical properties of the composites further improved on the addition of the FBC fly ash to the mix. The load-bearing decking composites fabricated with the addition of FBC fly ash particles are shown in Figs. 48, 49, and 50. We also found that our composites could be sawed using an ordinary wood saw as shown in Fig. 51.

Figure 46. Load-bearing decking (4" x 4" x 2") composite developed from sulfite-rich scrubber material.

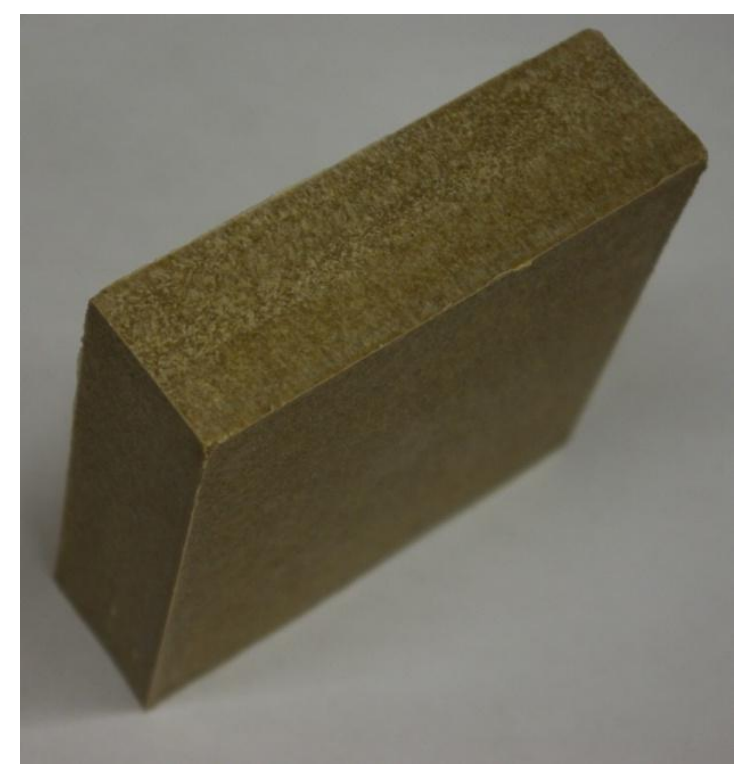

Figure 47. Load-bearing decking (4" x 4" x 2") composite developed from sulfite-rich scrubber material. 


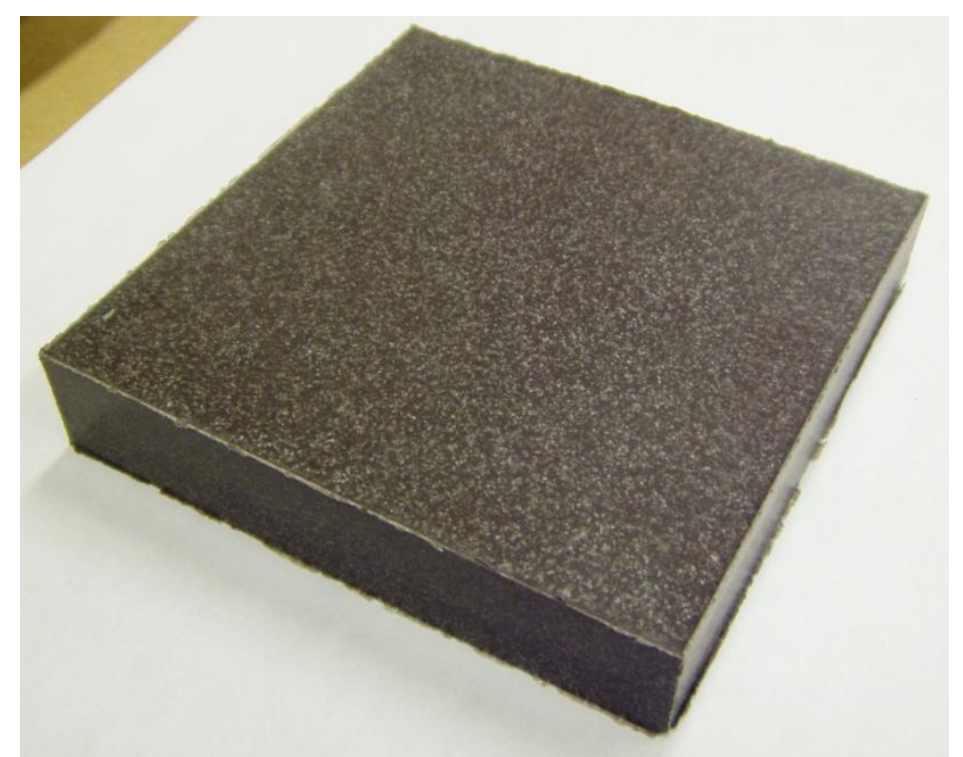

Figure 48. Load-bearing decking (4" x 4" x 2") composite developed from sulfite-rich scrubber material and FBC fly ash.

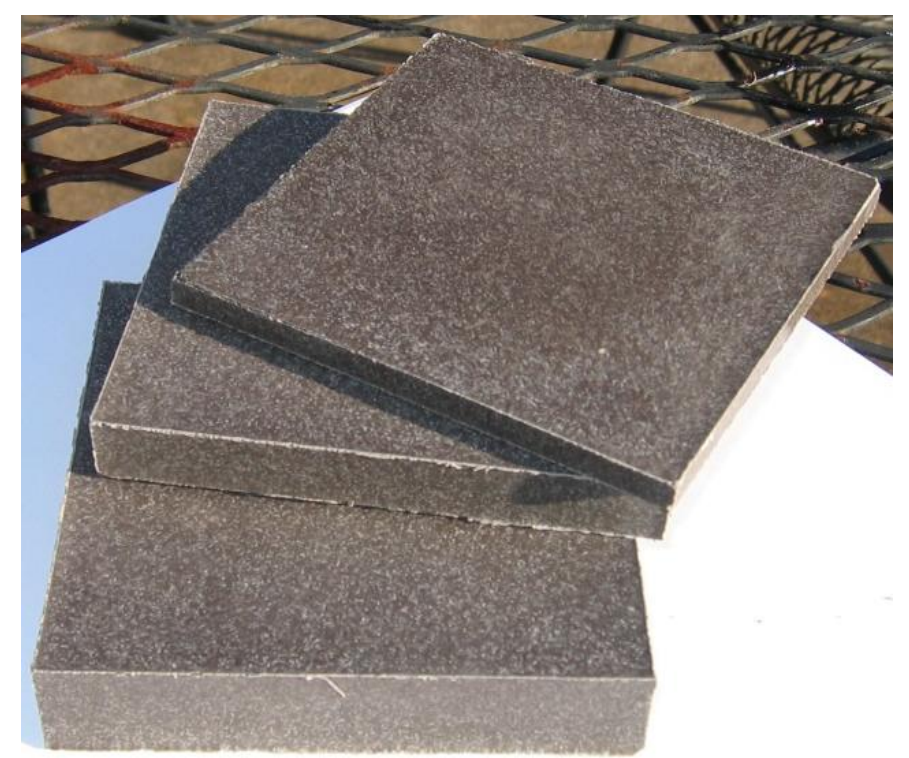

Figure 49. Load-bearing decking (4" x 4" x 0.5 - 2") composite developed from sulfiterich scrubber material and FBC fly ash. 


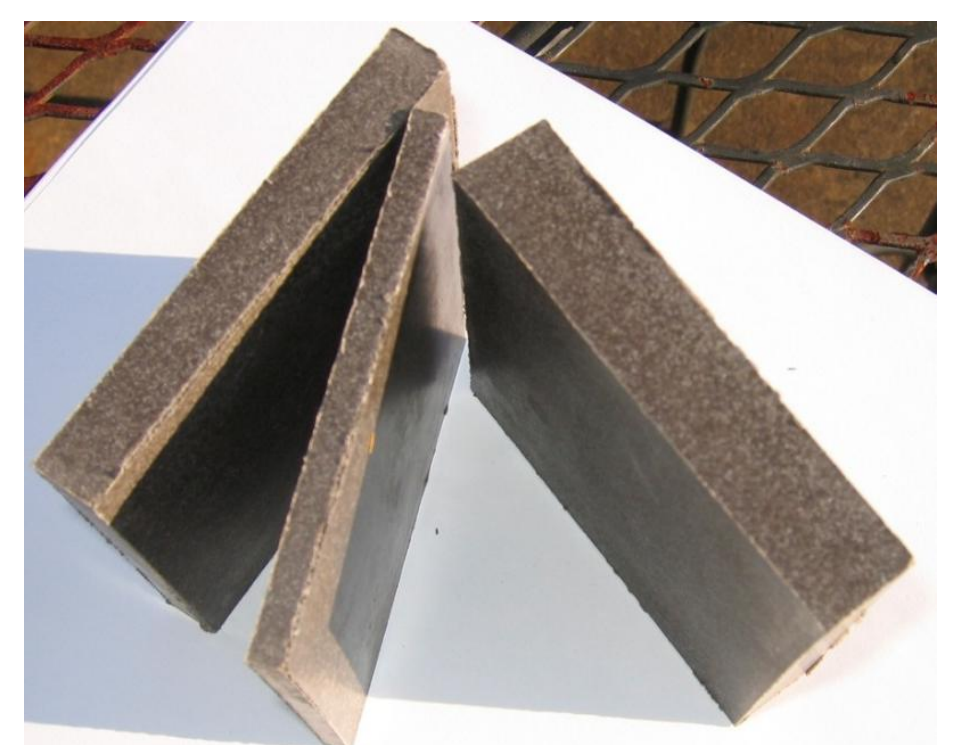

Figure 50. Load-bearing decking (4" x 4" x 0.5 - 2") composite developed from sulfiterich scrubber material and FBC fly ash.

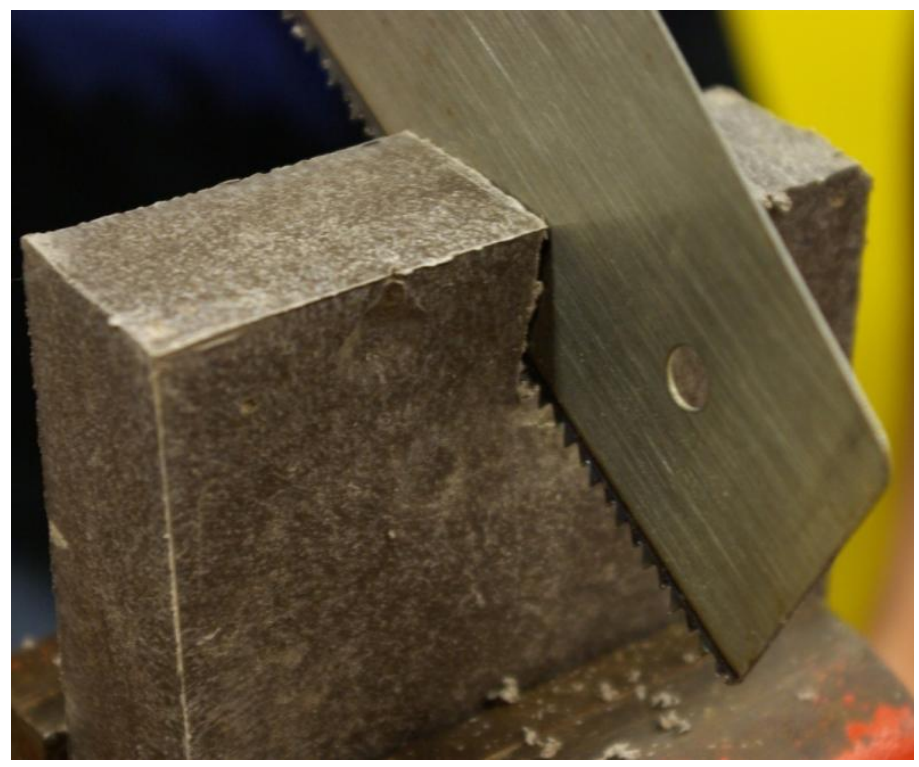

Figure 51. This figure shows that a regular wood saw could be used to cut our loadbearing composites derived from scrubber material and FBC fly ash.

\section{CONCLUSIONS}

In this project, we explored whether it was possible to develop wood-substitute products from FGD sulfite-rich scrubber material. To accomplish this, a range of characterization, mechanistic, and product development experiments was undertaken. The following summarizes the main findings of our project:

1. Gravimetric measurements suggested that water was rapidly lost at the ambient temperature from the scrubber cake for the first 24 hours, and thereafter there was 
a dramatic decrease in the rate of water evaporation. However, for our product manufacturing, 24 hours of scrubber cake drying would be adequate.

2. The physical structural analysis of the sulfite-rich scrubber material, obtained from two different power plants, indicated that the crystallites were typically hannebachite in appearance, i.e., platelet-like crystallites of $\mathrm{CaSO}_{3} \cdot 0.5 \mathrm{H}_{2} \mathrm{O}$. Our SEM measurements also revealed that the scrubber material from one of the power plants had a strong tendency to agglomerate in which crystallites stacked one over the other rather than forming spherical-looking agglomerates. The scrubber material from the second power plant did not show this behavior.

3. The XRD diffraction of the as-received, but air-dried, scrubber cake indicated peaks at 11.7, 16.1, and 16.7 degrees, thus, suggesting the scrubber cake to be a mixed phase of $\mathrm{CaSO}_{3} \cdot 0 \cdot 5 \mathrm{H}_{2} \mathrm{O}, \mathrm{CaSO}_{3} \cdot 4 \mathrm{H}_{2} \mathrm{O}$, and $\left(\mathrm{CaSO}_{4}\right)_{x} \cdot\left(\mathrm{CaSO}_{3}\right)_{1-\mathrm{x}} \cdot \mathrm{nH}_{2} \mathrm{O}$.

4. Our DSC measurements indicated that the products developed from the sulfite-rich scrubber materials would be stable as long as the temperature was $<400^{\circ} \mathrm{C}$.

5. Our results indicated that the mercury concentrations in sulfite-rich scrubber material should be determined at least after 14 days of air drying $\left(T<30^{\circ} \mathrm{C}\right)$ time because of continued water loss from the scrubber material.

6. On subjecting the scrubber material to high temperatures and pressures typically expected during our product development, we did not observe any statistically significant emission of mercury from the scrubber cake.

7. The detailed thermal measurements, i.e., TGA and DTA analyses at $50^{\circ} \mathrm{C} \leq \mathrm{T} \leq$ $1250^{\circ} \mathrm{C}$, on the scrubber materials suggested that there are four main thermal events by which scrubber material from both power plants decomposed. Consistent with the DSC results, TGA and DTA measurements also reinforced our suggestion that in our wood-substitute composites, the scrubber material would not decompose at $\mathrm{T}<400^{\circ} \mathrm{C}$. Above $400^{\circ} \mathrm{C}$, half water molecule were lost from the hannebachite crystallites, thus this might retard the flammability of our composites.

8. The exposure of sulfite-rich scrubber material to high-pressure (ambient pressure $\leq$ $\mathrm{P}<3000 \mathrm{psi})$ and high-temperature $\left(25^{\circ} \mathrm{C}<\mathrm{T}<250^{\circ} \mathrm{C}\right)$ resulted in the compression of hannebachite crystallites though they maintained their platelet-like shape. However, it was noticed that higher pressures, i.e., $\mathrm{P}>1100 \mathrm{psi}$, and higher-temperatures, i.e., $\mathrm{T}>200^{\circ} \mathrm{C}$, generated a considerable number of fines. The production of these fines during composite fabrication conditions could result in higher densities of the material. The vibrational (infrared) analysis of the scrubber materials, which were subjected to high-temperatures at high-pressure, indicated that the sulfite-rich scrubber materials retained their chemical structure under the above-mentioned conditions.

9. Our results showed that it was feasible to make composite materials from FGD sulfite-rich scrubber material with flexural strengths up to $90 \mathrm{MPa}(13,050 \mathrm{psi})$. Formation pressure and temperature played an important role, besides the ingredients, in determining the final strength and elastic properties.

10. Depending upon the type of polymer, it appeared that wood-substitute composites could be formulated with sulfite-rich scrubber material with a concentration ranging from $60 \mathrm{wt} \%$ to $75 \mathrm{wt} \%$. It also appears that the density of the composites derived from sulfite-rich scrubber material could be lowered either by the addition of fly ash 
or hollow spherical particles. However, hollow spherical particles were more effective in lowering the density yet maintaining the higher strength.

11. Our results suggest that post-curing the wood substitute composites developed from sulfite-rich scrubber material resulted in defect sites and micropores. This effectively reduced the density slightly though the strength of the composite also decreased by about $4 \mathrm{MPa}$. Therefore, it is recommended that wood-substitute composites fabricated from scrubber material not be subjected to post-curing.

12. We demonstrated that by combining recycled thermoplastics obtained from consumer recycled products with scrubber materials load-bearing wood plastic composites could be formulated. Flexural strengths in the range of $15 \mathrm{MPa}-$ $30 \mathrm{MPa}$ were achieved, which is comparable to other engineered-wood composites. Storage modulus at sub-ambient temperatures was improved with the addition of calcium sulfite into recycled thermoplastic. 


\section{REFERENCES}

1. Butalia, T. S., Wolfe, W. E., Lee, J. W. Fuel, 80, 845, 2001.

2. Malhotra, V. M., Valimbe, P. S., and Wright, M. Fuel, 81, 235, 2002.

3. American Coal Ash Association, www.acaa-usa.org (2008).

4. Stokke, D. D., Materials Res. Soc. Bulletin, XIX, 22-29 (1994).

5. Klyosov, A. A., "Wood-Plastic Composites", Wiley-Interscience, Hoboken, N.J.,2007.

6. Wallenberger, F. T., Weston, N., Eds., "Natural Fibers, Plastics, and Composites", Kluwer Academic, Boston, MA 2004.

7. Knop, A., Pilato, L. A., "Phenolic Resins: Chemistry, Application and Performance", Springger-Verlag, Berlin, Germany, 1985.

8. Markevicius, G., Malhotra, V. M., ANTEC conference proceedings, 2433-2436, 2004.

9. Markevicius, G., Jones, S.C., Malhotra, V. M., ANTEC conference proceedings, 2245-2249 (2007).

10. Markevicius, G., Hofer, S., Malhotra, V. M., ANTEC conference proceedings, 20262030 (2008).

11. Gadalla, A. M. and Gupta, A. Ind. Eng. Chem. Res. 33, 1145, 1994.

12. A. D. Randolph, D. J. Kelly, and B. Keough, "Calcium Sulfite and Calcium Sulfate Crystallization. Volume 1.: Effect of Crystallizer Type on Gypsum Size Distribution", EPRI Report 1013-3, 1986.

13. T. Zaremba, A. Dukowicz, J. Hehlmann, W. Mokrosz, and E. Kujawska, J. Thermal Analysis and Calorimetry, 74, 503, 2003. 